\title{
Review of Peritectic Solidification Mechanisms and Effects in Steel Casting
}

\begin{abstract}
GHAVAM AZIZI, BRIAN G. THOMAS, and MOHSEN ASLE ZAEEM
Surface quality and castability of steels are controlled greatly by initial solidification. Peritectic steels suffer more from surface quality problems, including deep oscillation marks and depressions, crack formation, and breakouts than other steels. This paper reviews current understanding of the fundamental mechanisms of initial solidification of peritectic steels that lead to these problems. First, different empirical relations to identify peritectic steel grades from their alloy compositions are summarized. Peritectic steels have equivalent carbon content that takes their solidification and cooling path between the point of maximum solubility in $\delta$-ferrite and the triple point at the peritectic temperature. Surface defects are related more to the solid-state peritectic transformation ( $\delta$-ferrite $\rightarrow \gamma$-austenite) which occurs after the peritectic reaction $(\mathrm{L}+\delta \rightarrow \gamma)$ during initial solidification. Some researchers believe that the peritectic reaction is controlled by diffusion of solute atoms from $\gamma$ phase, through the liquid, to the $\delta$ phase while others believe that $\gamma$ growth along the $\mathrm{L} / \delta$ interface involves microscale heat transfer and solute mixing due to local re-melting of $\delta$-ferrite. There is also disagreement regarding the peritectic transformation. Some believe that peritectic transformation is diffusion controlled while others believe that massive transformation is responsible for this phenomenon. Alloying elements and cooling rate greatly affect these mechanisms.
\end{abstract}

https://doi.org/10.1007/s11663-020-01942-5

(c) The Minerals, Metals \& Materials Society and ASM International 2020

\section{INTRODUCTION}

THE castability of high-quality steel depends on avoiding breakouts, cracks, and surface quality problems. The surface quality of steel products is mainly determined by the early stages of solidification in the meniscus region of the mold. ${ }^{[1-8]}$ Steels which undergo the peritectic transition are the most difficult to cast. $^{[2,9-14]}$ This is attributed to the volume contraction (shrinkage) associated with the peritectic phase transformation. ${ }^{[15-17]}$ This shrinkage leads to the formation of an air gap between the steel shell and the mold during the $\mathrm{CC}$ process and decreases the heat flux. This leads to locally thinner and hotter regions of the solidified shell,

GHAVAM AZIZI, BRIAN G. THOMAS, and MOHSEN ASLE ZAEEM are with the Department of Mechanical Engineering, Colorado School of Mines, 1610 Illinois Street, Golden, CO, 80401. Contact e-mail: bgthomas@mines.edu

Manuscript submitted April 14, 2020.

Article published online August 27, 2020. which causes uneven shell growth that leads to surface depressions, deep oscillation marks, cracks, and breakouts. ${ }^{[18-24]}$

Steels within the peritectic composition range include high-strength low-alloy (HSLA) Steels, and recently advanced high-strength steels (AHSS), which are all used extensively in different products due to their excellent mechanical properties, which include high strength and toughness. ${ }^{[25-28]}$ The automotive industry is increasingly utilizing steels with peritectic composition range (AHSS, HSLA, etc.), to reduce vehicle weight. Peritectic steels are widely applied in pipelines, navy vessels, and nuclear power plant components. ${ }^{[28,29]}$ Therefore, there is a great need to produce these steels without defects. ${ }^{[25]}$

Peritectic steel solidification occurs in two distinct stages involving liquid $(\mathrm{L})$, delta-ferrite $(\delta)$, and austenite $(\gamma)$ : the peritectic reaction $(\mathrm{L}+\delta \rightarrow \gamma$ ) followed by the peritectic transformation $(\delta \rightarrow \gamma) \cdot{ }^{[30-33]}$ The peritectic reaction occurs just below the peritectic temperature, when liquid and delta-ferrite are in contact and react to form austenite. This corresponds to the $\mathrm{L}+\delta+\gamma$ three-phase point in the binary phase diagram, ${ }^{[34]}$ or to the 3-phase region on sections through a multicomponent phase diagram, such as shown in Figure 1(a). During the peritectic reaction, an austenite layer grows 


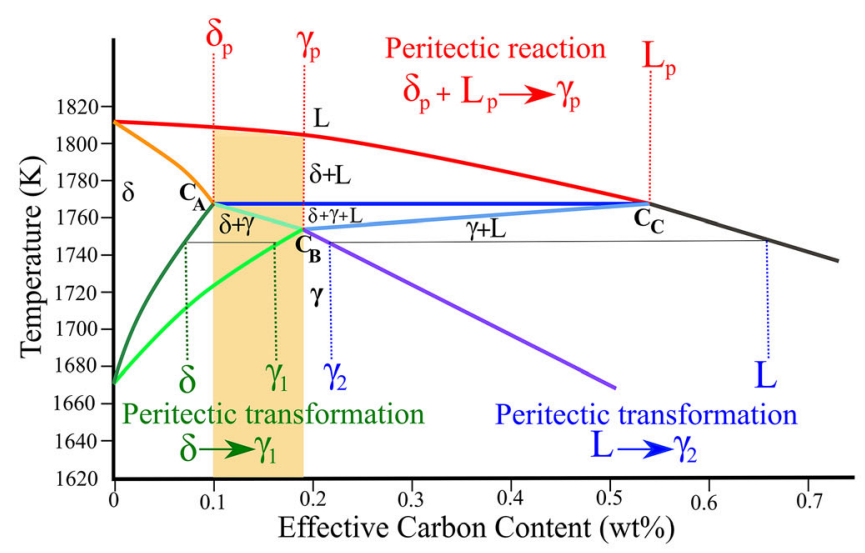

(a)

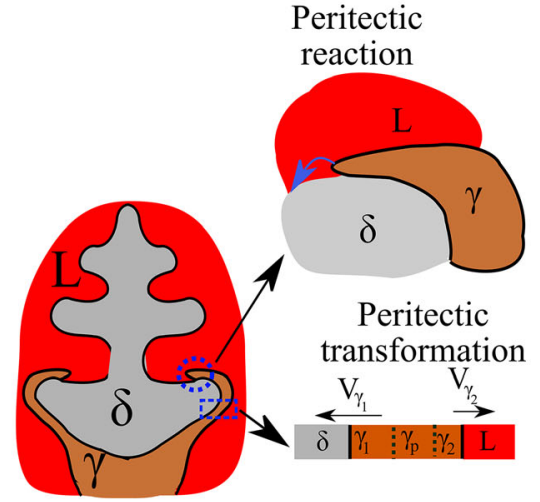

(b)

Fig. 1-(a) Iron-carbon phase diagram showing peritectic steels (shaded) and their phase transformations and (b) schematics of the peritectic reaction and subsequent peritectic transformation.

along the $\mathrm{L}+\delta$ interface, as pictured in the upper right frame of Figure 1(b). After the liquid locally runs out, then the remaining $\delta$-ferrite transforms to austenite by solid-state transformation. The peritectic transformation starts by thickening of the austenite layer immediately behind the tip of this advancing $\gamma$ platelet, as shown in Figure 1(b), ${ }^{[35]}$ where it proceeds on two fronts, growing into both the liquid on one side of the platelet and the $\delta$ interior on the other. Later, toward the center of the dendrite, the interior $\delta-\gamma$ interface has moved far away from the liquid, so further austenite growth into the $\delta$ ferrite involves only a single moving interface. Note that spatially, these different steps of peritectic solidification occur at different places, and proceed in different directions relative to the thermal gradient, which is oriented downwards in Figure 1(b).

In this paper, the proposed mechanisms of peritectic solidification are reviewed in detail and then the effects of peritectic solidification on surface quality, austenite grain size, hot ductility, segregation, and crack formation of cast product are discussed. But first, the different calculations used to identify peritectic steel grades from their compositions are summarized.

\section{IDENTIFICATION OF PERITECTIC STEELS}

As casting of peritectic steels is difficult, it is important to identify a peritectic steel from its composition. If a new grade of steel is predicted to be a peritectic, then appropriate actions can be taken at the caster, such as applying appropriate mold powders with high solidification temperature to lower the surface cooling rate ${ }^{[36-38]}$ and/or casting at a lower speed. ${ }^{[10]}$ Low-alloy commercial steels can be characterized by their carbon content, with corrections according to the other alloying elements. Predicting the occurrence of the problematic peritectic transformation in high-alloy steels is more difficult, and involves the relative amounts of more than one other elements (such as carbon, nickel, and chromium in stainless steels, ${ }^{[39]}$ or in $\mathrm{AHSS}^{[40,41]}$ ).
In the $\mathrm{Fe}-\mathrm{C}$ phase diagram for low-alloy steels, shown in Figure 1, four different solidification behaviors can be categorized according to their effective carbon content. These include range I, for effective carbon content less than point $C_{\mathrm{A}}$, range II for carbon between $C_{\mathrm{A}}$ and $C_{\mathrm{B}}$, range III for carbon between $C_{\mathrm{B}}$ and $C_{\mathrm{C}}$, and range IV, for carbon above $C_{\mathrm{C}}$. Steels in range II are known as peritectic steels and are the most difficult to cast because they experience transformation from $\delta$ to $\gamma$ that coincides with the final stage of solidification. While in range I, $\delta$ to $\gamma$ transformation starts and ends in the solid state. In range III, the transformation occurs in the presence of liquid and in range IV, the steel solidifies as austenite so the $\delta$ to $\gamma$ transformation does not take place at all and there is no contraction.

The position of points $C_{\mathrm{A}}, C_{\mathrm{B}}$, and $C_{\mathrm{C}}$ in the pseudo-binary phase diagram of $\mathrm{Fe}$ and effective carbon content have been defined in different ways in previous research. When carbon is the only significant alloying element, Point $C_{\mathrm{A}}$ is given between $0.088 \mathrm{wt}$ pet $\mathrm{C}^{*}$ and 0.1 pet $\mathrm{C}^{[42-44]}$ point $C_{\mathrm{B}}$ ranges from 0.16 to 0.18 pet $C^{[41,43,44]}$ and $C_{\mathrm{C}}$ is about 0.53 pct $C^{[43]}$ The position and temperature of points $C_{\mathrm{A}}, C_{\mathrm{B}}$, and $C_{\mathrm{C}}$ change significantly according to the alloy content, however. Alloying elements change the effective carbon content, and are classified as either ferrite formers, which tend to shift the points to the right (higher carbon) or austenite formers, which have the opposite effect. Increasing alloy content also extends the ternary $(\mathrm{L}+\delta+\gamma)$ phase region in Figure 1. Different experiments ${ }^{[41,45-49]}$ have been conducted to determine if a steel exhibits peritectic behavior, and different empirical equations ${ }^{[50-55]}$ have been proposed to predict this, as discussed in the next sections.*

*All alloy compositions in this paper are given in weight pct. 


\section{A. Experimental Measurements}

Differential scanning calorimeter (DSC) measurements can identify the temperatures of phase transformations in steels, ${ }^{[56-61]}$ based on detecting the accompanying small changes in enthalpy. This includes the ability to identify peritectic steel grades from the distinctive second peak in their enthalpy rate-temperature profile during cooling. ${ }^{[46,48,49,62]}$ Confocal microscopy, discussed in Section III can augment the DSC measurements by visualizing these phase transformations. ${ }^{[62]}$ The ultimate test is behavior in the commercial caster, where peritectic steels experience more variations and defects than other steels, as discussed in Section IV.

All alloys show a large peak in the DSC curves at high temperature during the phase transformation between the molten steel and either $\delta$-ferrite or austenite. ${ }^{[46]}$ The peritectic reaction, when present, generates a significant second peak, at the lower "peritectic temperature" $[46,62]$ because it involves austenite forming at the expense of liquid, in addition to $\delta$ ferrite. This second peak may not appear in DSC cooling curves, however, if the cooling rate is too high, for reasons discussed later. ${ }^{[46,62]}$ The solid-state transformation from $\delta$ ferrite to austenite has a small third peak, ${ }^{[46,62]}$ which is often difficult to detect.
As an example, Figure 2 shows typical DSC results for four steels, ${ }^{[1]}$ which are supported by high-temperature confocal laser scanning microscopy (HT-CLSM) observations. Figure 2 shows one heating curve for a typical non-peritectic steel (top left frame with $0.08 \mathrm{pct}$ C), so there is no significant enthalpy peak before melting. The other three frames in Figure 2 all show a second large, sharp peak due to the peritectic reaction, indicating that these are all peritectic steels. This includes a new advanced high-strength steel (lower right frame with 2 pct $\mathrm{Al}$ ), which is not correctly identified as being peritectic by current models, which are discussed in the next section.

\section{B. Calculation Methods}

Several different methodologies have been proposed to predict if a steel is a peritectic, based on its exhibiting adverse solidification behavior, such as susceptibility to depressions and cracks. These methods include empirical equations based on an equivalent carbon content range, alloy-dependent critical points, ferrite potential, and CALculation of PHAse Diagrams (CALPHAD) methods. These are discussed in turn below.
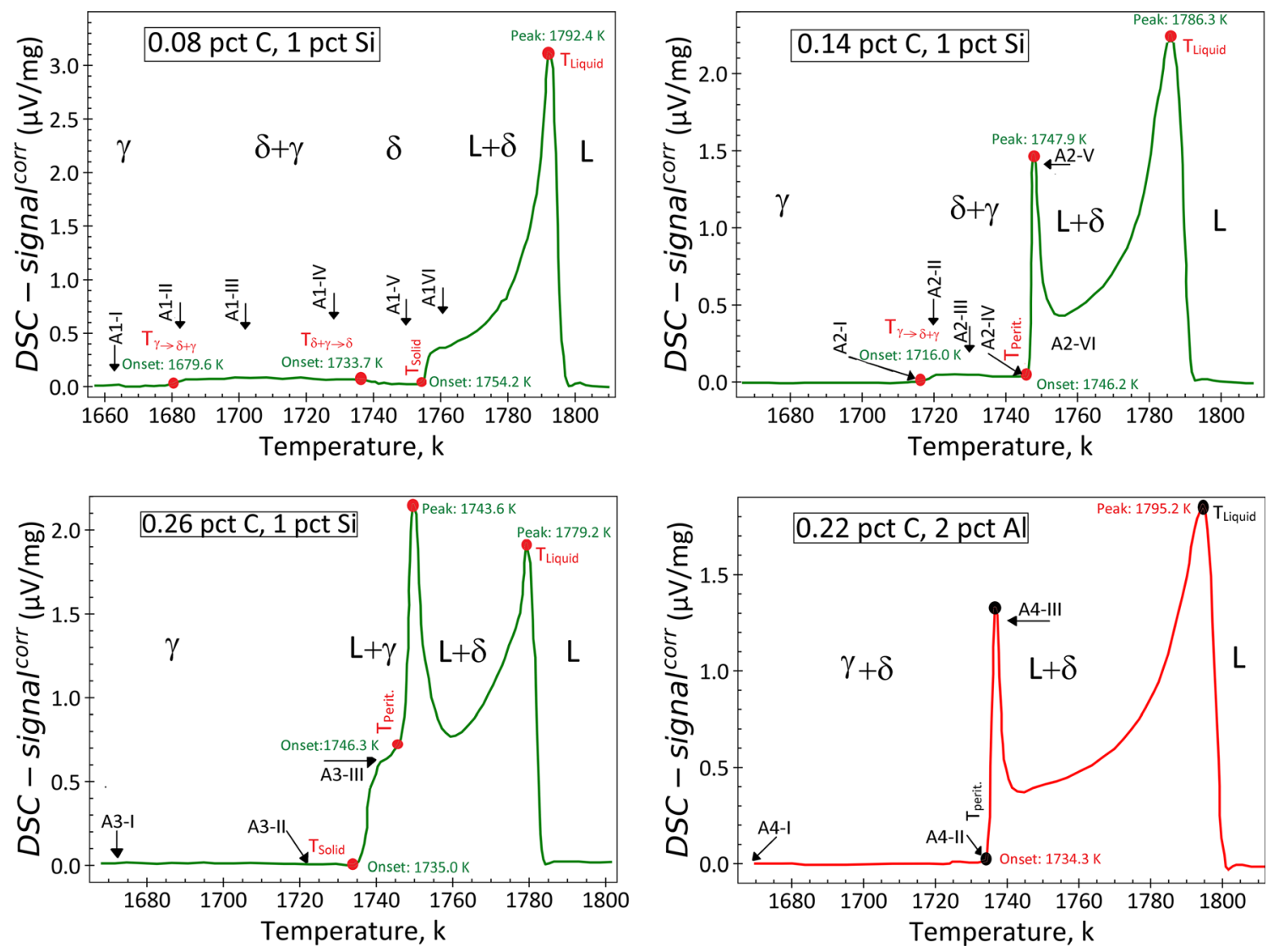

Fig. 2-The DSC measurement of different steel grades. Reprinted with permission from Ref. [41]. 


\section{Carbon equivalent range methods}

Several different models have been proposed to predict if a steel exhibits peritectic behavior based on calculating the carbon equivalent $\left(C_{\mathrm{P}}\right)$ of the steel alloy. If the calculated carbon equivalent is between a critical range, such as falling between $C_{\mathrm{A}}=0.09$ pct $\mathrm{C}$ and $C_{\mathrm{B}}=0.17$ pct $\mathrm{C}$ (peritectic region in Figure 1) then the steel is considered to be peritectic and its sensitivity to depressions and cracks is high. Wolf ${ }^{[52]}$ proposed the following equation for carbon equivalent.

$$
\begin{aligned}
C_{\mathrm{P}}= & {[\mathrm{C}]+0.02[\mathrm{Mn}] } \\
& +0.04[\mathrm{Ni}]-0.1[\mathrm{Si}]-0.04[\mathrm{Cr}]-0.1[\mathrm{Mo}],
\end{aligned}
$$

where brackets contain weight percent of alloying elements. Howe ${ }^{[63]}$ proposed the following alternative.

$$
\begin{aligned}
C_{\mathrm{P}}= & {[\mathrm{C}]+0.04[\mathrm{Mn}]+0.1[\mathrm{Ni}] } \\
& +0.7[\mathrm{~N}]-0.14[\mathrm{Si}]-0.04[\mathrm{Cr}]-0.1[\mathrm{Mo}]-0.24[\mathrm{Ti}] .
\end{aligned}
$$

Xia et al. ${ }^{[50]}$ suggests the following equation for calculation of carbon equivalent.

$$
\begin{aligned}
C_{\mathrm{P}}= & {[\mathrm{C}]+0.02[\mathrm{Mn}]-0.037[\mathrm{Si}] } \\
& +0.023[\mathrm{Ni}]-0.0189[\mathrm{Mo}]-0.7[\mathrm{~S}]+0.0414[\mathrm{P}] \\
& +0.003[\mathrm{Cu}]-0.0254[\mathrm{Cr}]-0.0267[\mathrm{Ti}]+0.7[\mathrm{~N}] .
\end{aligned}
$$

Normanton and other researchers at Trico Steel and British Steel ${ }^{[64]}$ proposed two more equations for the calculation of carbon equivalent, ${ }^{[64]}$

$$
\begin{aligned}
C_{\mathrm{P}}= & {[\mathrm{C}]+0.01[\mathrm{Mn}]+0.009[\mathrm{Si}]+0.02[\mathrm{Ni}] } \\
& +0.003[\mathrm{Cr}]-0.007[\mathrm{Mo}]+0.009[\mathrm{~V}]+0.008[\mathrm{P}] \\
& +0.147[\mathrm{~S}]+0.5[\mathrm{~N}]+0.007[\mathrm{Cu}]+0.007[\mathrm{Ti}] \\
& +0.05[\mathrm{Al}]+0.04[\mathrm{Nb}],
\end{aligned}
$$

$$
\begin{aligned}
C_{\mathrm{P}}= & {[\mathrm{C}]+0.043[\mathrm{Mn}]-0.14[\mathrm{Si}] } \\
& +0.1[\mathrm{Ni}]-0.083[\mathrm{Cr}]-0.063[\mathrm{Mo}]-0.13[\mathrm{~V}] \\
& +0.029[\mathrm{P}]+0.11[\mathrm{~S}]+1.06[\mathrm{~N}] \\
& +0.037[\mathrm{Cu}]-0.024[\mathrm{Ti}] .
\end{aligned}
$$

As can be seen in Eqs. [1] through [5], the equivalent weight concentrations of austenite-forming elements $(\mathrm{Mn}, \mathrm{Ni}, \mathrm{Cu}$, and $\mathrm{N}$ ) are added to the $\mathrm{C}$ content and the ferrite-forming element $\mathrm{Mo}$ is subtracted, as expected. The elements $\mathrm{P}, \mathrm{Al}$, and $\mathrm{Nb}$ are ferrite-forming elements, ${ }^{[65]}$ yet their terms are added to the $\mathrm{C}$ content in several equations. The effects of $\mathrm{Si}, \mathrm{Cr}, \mathrm{Ti}, \mathrm{V}$, and $\mathrm{S}$ are not consistent between equations.

\section{Alloy-dependent critical points methods}

Blazek et al. ${ }^{[66]}$ proposed a different method, defining a steel as peritectic when its carbon content is between $C_{\mathrm{A}}$ and $C_{\mathrm{B}}$, which change with alloy composition as follows:

$$
\begin{aligned}
C_{\mathrm{A}}= & 0.0896+(0.0458 \mathrm{Al})-(0.0205 \mathrm{Mn})-(0.0077 \mathrm{Si}) \\
& +\left(0.0223 \mathrm{Al}^{2}\right)-(0.0239 \mathrm{Ni})+(0.0106 \mathrm{Mo}) \\
& +(0.0134 \mathrm{~V})-(0.0032 \mathrm{Cr})+\left(0.00059 \mathrm{Cr}^{2}\right) \\
& +(0.0197 \mathrm{~W}),
\end{aligned}
$$

$$
\begin{aligned}
C_{\mathrm{B}}= & 0.1967+(0.0036 \mathrm{Al})-(0.0316 \mathrm{Mn})-(0.0103 \mathrm{Si}) \\
& +\left(0.1411(\mathrm{Al})^{2}\right)+(0.05(\mathrm{AlSi}))-(0.0401 \mathrm{Ni}) \\
& +(0.03255 \mathrm{Mo})+(0.0603 \mathrm{~V})+(0.0024 \mathrm{Cr}) \\
& +\left(0.00142\left(\mathrm{Cr}^{2}\right)-(0.00059(\mathrm{CrNi}))+0.0266 \mathrm{~W}\right.
\end{aligned}
$$

This relation, which was based on thermodynamic calculations with ThermoCalc ${ }^{[67]}$ is reported to be accurate for many steel grades, ${ }^{[6]}$ and has successfully been implemented into several steel plants to enable appropriate choice of mold powder and casting practice. ${ }^{[66]}$ However, this relation may be inaccurate for steels with high Si content. The sign of the Si term in the effective carbon equations is negative (shift $C_{\mathrm{A}}$ to the left), which may be opposite to expectations, so this term is controversial. Other studies ${ }^{[3]}$ have confirmed that increasing $\mathrm{Mn}$ shifts the peritectic range to the left and agrees with Blazek $^{[66]}$ that $\mathrm{Al}$ shifts the peritectic range to the right. Those studies also found that $\mathrm{S}$ shifts the peritectic range to the left and $\mathrm{P}$ shifts it to the right. ${ }^{[53]}$ Clearly, there is still some disagreement regarding the effects of several elements on peritectic formation.

\section{Ferrite potential}

Wolf introduced the term, "ferrite potential," as a measure of the extent of peritectic behavior experienced with a given steel alloy. ${ }^{52]}$ "Ferrite potential" is also defined as the solid fraction of primary ferrite during solidification. Using the ferrite potential concept, steels can be categorized into depression-sensitive and sticker-sensitive grades. Peritectic steels are depression sensitive, owing to their greater shrinkage, and tend to suffer from deep oscillation marks and uneven shell growth, leading to surface cracks and other defects, as discussed in Section IV. Non-peritectic steels are more sticker-sensitive, tending to stick to the mold walls, which leads to a higher risk of sticker breakouts. ${ }^{[68-70]}$ Although the ferrite potential is affected most by the carbon content, it is also affected by other alloying elements. ${ }^{[52]}$ Some elements stabilize the austenite $(\mathrm{Ni}$, $\mathrm{Mn}, \mathrm{Co}, \mathrm{N}$, and $\mathrm{Cu}$ ) while others are believed to stabilize the ferrite $(\mathrm{Cr}, \mathrm{W}, \mathrm{Mo}, \mathrm{Al}$, and $\mathrm{Si}) .{ }^{[65]}$ For low-alloy steels, the ferrite potential (FP) can be calculated as follows ${ }^{[52]}$ :

$$
\mathrm{FP}=1.25-2.5\left[C_{\mathrm{P}}\right],
$$

where $C_{\mathrm{P}}$ is carbon equivalent and is calculated using Eq. [1], where $0<\mathrm{FP}<1$ indicates that the peritectic reaction takes place during solidification. When FP is in the range of 0.85 to 1.05 (peritectic behavior range), 
the tendency for depressions, crack formation, and uneven shell growth is high. Steels in this range are depression-sensitive grades (steel type A) and steels outside this range $(\mathrm{FP}<0.85$ or $\mathrm{FP}>1.05)$ are sticker-sensitive grades (steel type B). ${ }^{[52]}$ The effect of ferrite potential on the tendency of depression formation is shown in Figure 3.

Sarkar et al. ${ }^{[55]}$ generalized the Wolf ferrite potential for peritectic solidification by including the effects of alloying elements on the $C_{\mathrm{A}}, C_{\mathrm{B}}$, and $C_{\mathrm{C}}$ points, as follows:

$$
\begin{aligned}
C_{\mathrm{A}}= & 0.0927+(0.0471 \mathrm{Mn})-(0.0859 \mathrm{Si})-(0.0237 \mathrm{Ni}) \\
& -(0.5429 \mathrm{~S})-(0.3553 \mathrm{~N})-(0.0361 \mathrm{Ti})-(0.0136 \mathrm{Nb}) \\
& +(0.0106 \mathrm{~V})+(0.1097 \mathrm{Mn} \mathrm{Si})-(5.6239 \mathrm{MnS}) \\
& -\left(0.0165 \mathrm{Mn}^{2}\right),
\end{aligned}
$$

$$
\begin{aligned}
C_{\mathrm{B}}= & 0.1716-(0.0589 \mathrm{Mn})-(0.1776 \mathrm{Si})-(0.0053 \mathrm{Cr}) \\
& -(0.0410 \mathrm{Ni})+(0.0473 \mathrm{Al})-(0.9453 \mathrm{~S}) \\
& -(0.0160 \mathrm{P})-(0.6884 \mathrm{~N})+(0.0283 \mathrm{Ti})-(0.0147 \mathrm{Nb}) \\
& +(0.0285 \mathrm{~V})+(0.2342 \mathrm{MnSi}),
\end{aligned}
$$

$$
\begin{aligned}
C_{\mathrm{C}}= & 0.5274-(0.0124 \mathrm{Mn})-(0.1424 \mathrm{Si})-(0.0154 \mathrm{Cr}) \\
& -(0.0981 \mathrm{Ni})+(0.0934 \mathrm{Al})-(0.3871 \mathrm{~S}) \\
& -(0.0533 \mathrm{P})-(2.0916 \mathrm{~N})+(0.1226 \mathrm{~V}) \\
& +(0.2363 \mathrm{MnSi})+(0.0729 \mathrm{MnP})-\left(0.0729 \mathrm{Mn}^{2}\right) .
\end{aligned}
$$

Using the same form as Wolf, ${ }^{[52]}$ they ${ }^{[55]}$ redefined ferrite potential as follows:

$$
\mathrm{FP}=\frac{C_{\mathrm{C}}-[\mathrm{C}]}{C_{\mathrm{C}}-C_{\mathrm{A}}},
$$

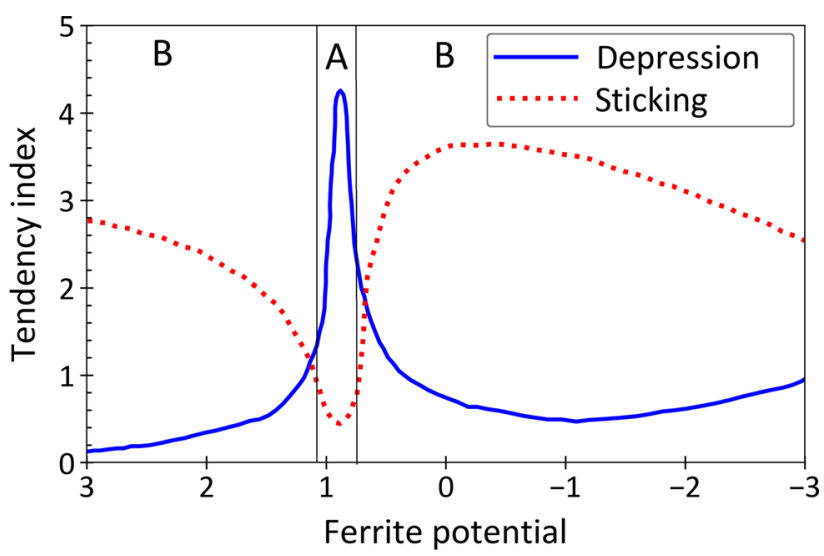

Fig. 3-Ferrite potential indicator of peritectic steel behavior showing sensitivity of these (type A) steels to depressions, contrasted with sticking tendency of other (type B) steels. Redrawn with permission from Ref. [52]. where $[\mathrm{C}]$ is the carbon weight percentage. When $\frac{C_{\mathrm{C}}-C_{\mathrm{B}}}{C_{\mathrm{C}}-C_{\mathrm{A}}}<\mathrm{FP}<1$ the steel is a depression-sensitive, or "peritectic," grade and when $0<\mathrm{FP}<\frac{C_{\mathrm{C}}-C_{\mathrm{B}}}{C_{\mathrm{C}}-C_{\mathrm{A}}}$ or $\mathrm{FP}>1$ the steel is a sticking-sensitive grade. This new ferrite potential criterion ${ }^{[55]}$ has same critical range to define peritectic behavior as the Blazek method, $C_{\mathrm{A}}<[\mathrm{C}]<$ $C_{\mathrm{B}}$. This equation also matches the Wolf ferrite potential equation, for low-alloy steels containing $\mathrm{Mn}, \mathrm{Si}$, $\mathrm{Ni}, \mathrm{Cr}$, and Mo, without considering sulfur.

\section{CALPHAD method}

Calculation of multicomponent phase diagrams using commercial thermodynamics-based software like ThermoCalc ${ }^{[71]}$ is an important tool for help in identification of peritectic steels. Such modeling tools are better suited for high-alloy steels than the pseudo-binary assumption inherent in the empirical models presented in the previous sections. However, the accuracy of these software tools depends on their databases, which have been developed only for a limited set of conditions. Furthermore, reliable criteria are still needed to infer peritectic behavior from the phase diagram predictions. To do this, fundamental understanding of peritectic behavior is needed, which is reviewed next.

\section{MECHANISMS OF PERITECTIC SOLIDIFICATION}

Peritectic solidification has been investigated by many researchers ${ }^{[32,72-78]}$ and different mechanisms have been proposed to explain the details of this phenomenon. These include thermal diffusion of solute atoms, ${ }^{[76]}$ and/or re-melting of $\delta$ ferrite, ${ }^{[31]}$ to explain the peritectic reaction and diffusion or massive transformation to explain the peritectic transformation. ${ }^{[33,77-80]}$ Many models ${ }^{[32,72-74]}$ assume that the peritectic reaction and transformation are both controlled by the diffusion of solute atoms, especially carbon in plain-carbon steel and nickel in alloy steels. Some measurements, by diffusion couple ${ }^{[75]}$ and directional solidification experiments, ${ }^{[79]}$ agree with these diffusion-control mechanism. However, other experimental studies ${ }^{[31,33,76,80-82]}$ have shown that the rates of the peritectic reaction and transformation are very fast, especially $\gamma$-austenite layer growth along the liquid $/ \delta$-ferrite interface in the peritectic reaction, and especially under realistic, non-equilibrium conditions. Recent phase-field simulations suggest that these high rates can be explained by diffusion. ${ }^{[83-85]}$ Other researchers claim that these observations cannot be explained by diffusion mechanism(s) alone, and have suggested other mechanisms, including microscale heat transfer and fluid mixing involving $\delta$-ferrite re-melting. ${ }^{[31,76,80]}$ and massive transformation. ${ }^{[31,33,86-89]}$ In the following sections, different proposed mechanisms for the peritectic reaction and peritectic transformation in steels are discussed in turn, after introducing the experimental methodologies used to obtain supporting measurements for these mechanisms and their models. 


\section{A. Experimental Methods for Studying Peritectic Solidification}

Four experimental methods have been widely used to study peritectic solidification, including the solid/liquid diffusion couple experiment, high-temperature confocal laser scanning microscopy (HT-CLSM), X-ray imaging, and directional solidification.

In the solid/liquid diffusion couple experiment, ${ }^{[75,90-94]}$ a steel alloy is melted in a crucible and then is slowly cooled down to a specific temperature (for example $1696 \mathrm{~K}$ ) to crystallize a small amount of the austenite, leaving residual liquid with an equilibrium carbon content at peritectic point. Then, a sample of a different steel alloy ( $\delta$-ferrite) from a lower temperature furnace is positioned just above the alloy already in the crucible. The two alloys are then brought into contact with each other for a preset length of time, forming a diffusion couple, before rapidly dropping into ice water. A longitudinal cross section is etched to reveal the solidification microstructure, and the thickness of the austenite formed between the regions formerly containing $\delta$-ferrite and liquid, as well as measuring the carbon distribution. Although it is a powerful technique to investigate solidification under isothermal conditions,${ }^{[95,96]}$ other methods are needed for realistic high cooling rates.

HT-CLSM,${ }^{[41,56]}$ is a powerful improvement to the conventional optical microscope that focusses a laser beam into a small area on the surface of a high-temperature sample of molten steel. ${ }^{[33,62,80,97-99]}$ While carefully cooling at a desired rate, solidification on the liquid surface can be observed by building up images pixel-by-pixel from photons emitted from the fluorophores. The different solid and liquid phases can be distinguished due to their emissivity differences. HT-CLSM can operate at high temperatures (over $1800{ }^{\circ} \mathrm{C}$ ), has controllable depth of field ${ }^{[100,101]}$ and high resolution $(0.15 \mu \mathrm{m}) .{ }^{[102]}$ It can record high-frequency images in real time for realistic cooling rates (e.g., 3000 $\left.{ }^{\circ} \mathrm{C} / \mathrm{min}\right)^{[102]}$ and sample sizes (e.g., $\left.8 \mathrm{~mm}\right) .{ }^{[102]}$ Even though only the surface can be seen, the ability of HT-CLSM to visualize peritectic solidification in situ and in real time is revolutionizing our understanding of the phenomenon.

Time-resolved X-ray imaging has recently been applied to investigate solidification of steels. ${ }^{[82,103-105]}$ In a synchrotron radiation facility, hard X-rays with photon energy ranging from 10 to $100 \mathrm{keV}$ can penetrate through the bulk metallic material to obtain X-ray images. These systems feature high-contrast, high-resolution images due to monochromatic light, high coherency, and high brightness. X-ray imaging has the big advantage over HT-CLSM of being able to observe the real three-dimensional microstructure evolution inside the bulk volume of the sample. ${ }^{[104]}$
Finally, directional solidification is a laboratory process in which molten metal is drawn downward at a controlled withdrawal speed, $V$, through a controlled temperature gradient, $G .^{[106-108]}$ Heating block temperatures beside the sample path are controlled to maintain steady-state conditions in the moving sample in the frame of reference of the laboratory, with a stationary solidification front located between the hot zone toward the top of the apparatus and the cold zone below. This continuous process enables controlled conditions for experimental measurements of solidification, which include the concentration and microstructure profiles. Although the thermal field tends to stabilize the process, the concentration field may produce fluid flow and morphological instabilities near the solidification front, depending on how the liquid density varies with solute concentration. ${ }^{[109]}$ These opposing effects may cause instabilities that equilibrate in amplitude, making this system an excellent vehicle for the careful study of phase transformation dynamics. ${ }^{[110]}$ Due to its ability to control the local casting conditions, which may enable high thermal gradients ${ }^{[11]}$ and deep supercooling, ${ }^{[12-114]}$ this technique is good for fundamental study of solidification behavior, especially when combined with X-ray imaging to observe the in situ microstructure evolution. $^{[115,116]}$

\section{B. Diffusion Control Mechanism for the Peritectic Reaction}

Many modeling and experimental investigations of the peritectic reaction in steel have concluded that it is controlled by the diffusion of solute atoms, especially carbon. ${ }^{[75,80,86,90,98,117]}$ According to the equilibrium Fe-C phase diagram (Figure 1), at the peritectic temperature, $\delta$-ferrite at only 0.1 pct $\mathrm{C}$ is in equilibrium with austenite at 0.18 pet $\mathrm{C}$ and liquid at 0.52 pct C. Growth of the austenite plate thus requires the rejection of solute (carbon) into the liquid, which is proposed by many to be limited by the rate of solute diffusion through the liquid away from the region, specifically carbon in this case. As this peritectic solidification phenomenon occurs at high temperatures $\left(1495{ }^{\circ} \mathrm{C}\right.$ in Fe-C binary alloys), early experimental investigations were rare. Thus, early studies of peritectic solidification applied analytical models based on diffusion laws to study the peritectic reaction of steel. ${ }^{[32,72-74]}$

Many models of the peritectic reaction have been developed to predict the growth rate of the austenite layer along the $\delta$-ferrite/liquid interface during the peritectic reaction, which are based on solving Fick's second law for the diffusion of solute atoms through the austenite phase and mass balances on solute transport across the interfaces. ${ }^{[72,73]}$ One analytical solution for the $\gamma$-platelet growth rate, $V_{\gamma}^{[74]}$ in a hypothetical binary $\mathrm{Fe}-\mathrm{m}$ system, includes the effects of tip radius on the interfacial diffusion: 


$$
\begin{gathered}
V_{\gamma}=\left(\frac{9}{8 \pi}\right)\left(\frac{D_{\mathrm{m}}^{\mathrm{L}}}{\rho}\right) \omega^{2}, \\
\omega=\frac{\Omega}{1-\frac{2 \Omega}{\pi}-\frac{\Omega^{2}}{2 \pi}}, \\
\Omega=\frac{\left(C_{\mathrm{m}}^{\mathrm{L} / \gamma}-C_{\mathrm{m}}^{\mathrm{L} / \delta}\right)}{\left(C_{\mathrm{m}}^{\mathrm{L} / \gamma}-C_{\mathrm{m}}^{\gamma / \mathrm{L}}\right)},
\end{gathered}
$$

where $D_{\mathrm{m}}^{\mathrm{L}}$ is the diffusion coefficient in the melt of the solute, $m$ such as carbon ${ }^{[33]}$ or nickel, ${ }^{[17]}$ through the liquid steel, $\rho$ is the tip radius of the edge of the growing austenite plate along the $\delta / \mathrm{L}$ interface (Figure 1(b)); $\Omega$ is relative dimensionless supersaturation of solute atoms in the liquid above equilibrium at the two interfaces; $C_{\mathrm{m}}^{\mathrm{L} / \gamma}$ and $C_{\mathrm{m}}^{\mathrm{L} / \delta}$ are the solute atom concentrations in the liquid in equilibrium with the $\gamma$ and $\delta$ phases, respectively; and $C_{\mathrm{m}}^{\gamma / \mathrm{L}}$ is carbon concentration in the $\gamma$ in equilibrium with the liquid. These diffusion models typically assume no barrier to $\gamma$-phase nucleation upon reaching the peritectic temperature. ${ }^{[73]}$ This model was extended to better consider surface tension and the capillarity (Gibbs-Thompson) effect between $\gamma$ austenite and $\delta$ ferrite ${ }^{[74]}$

$$
V_{\gamma}=\frac{27 D^{\mathrm{L}} R T\left(k_{\mathrm{fe}}^{\gamma / \mathrm{L}}-k_{\mathrm{m}}^{\gamma / \mathrm{L}}\right)\left(C_{\mathrm{m}}^{\mathrm{L} / \gamma}-C_{\mathrm{m}}^{\mathrm{L} / \delta}\right)}{128 \pi \sigma^{\delta / \gamma} V_{\mathrm{m}}^{\mathrm{L}}}\left(\frac{\Omega}{\omega}\right)^{3},
$$

where $R$ is the gas constant; $k_{\mathrm{fe}}^{\gamma / \mathrm{L}}$ and $k_{\mathrm{m}}^{\gamma / \mathrm{L}}$ are the partition coefficients of iron and solute, respectively, at the $\mathrm{L} / \gamma$ interface; $\sigma^{\delta / \gamma}$ is the surface tension between $\delta$ and $\gamma$ and is equal to the interface elastic strain energy per unit area at the interface between $\delta$ and $\gamma$; and $V_{\mathrm{m}}^{\mathrm{L}}$ is the molar volume of the liquid steel. Lateral growth rate is strongly dependent on $\Omega$, which determines by the shape of the phase diagram just below the peritectic temperature. The above calculations were conducted for an Fe-Ni binary system for different $\Omega$ values and the calculated growth rates agree reasonably well with measured growth rates. ${ }^{[80]}$

The peritectic reaction has been studied at different temperatures ${ }^{[75]}$ using the method proposed by Ueshima et al. ${ }^{[86]}$ The results showed that decreasing temperature increases the peritectic reaction rate. ${ }^{[75]}$ This is suggested to be due to the significant increase in carbon concentration gradient in the interfaces of austenite with liquid and $\delta$ ferrite caused by decreasing temperature. The accompanying decrease in the diffusion coefficient is too small to offset the increase in concentration gradient. ${ }^{[75]}$

Images in Figure 4 from a HT-CLSM study of a hyper-peritectic alloy with 5.1 pet $\mathrm{Ni}^{[80]}$ show that austenite appears at the triple point formed by the boundaries of two planar $\delta$ grains with the liquid. This austenite platelet grows very fast with lateral movement along the $\mathrm{L} / \delta$ interface, and thickens as it

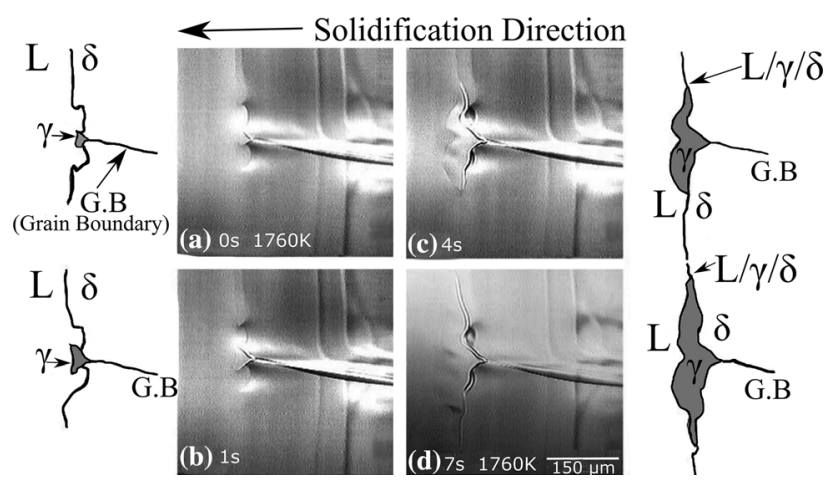

Fig. 4-Lateral growth of $\gamma$ at $\mathrm{L} / \delta$ interface in the early stages of the peritectic reaction of $\mathrm{Fe}-4.86$ pct $\mathrm{Ni}$ alloy. Reprinted with permission from Ref. [80].

simultaneously grows slowly into both the liquid and the $\delta$ ferrite. The measured lateral growth rate (peritectic reaction) increases from 30 to $145 \mu \mathrm{m} / \mathrm{s}$ with increasing cooling rate. ${ }^{[80]}$ This sequence of peritectic reaction steps has been reported for hyper-peritectic carbon steel $(\mathrm{Fe}-0.42 \text { pct C })^{[33]}$ and for Fe-Ni systems. ${ }^{[117]}$ Lateral growth (peritectic reaction) was much faster $(2970 \mu \mathrm{m} / \mathrm{s})$ in the Fe-C alloy than in the Fe-Ni alloy. This was attributed to the higher diffusion rate of carbon in $\mathrm{Fe}-\mathrm{C}$ liquid than $\mathrm{Ni}$ in $\mathrm{Fe}-\mathrm{Ni}$ liquid. ${ }^{[33]}$

In another experimental study on $\mathrm{Fe}-4.7$ pet $\mathrm{Ni}^{[98]}$ observing the growth rate of austenite platelets during the peritectic reaction, it was concluded that the nickel diffusion field controlled the growing austenite plates, which is greatly influenced by the tip radius at the edge of the plate. Three regimes were observed for austenite growth along the $\delta$-ferrite/liquid interface: (1) constant tip shape and velocity of two austenite platelets growing toward each other, while their diffusion fields are independent, (2) flattening tip shape and decreasing velocity, when the plates approach each other, and their diffusion fields likely begin to interact; and (3) sudden distortion of the platelet tips, and increasing velocity, when the adjacent growing austenite tips interfere, indicating that their diffusion fields have drastically changed. ${ }^{\text {98] }}$

\section{C. $\delta$-Ferrite Re-melting Mechanism for the Peritectic Reaction}

Based on experimental observations, several researchers have concluded that the peritectic reaction velocity is very fast and thus cannot be controlled only by diffusion of carbon through the $\gamma$ phase. ${ }^{[31,76,80]}$ The re-melting of ferrite ahead of advancing $\gamma$ phase during the peritectic reaction has been proposed by Hillert ${ }^{[118]}$ as an important mechanism that controls the peritectic reaction. This phenomenon has been confirmed by experimental observations $^{[31,76]}$ and phase-field simulations which include both diffusion and microscale heat transfer ${ }^{[85,119]}$ and are discussed in the following paragraphs.

Hillert ${ }^{[18]}$ proposed that re-melting of the $\delta$-ferrite interface occurs near the $\delta / \gamma / \mathrm{L}$ triple point near the edge of the growing austenite platelet tip. Furthermore, this re-melting was proposed as evidence for a new 


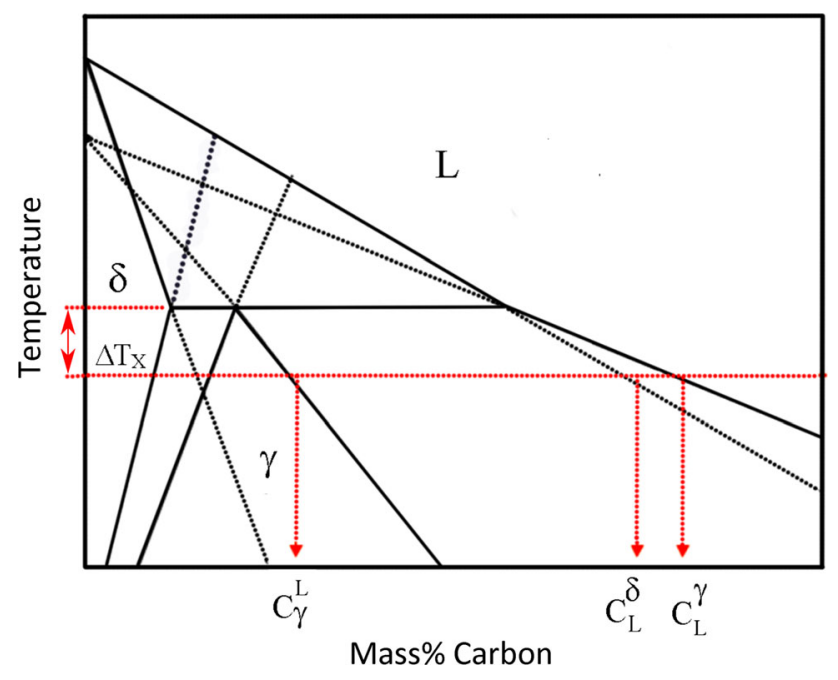

Fig. 5-Linearized Fe-C phase diagram showing phase compositions at different interfaces (solid black lines show equilibrium; dashed black lines show metastable extensions, and thick dashed red lines show undercooled conditions where peritectic reaction actually occurs). Reprinted with permission from Ref. [76] (Color figure online).

mechanism for control of the peritectic reaction rate. During cooling from above the peritectic reaction temperature, the formation of austenite with composition of $C_{\gamma}^{\mathrm{L}}$ causes the rejection of carbon into the liquid ahead of austenite plate which is growing along the $\mathrm{L} / \delta$ interface. In this situation, the carbon concentration at the $\mathrm{L} / \gamma$ interface $\left(C_{\mathrm{L}}^{\gamma}\right)$ is higher than the carbon concentration at the $\mathrm{L} / \delta$ interface $\left(C_{\mathrm{L}}^{\delta}\right)$, as shown in Figure 5. The $\delta$ ferrite is in contact with liquid which is enriched with carbon (above the equilibrium concentration) so it leads to some re-melting of ferrite.

Recent experiments ${ }^{[76]}$ by in situ HT-CLSM observation (Figure 6) obtained visual evidence of this proposed mechanism for the peritectic reaction, in which a thin austenite plate grows along the interface and re-melting of ferrite takes place at the edge of the growing austenite platelet. This landmark experimental observation revealed that the tip velocity at the edge of the growing austenite layer is in the range of $1.4 \times 10^{3}$ to $12.5 \times 10^{3}$ $\mu \mathrm{m} / \mathrm{s}$. These researchers argued that this rate is higher than that can be explained by diffusion of carbon alone, and that the rate-limiting step in the peritectic reaction is dissipation of the latent heat of transformation, rather than carbon diffusion. ${ }^{[120]}$ Although these experimental observations are very clear, other mechanisms cannot be dismissed, because surface phenomena might affect the behavior being visualized on the surface in these microscope images, relative to that in the bulk volume interior of the sample and the real process.

The analytical model in Eqs. [13] through [15] was used to calculate the growing velocity of an austenite plate $^{[76]}$ due to carbon diffusion, and even for a very low tip radius of $0.15 \mu \mathrm{m}$, the predicted tip velocity was much lower than the experimentally observed rate in an $\mathrm{Fe}-\mathrm{C}$ system $^{[76]}$ of 400 to $12,500 \mu \mathrm{m} / \mathrm{s}$ at high undercooling. Thus, it was concluded that the peritectic reaction is not controlled by carbon diffusion alone. ${ }^{[76]}$

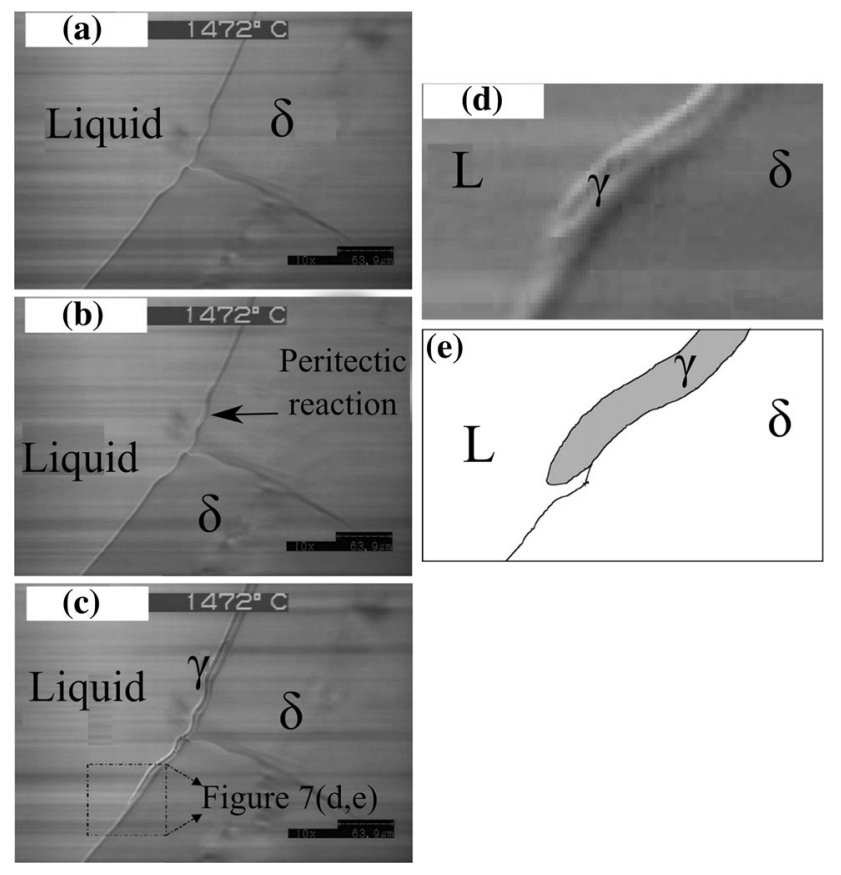

Fig. 6-HT-CLSM images of the peritectic reaction in Fe-0.18 pct $\mathrm{C},(a)$ start of peritectic reaction, $(b)$ initiation of austenite layer at liquid/ $\delta$-ferrite interface, $(c)$ growth of austenite layer along that interface, $(d)$ close-up of austenite layer showing re-melting of $\delta$-ferrite ahead of its growing edge, and (e) schematic of previous frame. Reprinted with permission from Ref. [76].

Considering the latent heat of transformation, the re-melting of $\delta$-ferrite was proposed to improve the prediction of the reaction rate. Growth rates were calculated using the following equation for directional solidification $^{[12]}$ :

$$
V_{\max }=\frac{K_{\mathrm{s}} G_{\mathrm{s}}}{\rho L},
$$

where $K_{\mathrm{s}}$ is the thermal conductivity, taken for $\delta$ ferrite, $G_{\mathrm{s}}$ is the thermal gradient in the solid $(\mathrm{K} / \mathrm{m}), \rho$ is density, and $L$ is the latent heat of fusion, taken to be $62.8 \mathrm{~kJ} / \mathrm{kg}$ for peritectic transformation in this $0.18 \mathrm{pct}$ $\mathrm{C}$ alloy, The calculated growth rates of the austenite platelet with and without considering re-melting are compared in Figure 7. Without considering re-melting, the tip velocities are 19 to $855 \mu \mathrm{m} / \mathrm{s}$ for thermal gradients of 1 to $45 \mathrm{~K} / \mathrm{mm}$, which are considerably lower than the measured velocities. Including $50 \mathrm{~kJ} / \mathrm{kg}$ of latent heat released by austenite formation to remelt some of the $\delta$-ferrite, the calculated reaction velocity increased to 315 to $12,500 \mu \mathrm{m} / \mathrm{s}$, which is in the range of the measurements.

Based on these findings, an alternative mechanism for the peritectic reaction was proposed. Some of the latent heat released by the austenite formation could remelt some nearby ferrite. Then, instead of requiring diffusion to transport carbon away from the solidifying austenite tip, the re-melted $\delta$ ferrite $(0.1$ pct $\mathrm{C})$ mixing with the enriched liquid $(0.52$ pct $\mathrm{C})$ ahead of the austenite tip $(0.18$ pct $\mathrm{C})$ could produce liquid at roughly the required composition for the solid austenite. The austenite tip 
therefore can grow into liquid at about the same composition, without the need for much carbon diffusion. This would enable the high austenite growth rates observed.

The re-melting phenomenon has also been observed by other HT-CLSM experiments. ${ }^{[31]}$ A sequence of events during intermittent austenite growth in a Fe-0.43 pct $\mathrm{C}$ alloy near equilibrium is shown in Figure 8, with a schematic illustrating the expected temperature evolution provided below. To explain the discontinuous growth in this figure, these authors argue that the re-melting of $\delta$-phase occurs first and causes the sudden $\gamma$ plate growth. When temperature is relatively constant, all three phases are proposed to be in equilibrium and no diffusion takes place (Figure 8 top frames 1, 3, 5, and 7). Decreasing temperature creates a driving force for diffusion. In both $\mathrm{Fe}-\mathrm{C}$ and $\mathrm{Fe}-\mathrm{Ni}$ systems, this driving force is much higher for the solute atoms than for the

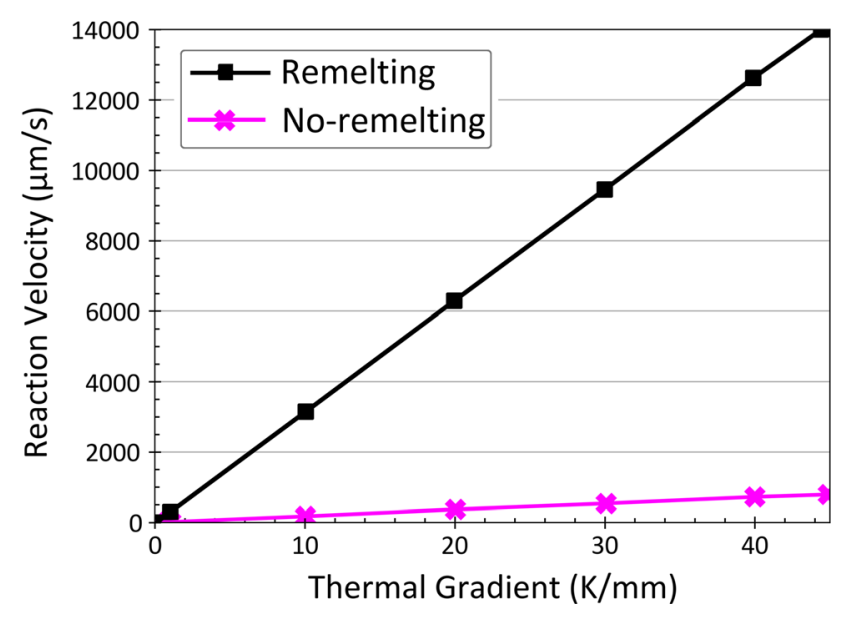

Fig. 7-Calculated growth rates of an austenite platelet along the liquid/ $\delta$-ferrite interface with and without consideration of $\delta$-ferrite re-melting. Reprinted with permission from Ref. [76]. iron atoms. Thus, the partitioning of solute atoms occurs first and causes re-melting of some $\delta$-ferrite phase (Figure 8 top frames 2, 4, 6 with dashed lines and temperature drops). After a certain amount (length dL) of $\delta$ has re-melted, the $\gamma$ phase grows into the re-melted region. This mechanism agrees with Hillert ${ }^{[118]}$ but contrasts with Phelan et al. ${ }^{[76]}$ who believe that the re-melting of $\delta$ ferrite takes place due to the dissipation of latent heat released during the growth of the $\gamma$. The re-melting phenomenon has been also reported in peritectic solidification of Fe-Ni alloys. ${ }^{[80]}$

The $\delta$-ferrite re-melting phenomenon has been confirmed by several phase-field modeling studies. ${ }^{84,122-124]}$ For example, Figure 9 shows how the $\delta / \gamma / \mathrm{L}$ triple point and associated interfaces move during $\gamma$ growth at different undercoolings. ${ }^{[85]}$ In addition to a sharper tip radius, increasing undercooling causes the $\delta / \mathrm{L}$ interface near this junction to move toward the $\delta$ phase, which indicates some re-melting of the $\delta$ region.

In another phase-field modeling study ${ }^{[119]}$ of the peritectic reaction focusing on the $\mathrm{L} / \delta / \gamma$ triple point, the liquid region expands toward the $\delta$ ferrite, as shown in Figure 10, again indicating melting of the $\delta$-phase in front of the growing $\gamma$ platelet. This melting reduces the local supersaturation, which enhances growth of the $\gamma$ platelet. Thus, it appears that the peritectic reaction is controlled by a complex mechanism that involves microscale heat transfer that causes some re-melting of $\delta$ ferrite near the tip of the advancing $\gamma$ platelet, and mixing of solute in the liquid phase, in addition to solute diffusion.

\section{Diffusion Control Mechanism for Peritectic Transformation}

Many researchers have proposed that the peritectic transformation in steel is controlled by diffusion. ${ }^{[31,32,74,75,125,126]}$ The austenite layer initially grows laterally along the $\mathrm{L} / \delta$ solidification front, and locally replaces the $\mathrm{L} / \delta$ interface with a thin layer of austenite,

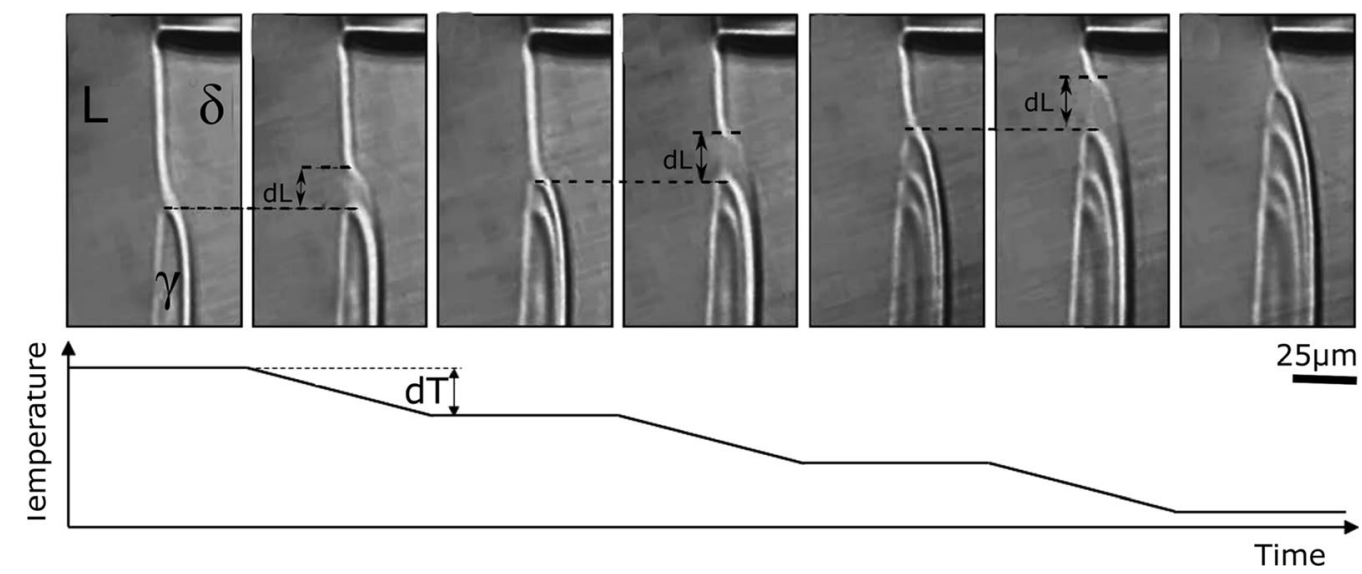

Fig. 8- Sequence of events during incremental growth of $\gamma$ in a Fe- 0.43 pct C alloy, showing temperature and microstructure at different times. Reprinted with permission from Ref. [31]. 

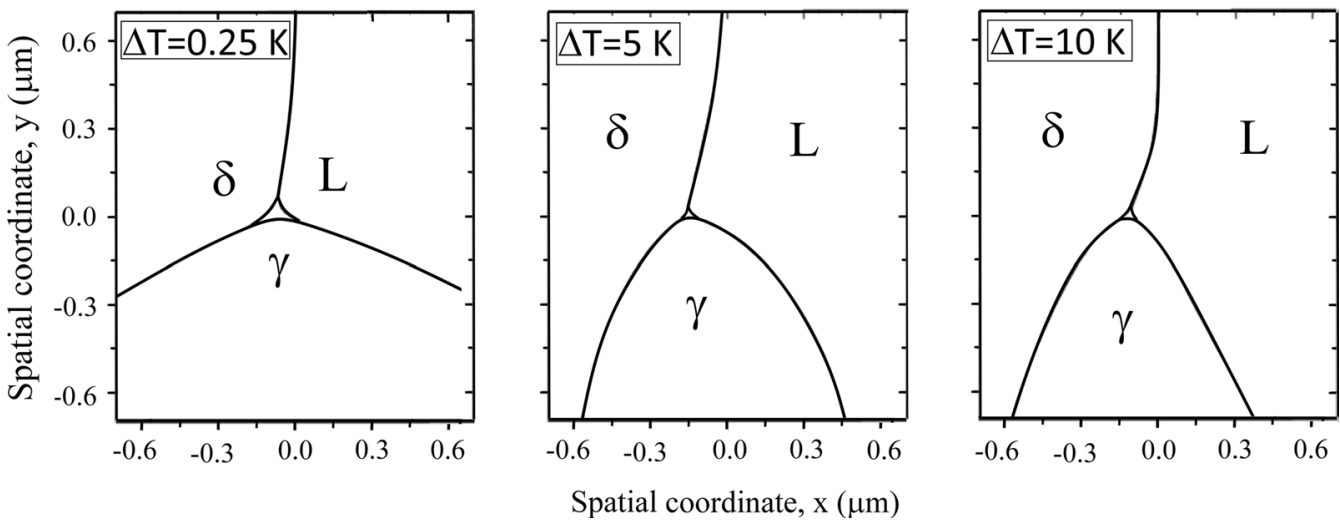

Fig. 9- Shape of interfaces calculated near the triple-point junction during the peritectic reaction at different undercoolings. Reprinted with permission from Ref. [85].

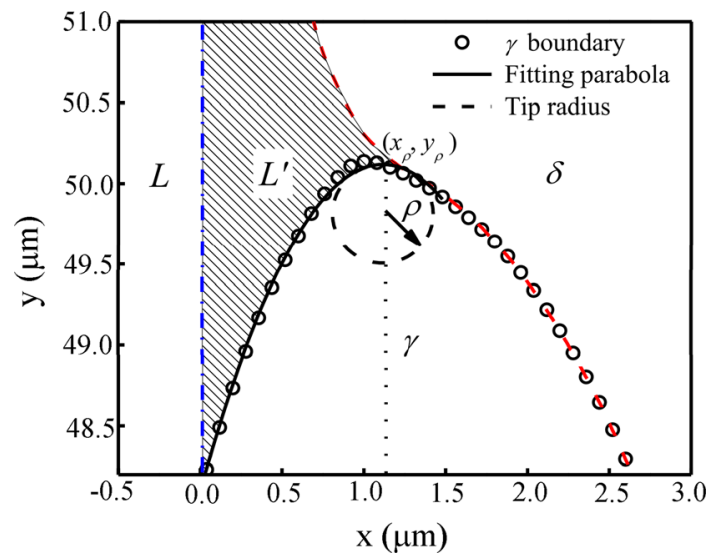

Fig. 10-Phase-field simulation of tip region of the growing $\gamma$ platelet, where $L$ represents the original liquid region, and $L^{\prime}$ represents the liquid region formed by melting some $\delta$ phase. Reprinted with permission from Ref. [119].

which is the peritectic reaction discussed in the previous sections. After the $L / \delta / \gamma$ triple-point junction has moved past, the remaining $\gamma$ layer thickens by growing into both the solid $\delta$ and into the liquid. This transformation of the $\delta$ ferrite and liquid to austenite, which takes place by solid-state phase transformation on one side of this layer $(\delta \rightarrow \gamma)$, and the direct solidification of austenite on the other side $(\mathrm{L} \rightarrow \gamma)$, is referred to as the peritectic transformation. In the mechanism discussed in this section, the growth of both sides of the austenite layer is controlled by diffusion.

Fredriksson and Nylén ${ }^{[32]}$ proposed that the peritectic transformation is controlled by diffusion of solute from the melt to the $\delta$ ferrite through the $\gamma$ austenite layer. They derived a theoretical model for the thickening rate of $\gamma$ during the peritectic transformation ( $\mathrm{F}-\mathrm{N}$ model) assuming that (1) the peritectic transformation is controlled by diffusion and proceeds at a low undercooling;
(2) the interface concentrations are in equilibrium; (3) the concentration gradients are linear in all three-phase regions:

$$
\begin{gathered}
\frac{\partial d_{\delta / \gamma}}{\partial t}=\frac{D_{\gamma}}{d_{\gamma}}\left(\frac{C_{\mathrm{m}}^{\gamma / \mathrm{L}}-C_{\mathrm{m}}^{\mathrm{L} / \gamma}}{C_{\mathrm{m}}^{\gamma / \delta}-C_{\mathrm{m}}^{\delta / \gamma}}\right), \\
\frac{\partial d_{\mathrm{L} / \gamma}}{\partial t}=\frac{D_{\gamma}}{d_{\gamma}}\left(\frac{C_{\mathrm{m}}^{\gamma / \mathrm{L}}-C_{\mathrm{m}}^{\gamma / \delta}}{C_{\mathrm{m}}^{\mathrm{L} / \gamma}-C_{\mathrm{m}}^{\gamma / \mathrm{L}}}\right),
\end{gathered}
$$

where $\frac{\partial d_{\delta / \gamma}}{\partial t}$ and $\frac{\partial d_{\mathrm{L} / \gamma}}{\partial t}$ are the growth rates of $\gamma$ toward $\delta$ and toward the melt, respectively; $d_{\gamma}$ is the instantaneous $\gamma$ layer thickness; $D_{\gamma}$ is the diffusion coefficient in $\gamma ; C_{\mathrm{m}}^{\gamma / \mathrm{L}}$ and $C_{\mathrm{m}}^{\mathrm{L} / \gamma}$ are the equilibrium concentrations of solute $\mathrm{m}$ in $\gamma$ and in the melt at the $\mathrm{L} / \gamma$ interface, respectively, and $C_{\mathrm{m}}^{\gamma / \delta}$ and $C_{\mathrm{m}}^{\delta / \gamma}$ are the corresponding equilibrium concentrations in $\gamma$ and in the $\delta$ ferrite at the $\delta / \gamma$ interface. Other researchers ${ }^{[125,127-130]}$ proposed similar analytical diffusion-based models for describing peritectic transformation in different alloys.

The F-N model was used ${ }^{[126]}$ to calculate $\gamma$ platelet growth due to carbon diffusion during the peritectic transformation in Fe-C systems. At an undercooling of $5{ }^{\circ} \mathrm{C}$ below the peritectic temperature, and a cooling rate of $1{ }^{\circ} \mathrm{C} / \mathrm{min}$, the calculated growth rate with this model agreed well with experimentally observed growth rates for Fe- 0.42 pct $\mathrm{C}$, as shown in Figure 11. ${ }^{[126]}$ Although the F-N model agrees reasonably well with measurements at low undercoolings for $\mathrm{Fe}-\mathrm{C}$ alloys, ${ }^{[31]}$ at high undercooling the F-N model predicts considerably slower growth rates than measured. ${ }^{[75,90]}$

In the F-N model it is assumed that there is complete mixing of solute in both the primary liquid and in the $\delta$ phase. This assumption may be reasonable for isothermal conditions or low cooling rates. However, when the 
cooling rate is fast, there is a substantial solute buildup in the liquid ahead of the $\gamma / \mathrm{L}$ interface, creating a solute gradient in the liquid. A diffusion-controlled analytical model of isothermal peritectic transformation was developed that considers solute diffusion in all three phases including this liquid solute gradient and reported good agreement with measurements. ${ }^{[131]}$

Experiments using the solid/liquid diffusion couple method measured ${ }^{[75]}$ austenite plate thickness growth, based on etching to resolve the prior $\mathrm{L} / \gamma$ and $\gamma / \delta$ interfaces. The measured growth of the austenite plates with time, while holding at $1696 \mathrm{~K}$ is shown in Figure 12.

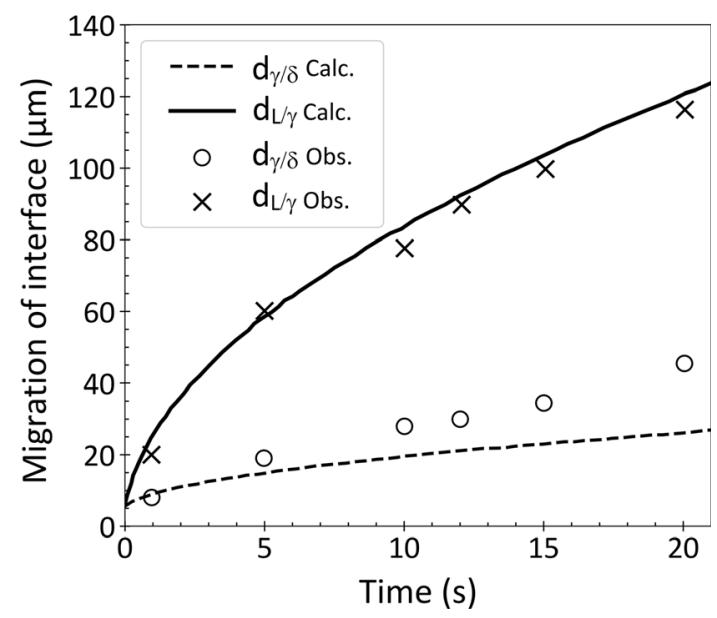

Fig. 11-Calculated and observed migration of the $\gamma$ layer toward $\delta$ and toward the melt during the peritectic transformation of Fe-0.42 pct C alloy. Reprinted with permission from Ref. [126].

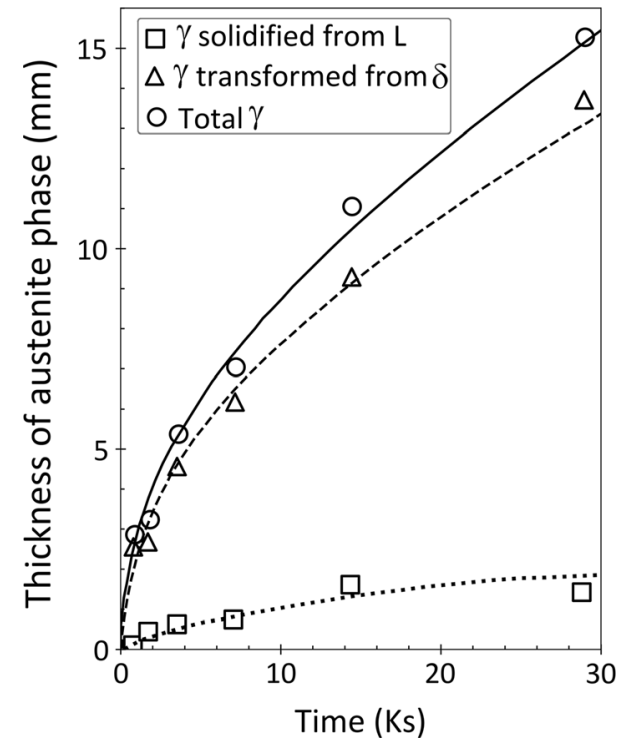

Fig. 12- Growth process of austenite phase at 1696 K. Reprinted with permission from Ref. [75].
The increase in measured thickness, $x$, fits roughly with the theoretical exponent of 0.5 for diffusional growth:

$$
\begin{gathered}
x_{\gamma / \mathrm{L}}=5.4 t^{0.57}, \\
x_{\gamma / \delta}=80 t^{0.5}, \\
x_{t}=85.7 t^{0.5},
\end{gathered}
$$

where $t$ is time (s), $x_{\gamma / \mathrm{L}}$ and $x_{\gamma / \delta}$ are the thickness $(\mu \mathrm{m})$ of the $\gamma$-phase solidified from the liquid phase and transformed from the $\delta$-phase, respectively, and $x_{t}$ is the total thickness of the $\gamma$ platelet. The measured growth rates in this experiment match the calculated growth rates, based on the diffusion-control mechanism. ${ }^{[74]}$

These curve-fits of measured results show that during peritectic transformation, the $\gamma / \delta$ interface does not move until carbon concentration at this interface increases, according to the solid-state partitioning observed between the solvus lines in the phase diagram (Figure 1). This solute buildup requires carbon atoms to diffuse from the liquid phase through the $\gamma$-phase to this $\gamma / \delta$ interface. As shown in Figure 13, when carbon concentration in the ferrite is less than 0.09 pct $C$, the interface moves very slowly until carbon concentration reaches saturation (equilibrium) at the interface. The growth rate then follows the classic parabolic growth (0.5 exponent function) expected for diffusion-controlled systems.

Other investigations of this peritectic transformation have confirmed this growth relationship with the square root of time using measurements based on HT-CLSM observations. ${ }^{[31,33]}$ The rate constant, $85.7 \mu \mathrm{m} / \sqrt{\mathrm{s}}_{\mathrm{s}}$ in Eq. [22], actually depends on the diffusion coefficient of carbon in austenite, and the difference of carbon concentration at the $\delta / \gamma$ and $\gamma / \mathrm{L}$ interfaces.

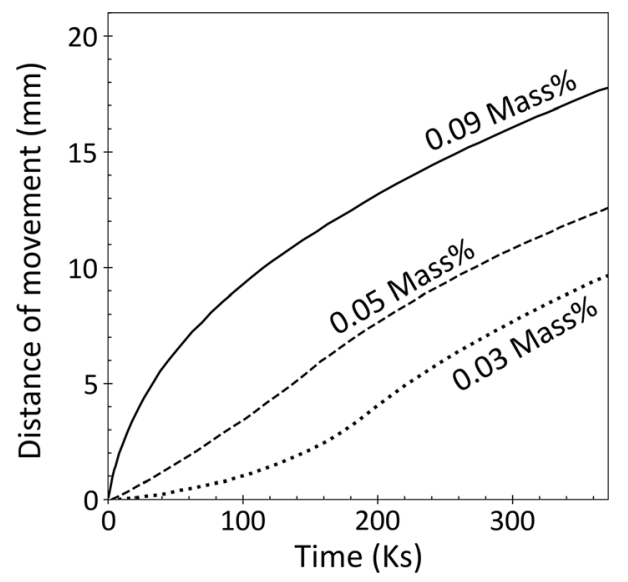

Fig. 13-Measured movement of the $\gamma / \delta$ interface during the peritectic transformation at $1763 \mathrm{~K}$ for various initial carbon contents in the $\delta$-phase. Reprinted with permission from Ref. [75]. 
HT-CLSM has also been used to measure isothermal peritectic reaction rates in $\mathrm{Fe}-\mathrm{Ni}$ systems and compared with model predictions. ${ }^{[117]}$ Observations showed that increasing undercooling caused increasing reaction rates. With low undercooling, the diffusion coefficient is high, so the driving force due to undercooling controls the reaction rate. ${ }^{[117]}$ At high undercooling, however, the reaction rate decreases due to decreasing diffusion coefficient, which comprises a diffusion-controlled regime. These trends were confirmed by calculations with another diffusion mode ${ }^{[72]}$ but that model considerably underpredicted the measurements. This was attributed to inaccurate diffusion coefficients in the molten metal and the neglect of diffusion in the solid.

Diffusion couple experiments showed that ${ }^{[132,133]}$ increasing cooling rate increased the migration rate of both $\delta / \gamma$ and $\mathrm{L} / \gamma$ interfaces. For all cooling rates, the $\delta / \gamma$ interface moved much faster than the $\mathrm{L} / \gamma$ interface. ${ }^{[75]}$ This has been attributed to the smaller difference in carbon concentration at the $\delta / \gamma$ interface. Figure 14 shows that at higher cooling rates, the total austenite thickness growth rates exceed the square root of cooling time relationship expected from simple diffusion.

It has been experimentally shown that the peritectic transformation in steel can be very fast and thus difficult to explain by diffusion alone. ${ }^{[33,77]}$ This implies that the peritectic transformation might be controlled by other mechanisms. Many researchers have used phase-field modeling to investigate these possibilities.

Phase-field models have become an efficient method to simulate phase boundary evolution during phase transformations. ${ }^{[134-138]}$ Phase-field models are based on minimizing total free energy everywhere in a highly refined computational grid of a representative solidifying domain, including bulk free energy, interfacial energy, and elastic strain energy. Its advantages over other methods include its ability to calculate the

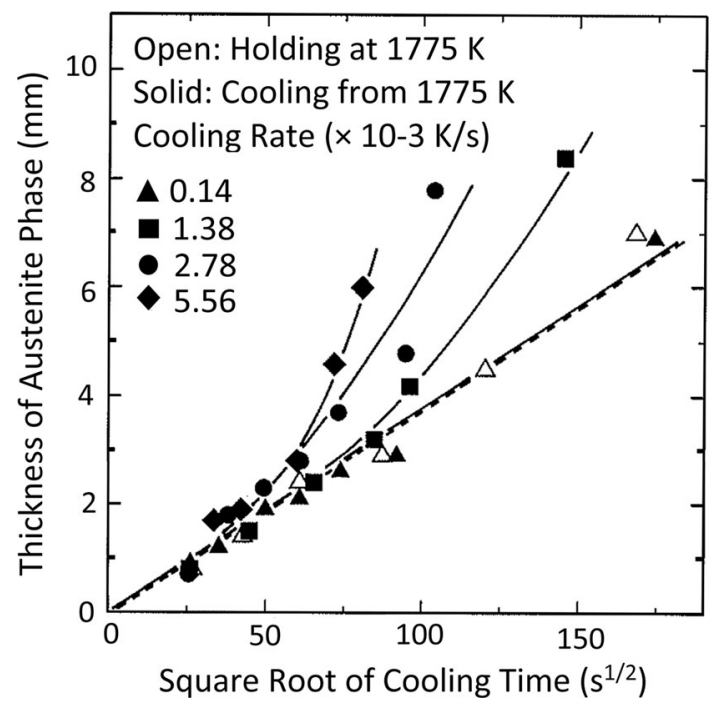

Fig. 14-Effect of cooling rate on the relationship between total austenite platelet thickness and square root of cooling time. Reprinted with permission from Ref. [132]. microstructure morphology, without needing to track the location of assumed interfaces, and to include the diffusion of multiple solute elements. ${ }^{[134]}$

Earlier works ${ }^{[75]}$ found that the $\delta / \gamma$ interface moves faster than the $\mathrm{L} / \gamma$ interface, as already mentioned. But phase-field simulations predict that increasing cooling rate from 10 to $100 \mathrm{~K} / \mathrm{min}$ should cause this trend to reverse, ${ }^{[87,120]}$ so at $100 \mathrm{~K} / \mathrm{min}$ the $\mathrm{L} / \gamma$ interface moves faster. This is due to changes in the solute profile in the liquid, as shown in Figure 15. A flatter solute profile is predicted at $10 \mathrm{~K} / \mathrm{min}$ than at $100 \mathrm{~K} / \mathrm{min}$. According to the diffusion mechanism, the carbon flux from austenite to the liquid depends on the carbon diffusion coefficient and the concentration gradient in the liquid, as per Fick's Law. Early researchers ignored this change of carbon concentration in the liquid so do not predict this reversal in the growth rate trend.

Peritectic solidification was simulated ${ }^{[83]}$ using another phase-field model which showed that growth rates of the $\gamma$ phase follow parabolic growth kinetics by focusing on the dependencies of the peritectic transformation on the values of the partition coefficient and solid diffusivities. ${ }^{[139]}$ The distance travelled by each interface is governed by a parabolic law $x_{i j}=a_{i j} t^{1 / 2}$ in which $a_{i j}$ is a "parabolic" rate constant. The dependence of this parabolic rate constant on the partition coefficient $\left(k_{\delta \gamma}\right)$ is shown in Figure 16. $a_{\mathrm{L} \gamma}$ is almost independent of partition coefficient, but $a_{\delta \gamma}$ decreases considerably as the partition coefficient increases. This is because the concentration difference at the $\gamma / \delta$ interface increases with increasing of $k_{\delta \gamma}$, while the value of $k_{\mathrm{L} \gamma}$ has no effect on the concentration difference at $\gamma / \delta$ interface. By raising concentration difference at the $\gamma / \delta$ interface, the amount of solute that must diffuse for $\delta / \gamma$ transformation increases, and consequently the migration distance of the $\gamma / \delta$ interface decreases.

The relationship between parabolic rate constant and diffusion coefficient is shown in Figure 17. The rate constant at the $\gamma / \mathrm{L}$ interface is independent of solid diffusivity but the constant rate at the $\gamma / \delta$ interface decreases with decreasing solid diffusivity. Migration of the $\gamma / \delta$ interface was more sensitive to $D_{\delta}$ than to $D_{\gamma}$, due to the larger concentration gradient in the $\gamma$ phase than in the $\delta$ phase. When the solid diffusivities are too small, the peritectic transformation rate is determined only by $\gamma$ solidification. These authors conclude that the peritectic transformation is initially controlled by solid-solid transformation, and when the solid-solid interface velocity decreases, austenite plate thickens by direct solidification.

Additionally, isothermal peritectic transformation has been simulated for dilute Fe-C alloys, by focusing on a single $\gamma$-platelet growing into the L- and $\delta$-phases. ${ }^{[119,131]}$ The interfaces were assumed to be in quasi-equilibrium and peritectic transformation governed by diffusion. The results matched expectations that by increasing undercooling, the tip growth velocity of platelet increases considerably, as seen in Figure 18. At the same time, the platelet thickness decreases. Experimental data for a Fe- 0.43 pet $\mathrm{C}$ alloy ${ }^{[77]}$ are also included in 

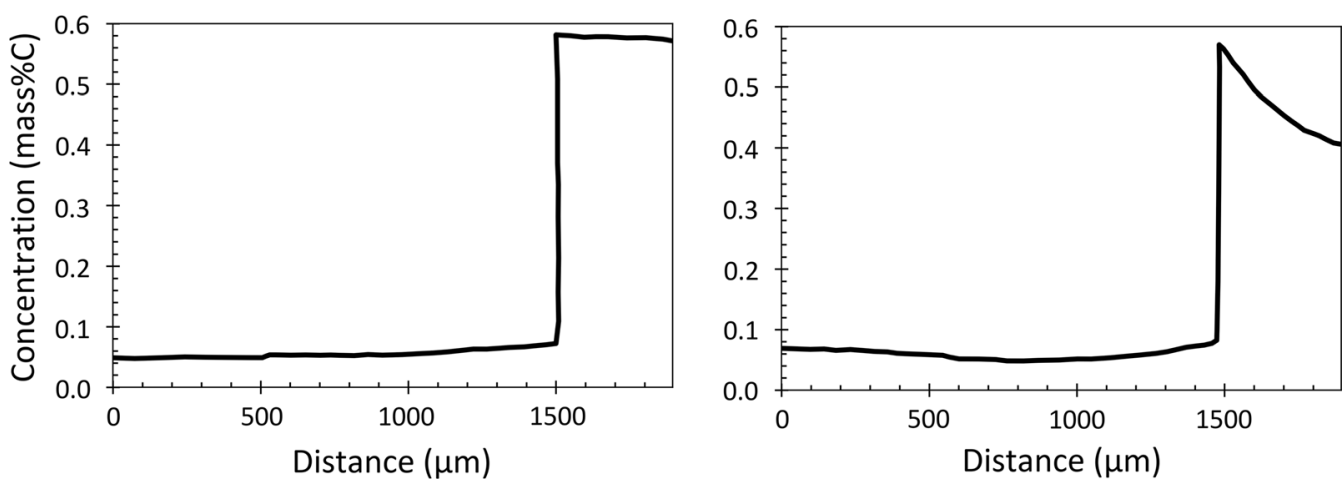

Fig. 15 - Comparison of simulated solute profiles at cooling rates of $10 \mathrm{~K} / \mathrm{min}$ (left) and $100 \mathrm{~K} / \mathrm{min}$ (right), in an Fe- 0.18 pct C alloy, under a temperature gradient of $200 \mathrm{~K} / \mathrm{cm}$, at the initiation of the peritectic transformation. Reprinted with permission from Ref. [120].

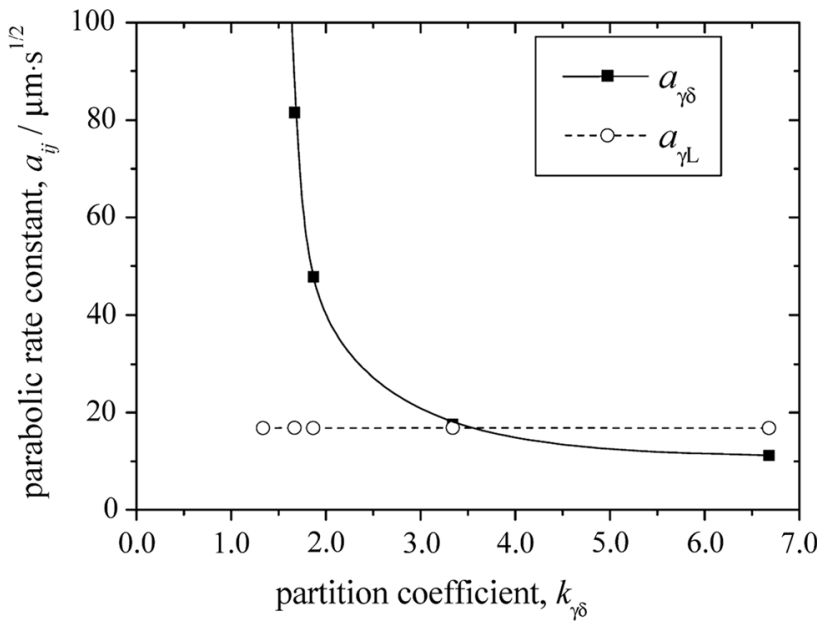

Fig. 16-Dependence of parabolic rate constant, $a_{i j}$, on partition coefficient, $k_{\gamma \delta}$. Reprinted with permission from Ref. [139].

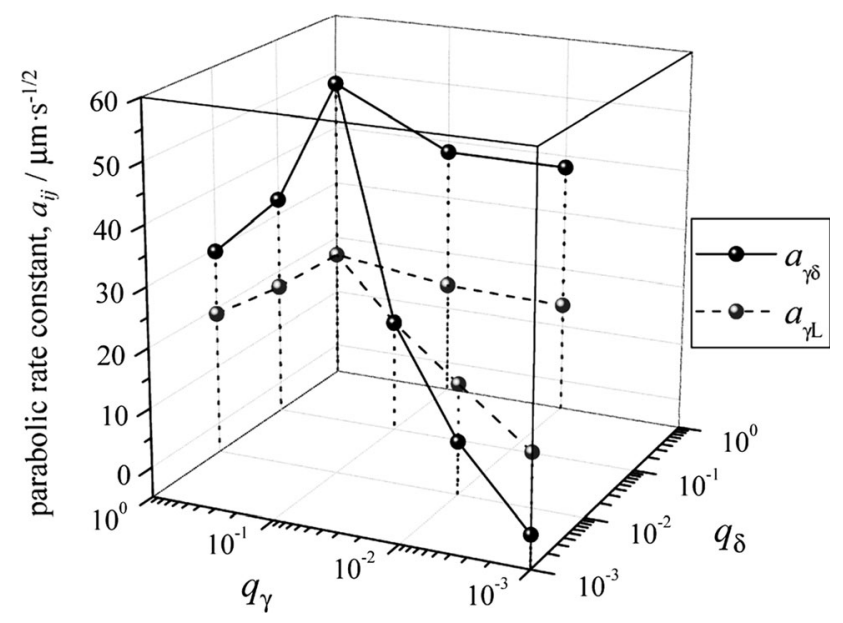

Fig. 17-Dependence of parabolic rate constant on the diffusion coefficient. The diffusion coefficients, $D_{\delta}$ and $D_{\gamma}$, were defined as $D_{\delta}$ $=q_{\delta} D_{\delta}^{\mathrm{i}}$ and $D_{\gamma}=q_{\gamma} D_{\gamma}^{\mathrm{i}}$, respectively, with $D_{\delta}^{\mathrm{i}}=4 \times 10^{-9}$ and $D_{\gamma}^{\mathrm{i}}$ $=6.0 \times 10^{-10}$. Reprinted with permission from Ref. [139].

this figure. Phase-field simulation of peritectic reaction and transformation in an $\mathrm{Fe}-\mathrm{Mn}$ system $^{[140]}$ again indicated that diffusion was rate controlling.

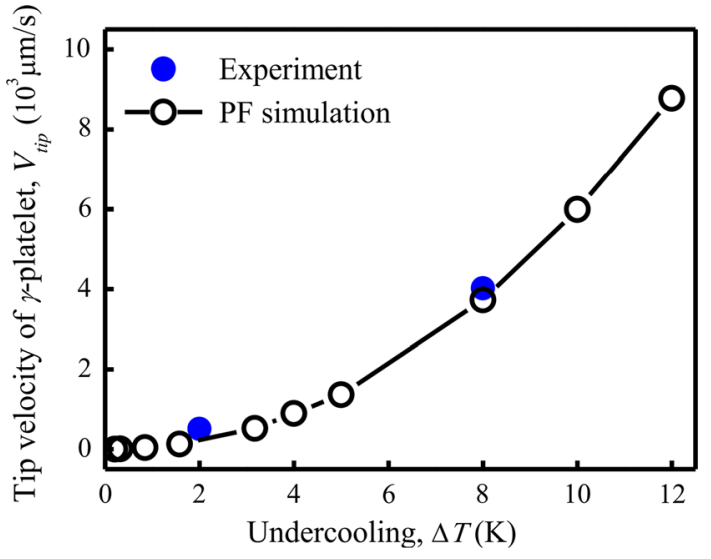

Fig. 18-Tip velocity of platelet as a function of undercooling. Reprinted with permission from Ref. [119].

\section{E. Massive Transformation Mechanism for the Peritectic Transformation}

Massive transformation has been proposed as another explanation of the high velocities observed for the peritectic transformation. ${ }^{[33,80-82,88,141]}$ Massive transformation involves a change in crystal structure on an atomic scale without compositional partitioning or solute diffusion, and typically occur during rapid cooling. ${ }^{[142,143]}$ Massive transformations are observed when the competing equilibrium transformations involving solute diffusion are prevented (constrained), such as the austenite to $\alpha$-ferrite transformation in steel at high cooling rates. ${ }^{[144,145]}$ Massive transformations are thermally activated, meaning that they proceed when a particular temperature is reached, more according to when the volume free energy of the new product phase is lower than the parent phase, more than when a certain diffusion-controlled compositional requirement is achieved. They require nucleation of the new phase and growth, due to the random migration of individual atoms across the interphase boundary ${ }^{[146,147]}$ and they involve length scales that are so short range that diffusion effects are very small. ${ }^{[147]}$ Once nucleation takes place, the new phase grows at high velocities (up to 1 to $2 \mathrm{~cm} / \mathrm{s}$ ) with approximately the same rate in all directions. The rate of massive transformation is 
between diffusional transformation rates $(\mathrm{nm} / \mathrm{s})$ and the diffusionless martensitic transformation, which occurs at a velocity near to the speed of sound $\left(\sim 10^{3} \mathrm{~m} / \mathrm{s}\right) .{ }^{[65]}$

As discussed in earlier sections, the rate of peritectic solidification of steel in undercooled conditions is very high, and is claimed by some researchers not to be explained by the diffusion models discussed previously. ${ }^{[33,80-82,88,141]}$ The observed high transformation rates have been attributed to massive phase transformation from $\delta$ to $\gamma$ or to direct solidification of $\gamma$ from liquid. In fact, non-equilibrium conditions were proposed to constrain the nucleation of $\gamma$ phase until considerable undercooling below the peritectic temperature and then upon nucleation, growth proceeds extremely fast. Different nucleation constraints and transformation mechanisms have been proposed and are discussed in the next sections.

Peritectic solidification in $\mathrm{Fe}-0.14$ pet $\mathrm{C}$ alloys was measured $^{[33]}$ to be very fast $(3.64$ to $5.45 \mathrm{~mm} / \mathrm{s})$ for the peritectic transformation (thickening of $\gamma$ austenite to ferrite and liquid). The thickening rate of austenite is between 3.64 and $5.54 \mathrm{~mm} / \mathrm{s}$. Also the migration rate of the $\gamma / \delta$ interface was measured to be faster than the migration rate of the $\mathrm{L} / \gamma$ interface during the peritectic transformation. In $\mathrm{Fe}-0.14$ pet $\mathrm{C}$, the peritectic transformation was believed to be too fast to be controlled by diffusion, ${ }^{[33]}$ which was instead attributed to massive transformation. On the other hand, in $\mathrm{Fe}-0.42$ pct $\mathrm{C}$, the peritectic transformation was believed to be controlled by diffusion. ${ }^{[33]}$ No explanation was provided to explain the difference between these two alloys.

Others researchers ${ }^{[80]}$ used HT-CLSM to study peritectic solidification in an Fe-5.1 pct Ni system. Again, high peritectic transformation rates were observed and attributed to massive transformation. This was attributed to the primary $\delta$-ferrite being a metastable phase which transformed massively to $\gamma$.

Peritectic solidification in a medium-alloy stee ${ }^{[81]}$ has been studied using directional solidification and thermal analysis. Segregation of chromium which was measured by EPMA appeared to cause direct solidification of austenite from liquid without a peritectic reaction. ${ }^{[148]}$ Based on the alloy segregation pattern and presence of lattice defects and thermal analysis, these authors argue that the peritectic transformation where austenite precipitates directly from $\delta$ ferrite is a diffusionless transformation, which started at $5 \mathrm{~K}$ undercooling. ${ }^{[81]}$ This transformation caused an observed sudden rise in temperature, followed by diffusion-controlled transformation.

Yasuda et al. ${ }^{[82]}$ investigated peritectic solidification in a $\mathrm{Fe}-0.45$ pet $\mathrm{C}-0.6$ pet $\mathrm{Mn}-0.3$ pet $\mathrm{Si}$ using a synchrotron radiation $\mathrm{X}$-ray system. Two different mechanisms were proposed for solidification of this alloy according to the cooling rate. At $10 \mathrm{~K} / \mathrm{min}$, the first $\delta$ dendrite grows and later transforms to $\gamma$ austenite, proceeding from the root to the tip of the dendrites, as illustrated in Figures 19(a) and (b). This transformation occurs in the mushy region and is essentially conventional, diffusion-controlled peritectic solidification.
At a higher cooling rate of $50 \mathrm{~K} / \mathrm{min}$, however, the specimen initially solidified without $\gamma$ phase formation and later after complete solidification, the $\delta$ grains all transform into $\gamma$ phase in the solid state suddenly, within 1 second. This transformation occurred $100 \mathrm{~K}$ below the liquidus temperature. Because the $\delta / \gamma$ phase transformation occurred in the single $\gamma$ phase region, these researchers argued that solute redistribution was not required. The relatively large undercooling suggested that $\gamma$ nucleation was difficult, so the eventual peritectic transformation from $\delta$ to $\gamma$ was governed by a massive transformation. Furthermore, the volume shrinkage of this transformation was suggested to induce melt flow to explain the white grooves in the specimen in Figure 19(d).

\section{F. Nucleation Constrained Peritectic Solidification Mechanism}

As discussed above, massive transformation may occur when diffusional transformations are constrained, which may occur with high cooling rates and undercoolings. In this situation, the delay of nucleation of the peritectic reaction step is proposed to combine it with the peritectic transformation step into a single massive transformation mechanism for peritectic solidification. ${ }^{[80-82,148]}$ Two different mechanisms have been proposed to constrain $\gamma$ nucleation, to enable massive $\delta / \gamma$ transformation, which are discussed in the following subsections.

\section{Nucleation constraint due to high $\delta / \gamma$ interface} energy

Several researchers have recently proposed that massive transformation is the mechanism for peritectic solidification, due to the delay of $\gamma$ nucleation in $\delta$ ferrite sufficiently to prevent the peritectic reaction, owing to high $\delta / \gamma$ interfacial energy. ${ }^{[82,141]}$ In situ observations of peritectic solidification using synchrotron radiation X-ray imaging in Fe- 0.45 pet C-0.6 pet $\mathrm{Mn}-0.3$ pet $\mathrm{Si}$ alloy were used to explain absence of a conventional peritectic reaction. Instead, at cooling rates above $0.3 \mathrm{~K} /$ s, very fast solid-state $\delta / \gamma$ transformation was observed. ${ }^{[82]}$ The $\delta / \gamma$ massive transformation needs much higher undercooling than the peritectic reaction, which suggests that difficulty with $\gamma$ nucleation was responsible for this undercooling. This nucleation difficulty was attributed to poor lattice matching between BCC $\delta$ ferrite and FCC austenite. ${ }^{[149]}$ Due to the high nucleation energy of $0.41 \mathrm{~J} / \mathrm{m}^{2}$ needed to create the $\delta / \gamma$ interface, ${ }^{[141]}$ the peritectic reaction to form $\gamma$ was prevented until high undercooling. ${ }^{[2]}$ Then, once the first austenite nucleus formed, the next nuclei of austenite grains form simultaneously.

To investigate the $\delta-\gamma$ massive phase transformation mechanism, the nucleation of $\gamma$ phase on various interfaces was investigated using phase-field modeling. ${ }^{[141]}$ The simulation results showed that after the first austenite nucleus forms on the $\delta / \gamma$ interface, the driving force (energy barrier) needed to form each 

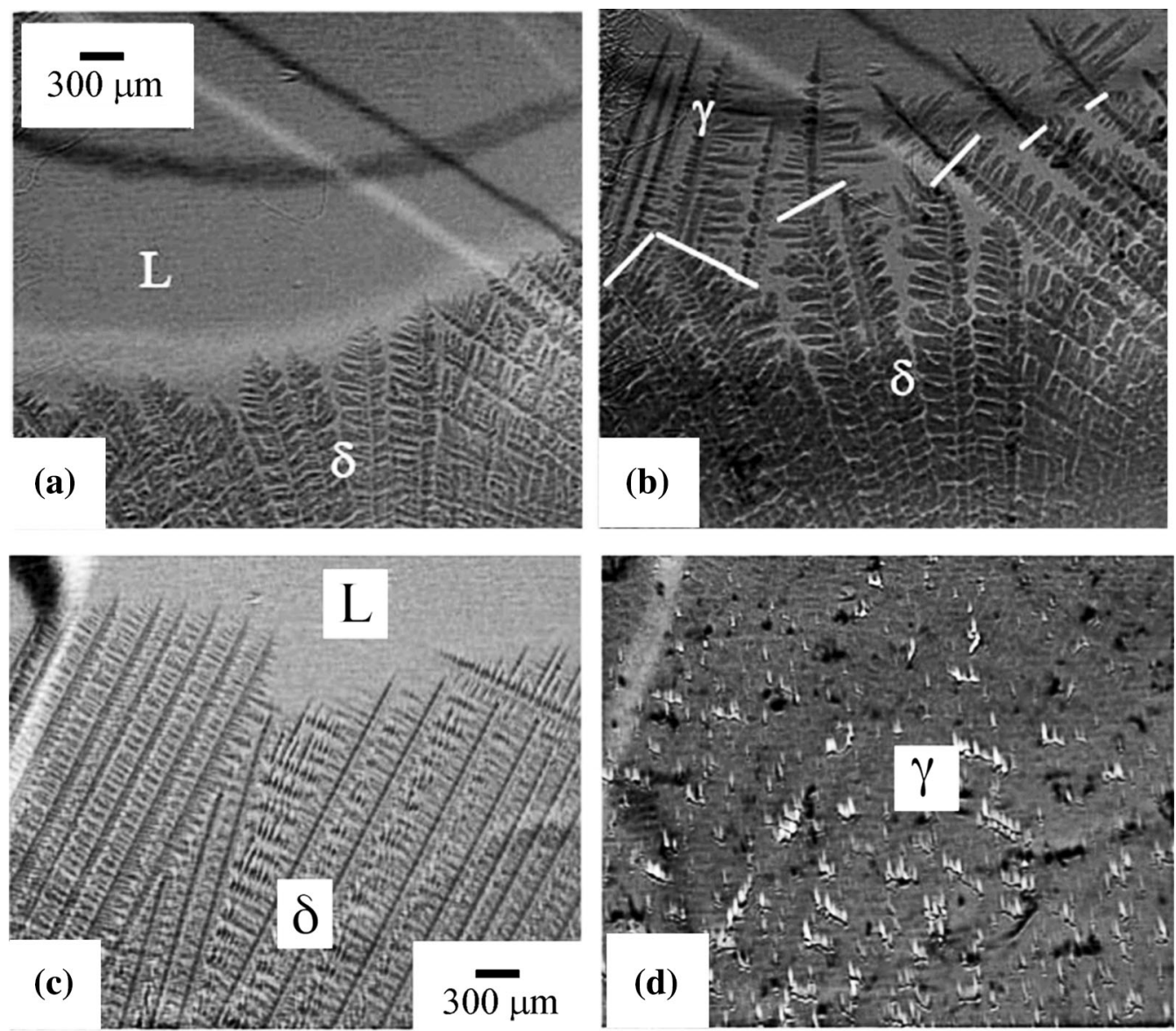

Fig. 19-X-ray images of Fe- 0.45 pct $\mathrm{C}$ alloy solidification suggesting diffusion-controlled peritectic reaction at $10 \mathrm{~K} / \mathrm{min}(a)$ early time and $(b)$ later time; and massive $\delta / \gamma$ transformation at $50 \mathrm{~K} / \mathrm{min}(c)$ early time and $(d)$ later time. Reprinted with permission from Ref. [82]

additional nucleus drops by half. This suggests the eventual possibility of athermal nucleation, where there is no need for thermal activation. Heterogeneous nucleation onto existing $\gamma$ phase is much easier than forming new nuclei. This is termed concurrent $\gamma$ phase nucleation, as sketched in Figure 20. ${ }^{[141]}$ Following initial nucleation at $\delta / \delta$ grain boundaries, subsequent nuclei form onto the initial nuclei, where the energy barrier is lower, and later at triple junctions. These predictions agree with in situ observations of $\delta / \gamma$ massive transformation which measured average $\delta / \gamma$ interface velocities of $200 \mathrm{~mm} / \mathrm{s}^{[89]}$ This accelerated nucleation mechanism deserves further study, including investigation of the role of solute redistribution, in order to clarify this massive transformation mechanism to explain peritectic solidification.

\section{Nucleation constraint due to solute diffusion}

Many experimental studies have reported considerable undercooling for nucleation of austenite in peritectic solidification, and propose that $\delta$ to austenite transformation takes place by massive transformation, due to atomic diffusion through the solute field at the $\mathrm{L} /$ $\delta$ interface. ${ }^{[77,85,150]}$
At non-equilibrium solidification conditions, there is a large solute gradient between liquid and $\delta$ ferrite. Prior to nucleation, clusters of atoms with an FCC crystal structure (austenite) are proposed to form within the solute diffusion field from liquid to $\delta$ ferrite and as solute atoms pass through these clusters, the rates of attachment and dissolution of atoms to the clusters differ. This flux of solute atoms through the cluster is proposed to increase its Gibbs free energy for $\gamma$ nucleation, which increases the undercooling required for nucleation. ${ }^{[88]}$

This mechanism to explain the high undercooling for $\gamma$ nucleation was investigated using a HT-CLSM coupled with a concentric solidification technique. ${ }^{[88]} \mathrm{Fe}-\mathrm{C}$ and $\mathrm{Fe}-\mathrm{Ni}$ alloys were examined for the same conditions and cooling rates $\left(7^{\circ} \mathrm{C} / \mathrm{s}\right)$ and it was observed that even though the concentration gradient of nickel was $\sim 10$ times higher than that of carbon, the higher diffusivity of carbon $\left(D_{\mathrm{C}}^{\delta}=5 \times 10^{-9} \mathrm{~m}^{2} / \mathrm{s}\right)$ led to a much higher flux $J_{\mathrm{C}}^{\delta}=0.15 \mu \mathrm{m} / \mathrm{s}$ of carbon atoms compared to the flux $J_{\mathrm{Ni}}^{\delta}=0.007 \mu \mathrm{m} / \mathrm{s}$ of nickel atoms $\left(D_{\mathrm{Ni}}^{\delta}=2.1 \times\right.$ $10^{-11} \mathrm{~m}^{2} / \mathrm{s}$ ). Measurements have shown that the necessary undercooling for $\delta / \gamma$ phase transformation in $\mathrm{Fe}-\mathrm{C}$ alloy is $8 \mathrm{~K}$, whereas in the $\mathrm{Fe}-\mathrm{Ni}$ alloy this 

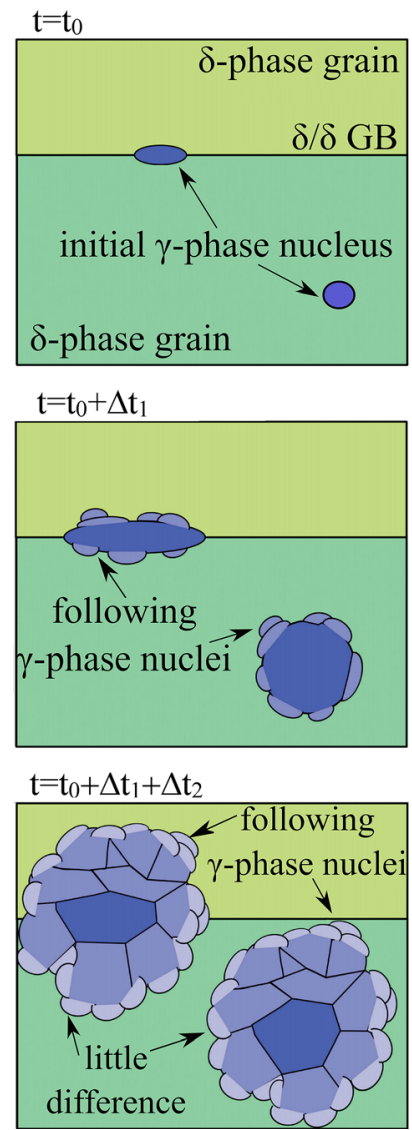

Fig. $20-$ Concurrent $\gamma$-phase nucleation as a possible mechanism of $\delta$ to $\gamma$ massive phase transformation in carbon steel showing austenite nuclei at different times. Reprinted with permission from Ref. [141].

undercooling is only $1 \mathrm{~K}$, so peritectic solidification takes place by massive transformation and diffusion of solute atoms, respectively. ${ }^{[88]}$

The solidification of steels with $0.1,0.18$, and 0.43 pct $\mathrm{C}$ was investigated using HT-CLSM, ${ }^{[77]}$ which noted the decrease in primary $\delta$ fraction with increasing $\mathrm{C}$ content, leading to different solute gradients at the $\delta / \gamma$ interface and different undercoolings observed for $\gamma$ nucleation. As shown in Figure 21, three different morphologies of peritectic transition were observed for the three steels, which were classified into three different solidification modes. In 0.43 pct $\mathrm{C}$ steel, the peritectic reaction takes place near equilibrium conditions at $63 \mu \mathrm{m} / \mathrm{s}$, with a planar morphology, so is proposed to be diffusion controlled. For 0.18 pct $\mathrm{C}$, the peritectic transformation proceeded with $3 \mathrm{~K}$ undercooling at $6000 \mu \mathrm{m} / \mathrm{s}$ followed by cellular/dendritic growth. Finally, in 0.1 pet $\mathrm{C}$ steel, massive transformation of $\delta$ into $\gamma$ occurred within a fraction of a second with $22 \mathrm{~K}$ undercooling below the equilibrium peritectic temperature. These results were confirmed by other researchers. ${ }^{[150]}$

\section{EFFECTS OF PERITECTIC SOLIDIFICATION}

Understanding peritectic solidification in steels is of great practical importance, because peritectic solidification causes many different problems during commercial casting processes such as continuous casting. These problems include the formation of deep oscillation marks, surface depressions, and interfacial gaps in the mold that lead to lower heat flux, thinner, and non-uniform (rippled) solidified shell thickness and accompanying catastrophic breakouts, increased susceptibility to surface crack formation and accompanying oxide slivers, larger austenite grain size leading to lower hot ductility, and consequently more defects in the final product, including internal cracks and accompanying macrosegregation. The following sections explore current understanding of these effects of peritectic solidification.

\section{A. Mold Heat Transfer and Shell Growth}

During casting of steel, heat flux from the solidifying steel to the mold is a strong function of carbon content, ${ }^{[9,22]}$ as seen in Figure 22, where the lowest heat transfer rate is measured for the peritectic 0.10 pct $\mathrm{C}$ steel. This landmark observation was first published by Singh and Blazek, ${ }^{[9]}$ based on continuous casting of 83 $\times 83 \mathrm{~mm}$ square billets on a laboratory caster at $21 \mathrm{~mm} /$ $\mathrm{s}$. The corresponding shell thickness profiles were also measured for different steel grades, by inducing breakouts during operation. The measured shell growth profiles roughly follow the parabolic relation, ${ }^{[151]}$

$$
s=k t^{0.5},
$$

where $s$ is solidified shell thickness, $t$ is solidification time below the meniscus in the mold, and $k$ is the solidification constant. The shell of the peritectic steel is thinner, as seen in the measurements in Figure 23, so the solidification constant in Eq. [23] is only 22 $\mathrm{mm} / \sqrt{ } \mathrm{min}$ for the peritectic $(0.1$ pct C) steel, compared with over $25 \mathrm{~mm} / \sqrt{ } \mathrm{min}$ for low-carbon $(0.05$ pct $\mathrm{C})$ and high-carbon $(>0.2$ pct $C)$ steels. Although the difference is small, it is very consistent and very significant to steel quality, as explained later. This slower shell growth of peritectic steels is caused by the generally lower mold heat transfer, shown in Figure 22, and was suggested to be caused by shrinkage differences related to the solid-state transformation from $\delta$-ferrite to $\gamma$, which is discussed in Section IV-C. ${ }^{[9]}$

More important than the thinner shell, however, is the jagged nature of the shell thickness profile for the peritectic steel, which indicates the much larger variability in shell growth of this steel grade. Figure 24 compares the appearance of the surface and interior of peritectic and non-peritectic steels. ${ }^{[9]}$ While non-peritectic $(0.4$ pct $\mathrm{C})$ steels solidify with a relatively smooth interior, the peritectic steel $(0.1 \mathrm{pct} C)$ experiences severe ripples on the inside of the shell. In commercial casters, these ripples, which represent local thin, hot, and weak 

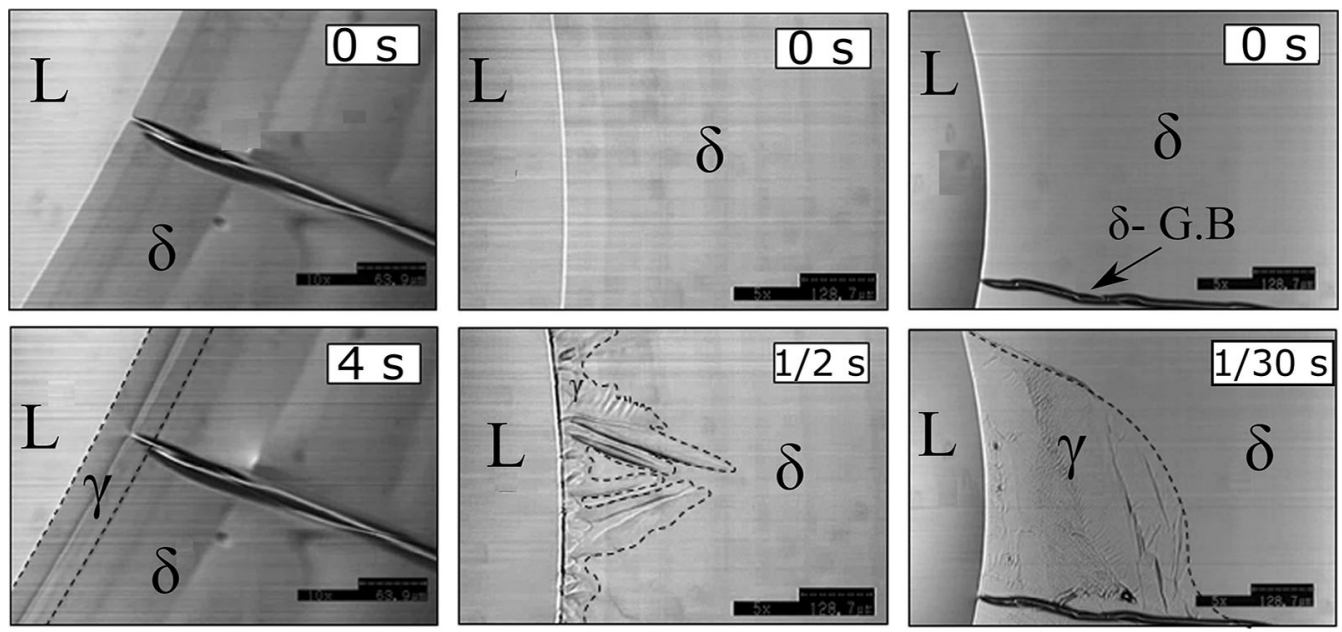

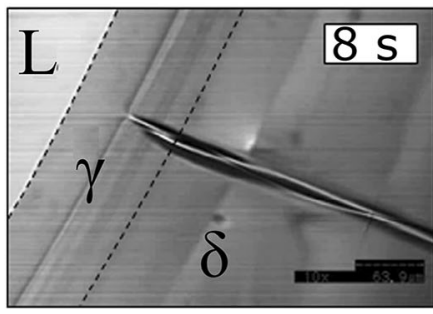

(a)

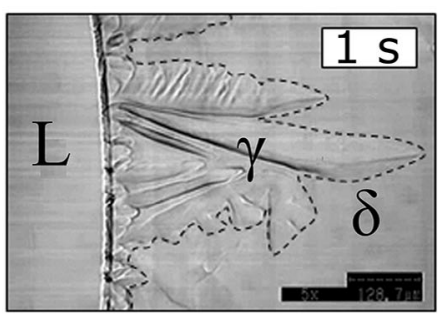

(b)

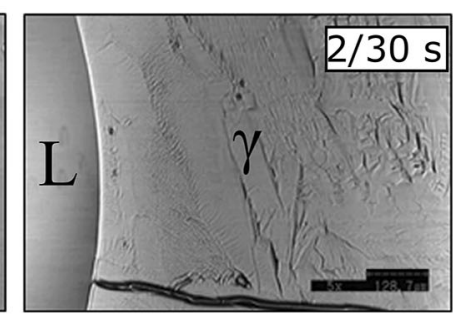

(c)

Fig. 21-Three different modes of the peritectic phase transition observed during concentric solidification in a HT-CLSM: (a) planar (diffusion-controlled), $(b)$ coarse cellular/dendritic (diffusion-controlled), and $(c)$ fine cellular/dendritic (massive transformation). Reprinted with permission from Ref. [77].

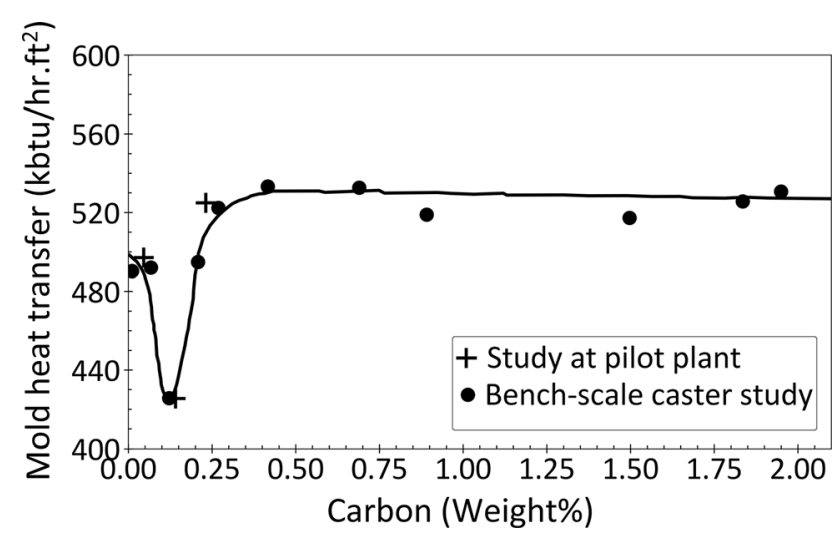

Fig. 22-Effect of carbon content on mold heat-transfer rate during continuous casting. Reprinted with permission from Ref. [9].

regions in the solidifying shell, are extremely detrimental because they often lead to dangerous and costly breakouts, which are more common in peritectic steels. ${ }^{[152]}$

These ripples and thin spots in peritectic steel shells are caused by corresponding deep depressions on the shell surface. Figure 24 also clearly shows the rough surface of the peritectic steel billet which contains many depressions. ${ }^{[9]}$ In contrast, the high-carbon (0.4 pct C) steel which has a smooth shell thickness profile also has a very smooth surface. A close-up of a breakout shell in Figure 25 shows that each oscillation mark or depression on the shell surface causes a thin region in the shell, in proportion to its severity. ${ }^{[153]}$ The cause of the surface

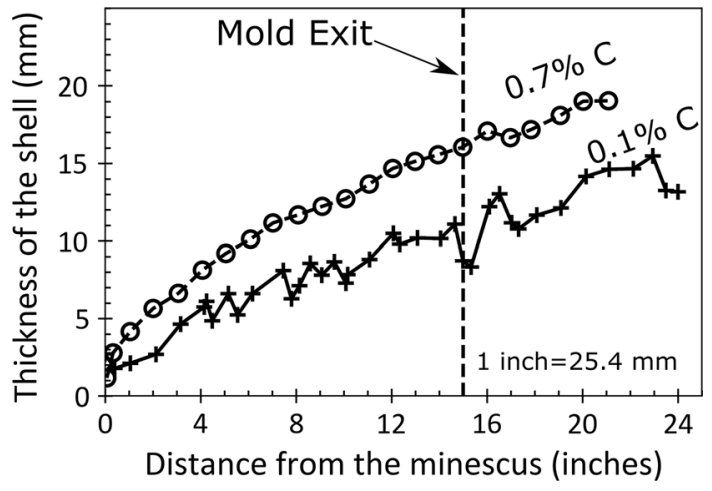

Fig. 23-Steel shell growth profiles during continuous casting, comparing peritectic $(0.10$ pct $\mathrm{C})$ and non-peritectic $(0.7$ pct $\mathrm{C})$ steel grades. Reprinted with permission from Ref. [9].

depressions is not due to variations in oscillation of the mold, because the mold in this study was not oscillated. ${ }^{[9]}$

\section{B. Surface Depressions and Air Gap Formation}

Depressions and oscillation marks in the as-cast shell surface can be characterized by the surface roughness, which during initial solidification corresponds to deeper interfacial gaps between the shell and the mold. Measurements of commercial-cast steel show that peritectic steels and ultra-low-carbon (ULC) steels experience much more surface roughness problems than other steel 


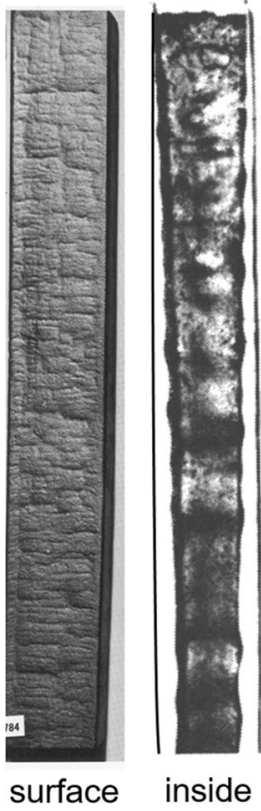

(a) $0.1 \% \mathrm{C}$

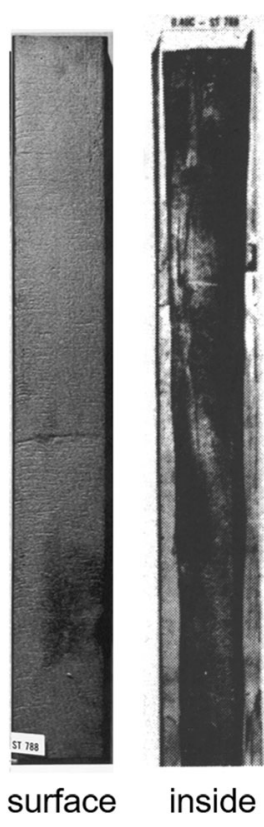

(b) $0.4 \% \mathrm{C}$
Fig. 24-Surface and cross section views of solidified shells of continuous-cast steel billets, comparing $(a)$ peritectic steel and $(b)$ non-peritectic steel. Reprinted with permission from Ref. [9].

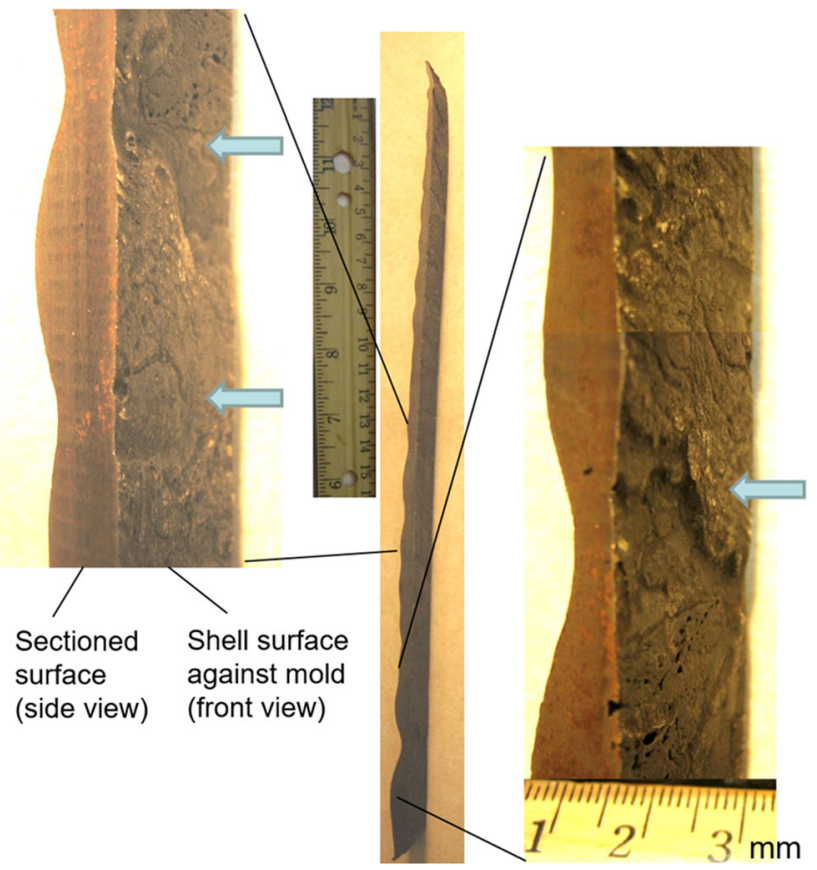

Fig. 25-Close-up of steel breakout shell showing local thin regions caused by corresponding deep surface depressions. Reprinted with permission from Ref. [153].

grades, as shown for example in Figure 26. ${ }^{[17]}$ This figure is clearly the inverse of Figure 22 (with the addition of data points for ULC steel), which indicates that the rougher surface increases the thermal resistance of the interface between the mold and shell, which

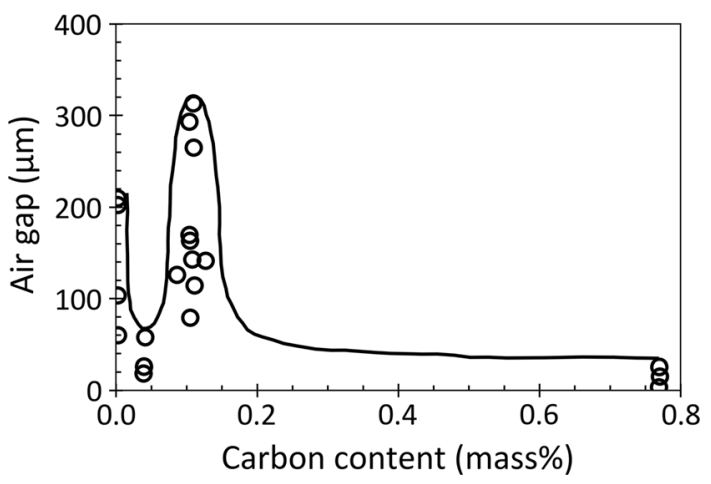

Fig. 26-Effect of carbon content on the surface roughness of the solidified shell. Reprinted with permission from Ref. [17].

directly causes lower heat transfer. Many other studies have confirmed that peritectic steels experience deeper air gaps and rougher as-cast surfaces. ${ }^{[19,21,154-156]}$

Fundamental experimental investigation of this behavior can be obtained from the study of free deformation of a solidifying droplet, which was measured for different steels by Dong. ${ }^{[157]}$ Steel droplets solidified onto a chill plate exhibit a curved bottom shape, with a curvature that varies strongly with carbon content. The greatest curvature, indicating lift-off from the plate, was observed with near to pure iron (or "ultra-low" carbon steel) and with near to 0.1 pct C (peritectic steel). Both plain low-carbon hypo-peritectic steel (e.g., 0.05 pct C) and higher-carbon hyper-peritectic steel (e.g., 0.2 pct C) show much less curvature (flatter surface) and consequently less gap formation and depression-related problems.

\section{Steel Shrinkage Behavior}

A direct measurement of the effect of carbon content on solidification shrinkage with time in a steel ingot casting is shown in Figure 27. ${ }^{[16]}$ A peak in shrinkage is observed for the peritectic steel $(0.1 \mathrm{pct} C)$. Note that this peak arises very early during solidification. The increase in shrinkage relative to other grades is about 0.3 $\mathrm{mm}$, which remains constant during subsequent solidification. ${ }^{[16]}$

Measurements of thermal contraction in binary alloys $^{[158]}$ naturally show a peak for peritectic steels (0.1 pct C), as shown in Figure 28. Shrinkage contraction during the solidification of steels with 0.05 to $0.2 \mathrm{pct}$ $\mathrm{C}$ has been measured. ${ }^{[159,160]}$ Peritectic steels $(0.1$ and 0.13 pct $\mathrm{C}$ ) achieved their maximum contraction within a few seconds of solidification, perhaps explaining their propensity for surface depressions. In low-carbon steels, the maximum contraction arises after solidification is complete. ${ }^{[159,160]}$

The root cause of the shrinkage peak in peritectic steels is the $\delta \rightarrow \gamma$ transformation from body-centered-cubic $\delta$ to face-centered-cubic $\gamma$, which decreases the molar volume by 2.5 to 3.0 pct. ${ }^{[161]}$ Shrinkage calculations of a solidifying steel shell, such as given in Figure 29, show that linear shrinkage increases with time for all steel grades. ${ }^{[17]}$ For peritectic steel $(0.126 \mathrm{pct}$ 


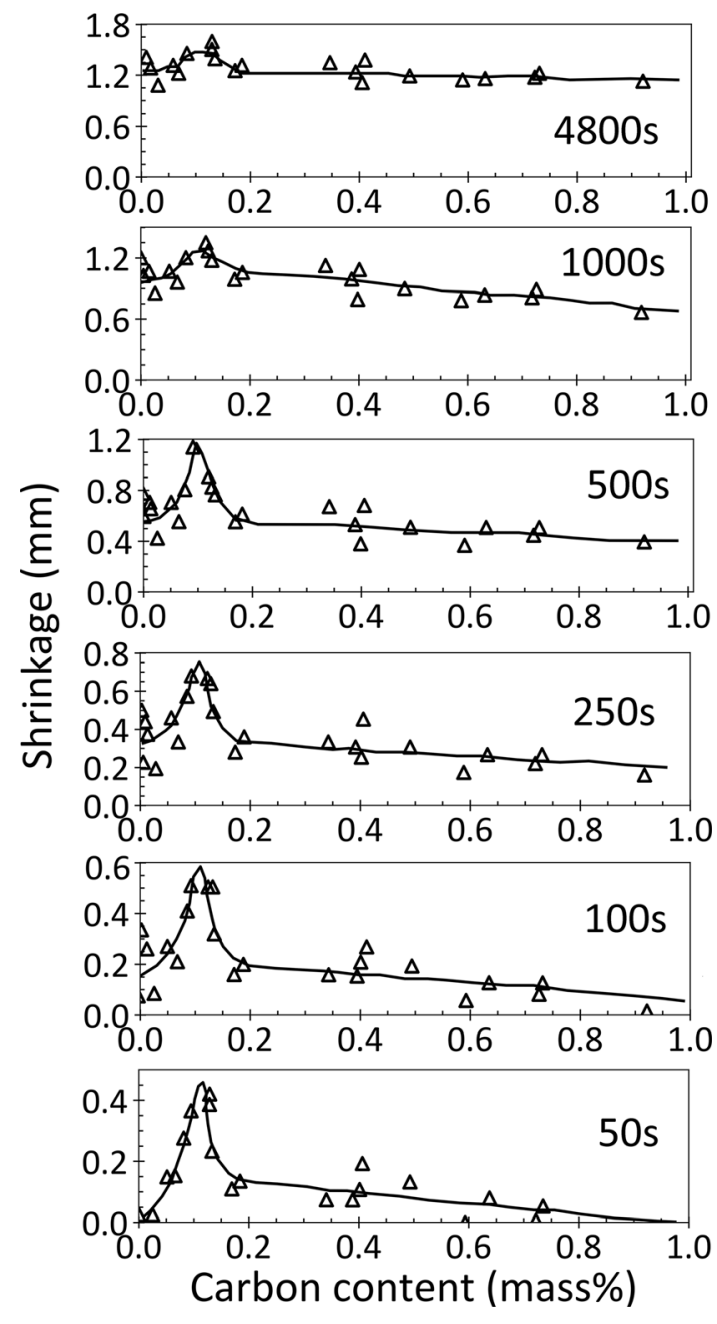

Fig. 27-Influence of carbon content on shrinkage of steel ingots at various times. Reprinted with permission from Ref. [16].

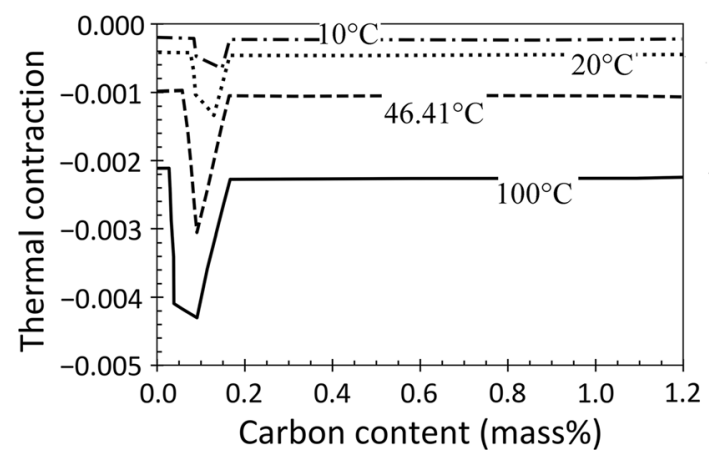

Fig. 28-Influence of carbon content on thermal contraction of iron-carbon alloys at different temperature intervals below solidus temperature. Reprinted with permission from Ref. [158].

C), the shrinkage is considerably larger, especially near the start of solidification. With low-carbon steels, the $\delta$ to $\gamma$ transformation occurs somewhat later, after the solidified shell is thick enough to withstand the shrinkage, so perhaps is the reason for less bending deformation due to shrinkage in these grades. ${ }^{[17]}$

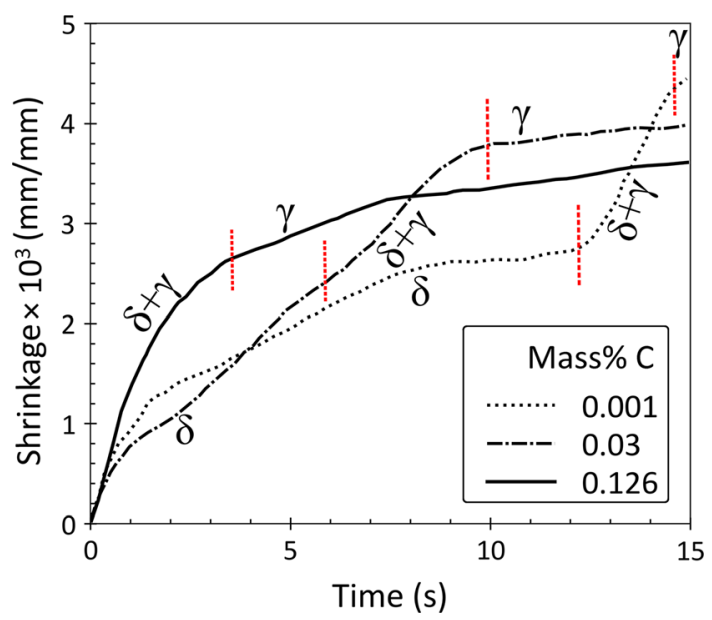

Fig. 29-Calculated shrinkage of solidifying shell vs. time from the start of casting. Reprinted with permission from Ref. [17].

Another study of shrinkage behavior with steel grade $^{[15]}$ noted that in low-carbon ( 0.05 to 0.09 pct C) steel, the temperature range of the $\delta / \gamma$ transformation is 12 to $40 \mathrm{~K}$, while for ultra-low-carbon $(0.003$ pct C) and peritectic steel $(0.18$ pct $C)$ this transformation theoretically occurs at a unique temperature. Thus, they concluded that ULC and peritectic steels should experience more severe shrinkage problems, owing to the narrow temperature range and accompanying high rate of $\delta / \gamma$ transformation. In contrast, the $\delta / \gamma$ transformation is much slower in low-carbon steels, so the shrinkage is presumably less. ${ }^{[15]}$ In a hyper-peritectic steel containing 0.45 pct $\mathrm{C}$ or more, all of the $\delta$ ferrite transforms to $\gamma$ while liquid is still present, leaving $\gamma$ to solidify directly from the residual molten steel after the peritectic reaction is completed. Thus, the volume shrinkage accompanying the $\delta / \gamma$ transformation can be accommodated by liquid infiltration and does not lead to shrinkage problems, which require relative shrinkage between two solid (or nearly solid) phases. The rate of $\delta /$ $\gamma$ transformation is suggested to play an important role on the formation of shrinkage depressions and their consequences of air gap formation and cracks. ${ }^{[15]}$

Other researchers ${ }^{[9]}$ explored the reason for more uneven shell growth in ULC and peritectic steels (relative to low-carbon and hyper-peritectic steels), building on that the idea that the rate of the $\delta / \gamma$ transformation is faster in ULC and peritectic steels. A "stress index" was proposed by simply calculating the product of the shrinkage volume occurring for solid fraction from 0.7 to 1.0 , and the estimated $\delta / \gamma$ transformation rate. This index is shown in Figure 30 as a function of carbon content. ${ }^{[19]}$ The agreement of this index with measured trends suggests that uneven shell growth may worsen with increased cooling rate. ${ }^{[15]}$

Another index of solidification shrinkage was also proposed as a criterion for crack susceptibility, $R_{\mathrm{v}}$, as follows, ${ }^{[20]}$ 


$$
R_{\mathrm{v}}=\Delta V(1-L)
$$

where $L$ is the mass fraction of liquid remaining after peritectic solidification estimated from the lever rule on the Fe-C phase diagram, and $\Delta V$ is the volume shrinkage of peritectic solidification, calculated from

$$
\Delta V=\frac{\frac{1}{\rho_{1}}-\frac{1}{\rho_{2}}}{\frac{1}{\rho_{1}}},
$$

where $\rho_{1}$ is the density of $(\mathrm{L}+\delta)$, and $\rho_{2}$ is the density of $\gamma,(\mathrm{L}+\gamma)$ or $(\delta+\gamma)$, using measured steel density at different temperatures and phase fractions. ${ }^{[20]}$ This $R_{\mathrm{v}}$ index is shown in Figure 31 to reach a peak for peritectic steels as expected, and again suggests that solidification shrinkage due to the $\delta / \gamma$ volume change is the main reason for depression problems in these grades. This figure also suggests that the peak moves to higher carbon contents with segregation and non-equilibrium cooling conditions.

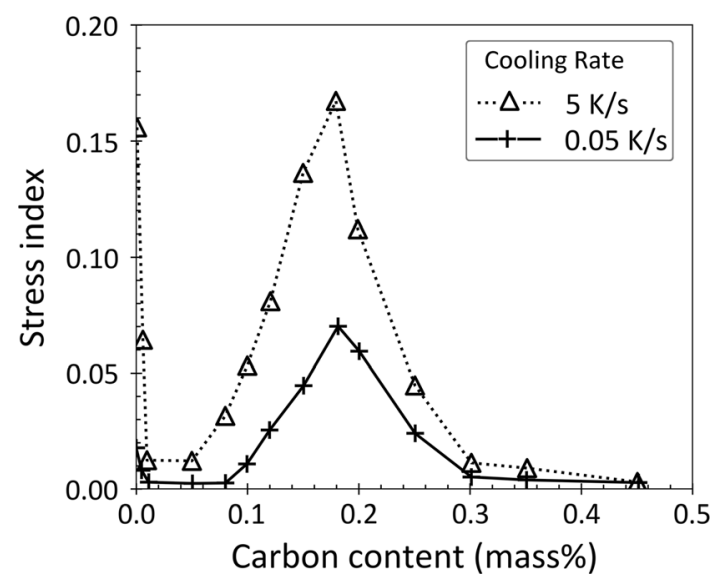

Fig. 30-Effect of carbon content on stress index (product of solidification volume and $\delta / \gamma$ transformation rate). Reprinted with permission from Ref. [19].

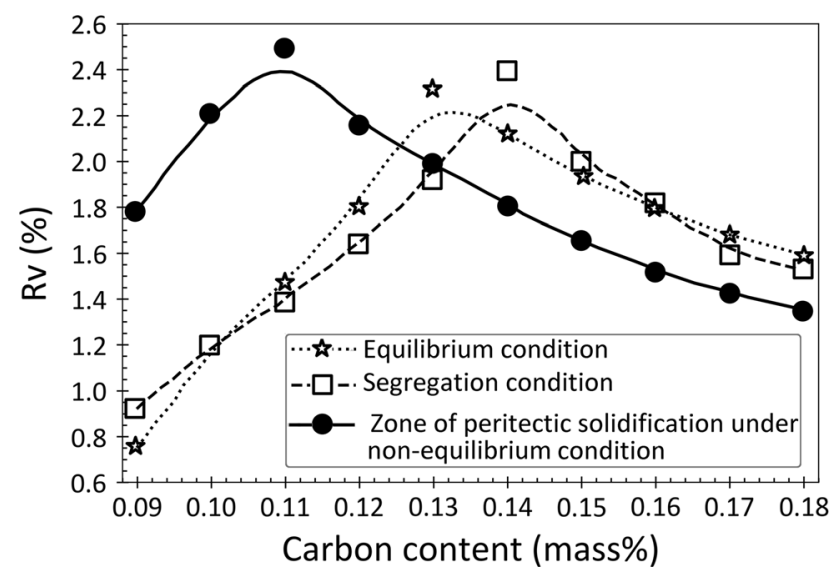

Fig. $31-R_{v}$ shrinkage index variation with carbon content for different cooling conditions. Reprinted with permission from Ref. [20].
To explain how $\delta / \gamma$ shrinkage leads to depressions, it is important to note that bending to form a depression is more complex than simple linear shrinkage. Temperature gradients leading to shrinkage gradients is one mechanism to explain this behavior. Wolf and others have proposed another mechanism, that microstructure non-uniformities during the peritectic transformation may also contribute: Figure 32 suggests two different possible scenarios. ${ }^{[162]}$ At high cooling rates, or with peritectic steels which may have insufficient carbon diffusion to the interior of the dendrites, Figure 32(a) illustrates how austenite might nucleate first on the dendrite exterior, with mainly transverse movement of the $\gamma / \delta$ interface inwards, leaving $\delta$ ferrite along the center of each dendrite. When that $\delta$ ferrite eventually transforms to $\gamma$, the shrinkage would be mainly transverse (perpendicular to the solidification direction), leading directly to bending strain (and depressions) or to interdendritic hot-tear cracks, if the bending were constrained. At low cooling rates, or with higher carbon content, Figure 32(b) depicts how the $\delta / \gamma$ interface might propagate from the dendrite tip to its root, following the isotherms under equilibrium conditions. This would lead to axial shrinkage of the dendrite length in the solidification direction, which would not tend to cause any bending or tensile stress across the interdendritic region. Such microstructural effects should be explored as a potential mechanism for the increased bending and cracks observed in peritectic steels.

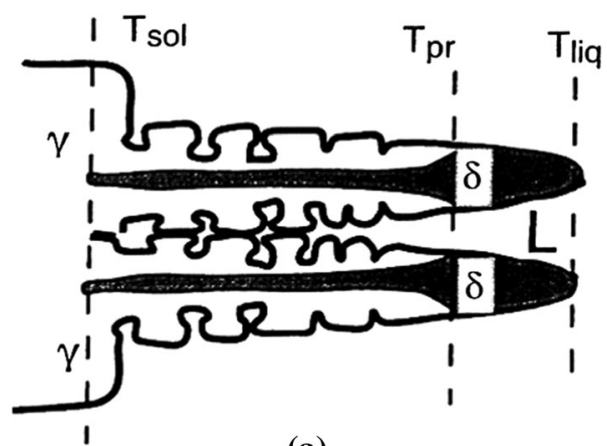

(a)

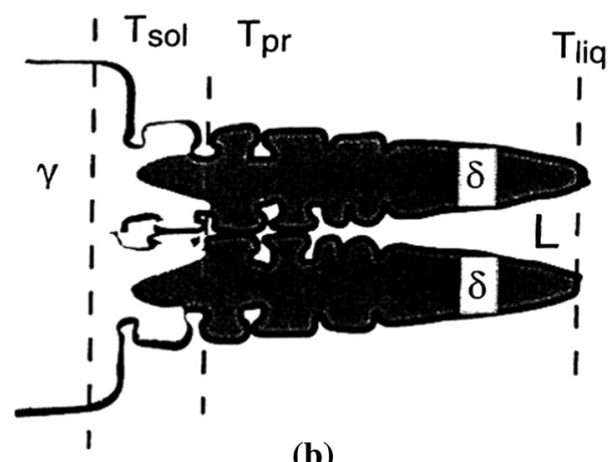

(b)

Fig. 32-Schematic of different directions of the peritectic transformation, (a) transverse shrinkage at high cooling rates or carbon starved (peritectic), which leads to depressions and cracks and $(b)$ axial shrinkage at low cooling rates or high carbon, $C>0.2$ pct which leads to no problems. ${ }^{[162]}$ 
In addition to the importance of increased shrinkage on the behavior of peritectic steels, many researchers have noted that austenite is much stronger than $\delta$-ferrite at a given temperature. ${ }^{[12,163,164]}$ Advanced thermal-mechanical computational models have been applied to investigate the effect of steel alloy (carbon content) on thermal distortion of the bottom of solidifying steel droplets, ${ }^{[165]}$ and on deflection of the tip of the solidifying steel shell during a level drop in a continuous casting machine near the meniscus. ${ }^{[12,163]}$ These models include the temperature, phase fraction, and composition dependency of both the steel density (and corresponding shrinkage) and the strength, using an elastic-viscoplastic constitutive relation. The predictions of these models match the observed trends of increased bending deformation in ULC and peritectic steels. Sample results, shown in Figure 33, reveal that these steels experience deeper depressions, which become much more severe with level fluctuations. ${ }^{[12,163]}$

\section{High-Temperature Ductility and Hot Tearing}

Cracks form during commercial casting processes due to a combination of metallurgical embrittlement and tensile stress. Most longitudinal surface cracks and internal cracks are caused by a hot-tearing mechanism during initial solidification that involves severe embrittlement and failure strains of only about 1 pct. Steel composition plays a critical role, in part, because it controls the high-temperature ductility. Many studies have been conducted on steel ductility, as reviewed elsewhere, ${ }^{[166-168]}$ so only a few points relevant to peritectic steels are emphasized here.

Metallurgical properties during solidification are shown schematically in Figure 34 . Above the zero strength temperature (ZST), the steel behaves like liquid, and any applied tensile strain will simply pull apart the dendrites, and draw liquid in to fill the space. Below the liquid impenetrable temperature (LIT), the feeding of bulk liquid is prevented by the dendrite network. Below the zero ductility temperature (ZDT) or non-equilibrium solidus temperature, solidification is sufficiently complete that the solid can withstand significant load and ductility is high. Between LIT and ZDT is a brittle temperature range that is susceptible to hot tearing. Others suggest a brittle temperature range between the ZST and ZDT. ${ }^{[169]}$ In these critical temperature ranges, strength is low due to the liquid matrix, so any applied tensile strain will open up a crack, which is filled by drawing in surrounding segregated liquid. Strain sources include mechanical deformation, thermal contraction, and the $\delta / \gamma$ phase transformation. The typical solid

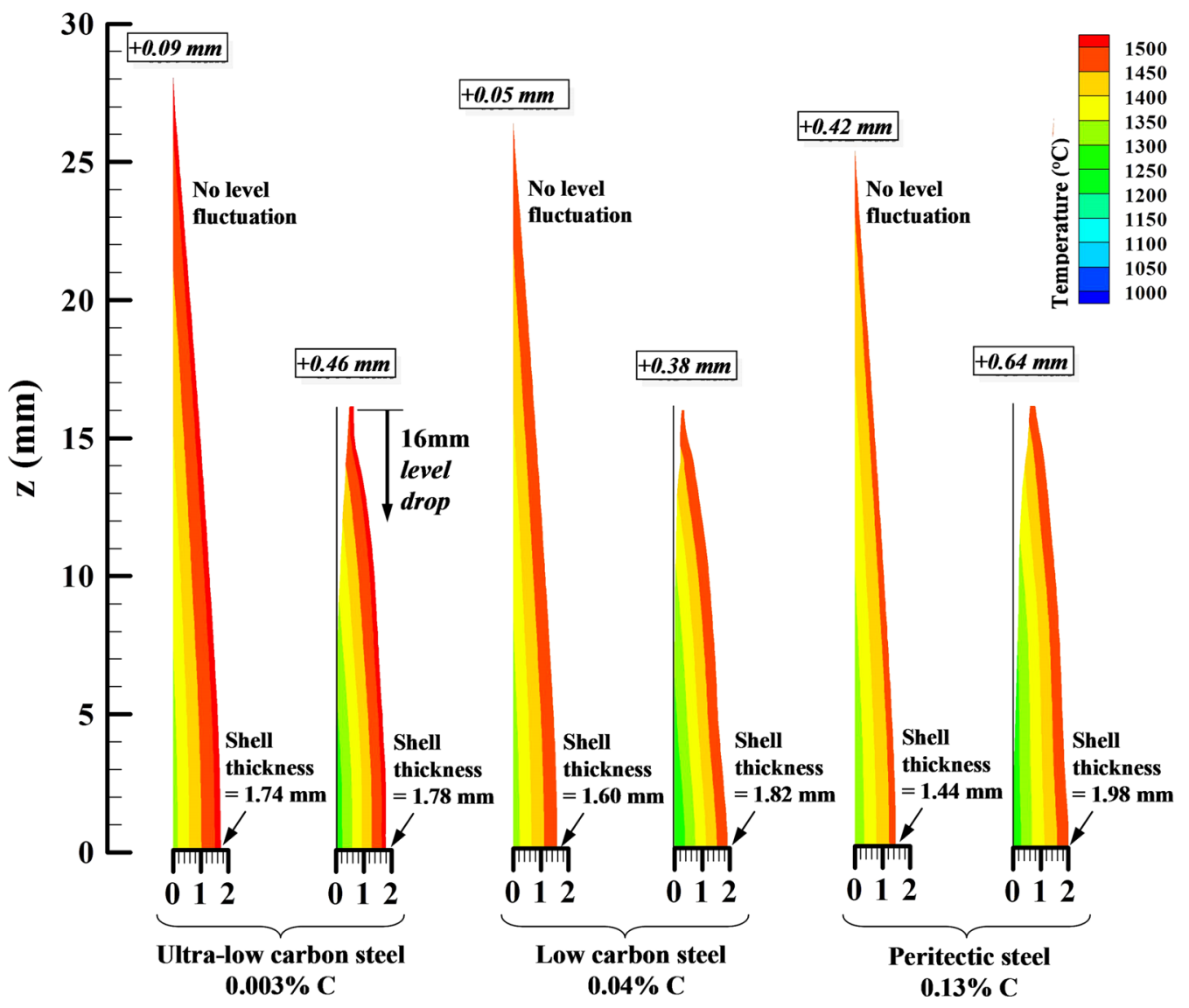

Fig. 33 - Simulated shell tip distortion for three steel grades with and without level fluctuations, showing increased depressions in ULC and peritectic steels. Reprinted with permission from Ref. [12]. 
fraction between LIT and ZDT is 0.9 to 0.99 , which extends with increasing cooling rate, to below the equilibrium solidus temperature. ${ }^{[3,170]}$

Many researchers have investigated the important effect of alloying elements on high-temperature steel ductility. ${ }^{[171-178]}$ Residual impurity elements, such as S, $\mathrm{P}, \mathrm{Cu}, \mathrm{Sn}, \mathrm{Sb}$, and $\mathrm{Zn}$, are well known to be detrimental because they segregate into the interdendritic liquid, lowering the ZDT and thereby decreasing the failure strain. ${ }^{[168,171]}$ Many of these elements have low partition coefficients, leading them to concentrate in the austenite phase. ${ }^{[2]}$ Phosphorus, for example, segregates during solidification to austenite over 10 times more than when solidifying to ferrite. ${ }^{[2]}$ Alloys which undergo the

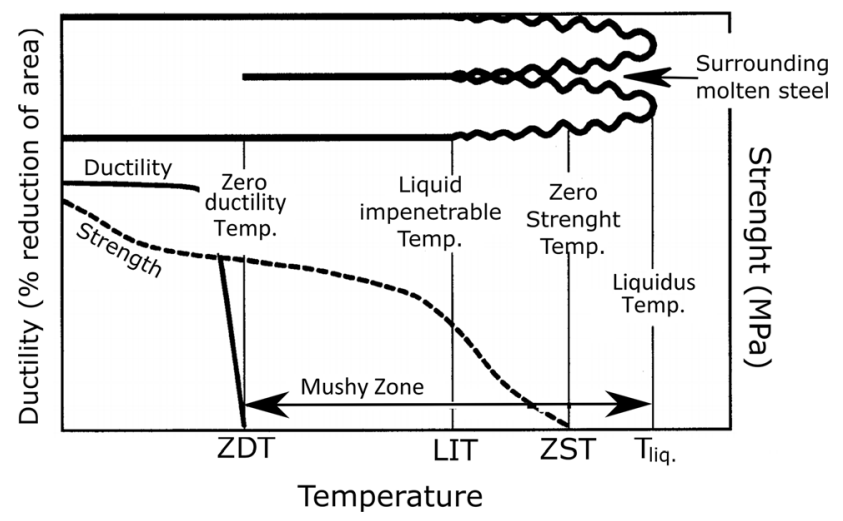

Fig. 34-Schematic of temperatures relevant to high-temperature embrittlement and hot-tearing cracks during steel solidification. Reprinted with permission from Ref. [171].

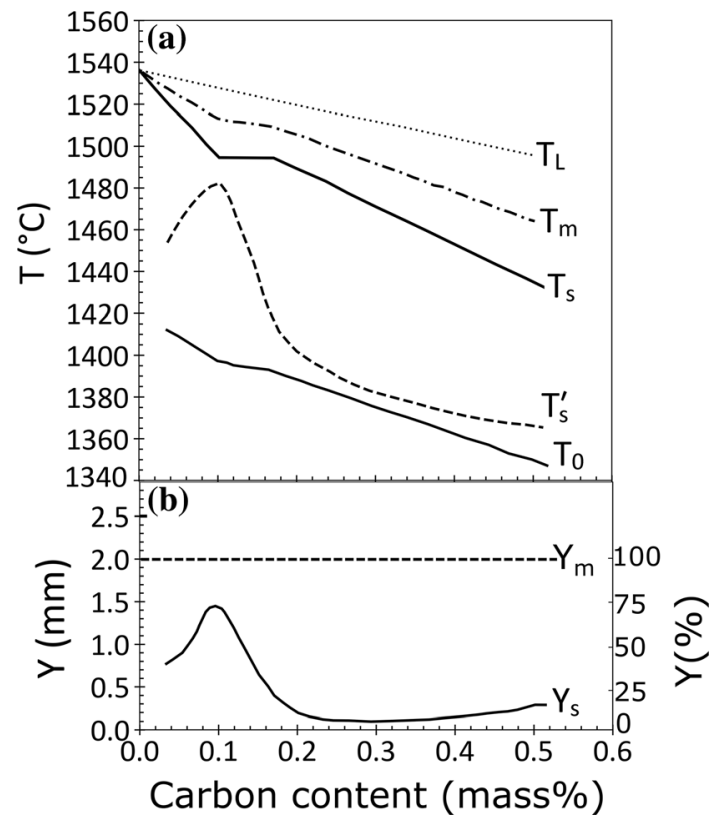

Fig. 35-Influence of $\mathrm{C}$ content on $(a)$ characteristic temperatures in the strand shell and $(b)$ assumed constant planar interface position, $Y_{\mathrm{m}}$, and effective shell thickness, $Y_{\mathrm{s}}$, considering P-segregation. Reprinted with permission from Ref. [2]. peritectic reaction, change their solidification mode from ferritic to austenitic, leading to more segregation, lower ZDT, and lower high-temperature ductility.

Alloys with higher segregation have lower non-equilibrium solidus temperature $\left(T_{\mathrm{s}}\right)$ and consequently have thinner effective shell thickness, that is completely solid with mechanical strength. Figure 35 shows that the peritectic steels $(0.1$ pct $C)$ have the highest effective shell thickness, while high-carbon steels suffer the most embrittlement and are thus more prone to hot-tear cracks. ${ }^{[2]}$ However, the thicker effective shell of the peritectic steels experiences more bending and being stronger, can support a higher ferrostatic pressure, thus leading to deeper surface depressions. Consequently, increased interfacial gap resistance, leading to lower heat flux in the mold decreases the shell growth locally and creates hot spots, so it increases the risk of surface crack formation and breakouts. ${ }^{[3,11,13,18-20]}$

\section{E. Internal Cracks}

Internal cracks are one the most important problems affecting commercial steel casting processes, such as continuous casting. These cracks form due to hot tearing as a result of tensile stresses which are induced by mechanical deformation, thermal contraction, and phase transformation, combined with the loss of hot ductility near the solidus temperature discussed in the previous section. They are generally not actually cracks, because interdendritic liquid is drawn in between the separating dendrites to prevent an actual void. However, this results in a region of macrosegregation in the shape of the crack. This macrosegregation is a worse product defect than a void, because it cannot be closed or otherwise removed by rolling or other subsequent operations. It is important to note that during initial solidification, the mushy zone is at the surface of the steel strand, so surface cracks, especially longitudinal surface cracks, can initiate at the meniscus due to the same high-temperature embrittlement and hot-tearing mechanism as internal cracks.

Many investigations on cracks due to hot tearing during casting of steel alloys have been conducted and are discussed in this section. Different criteria for hot-tear crack formation have been proposed, including critical strain ${ }^{[169,171,179-183]}$ and critical fracture stress. ${ }^{[184,185]}$ Critical strain for internal crack formation has been reported to range from 0.5 to 3.8 pct, ${ }^{[169,181,182,186]}$ or from 1.6 to 2 pct, ${ }^{[187,188]}$ depending on the steel composition. One critical strain criterion for peritectic steel $(0.14$ pct $C)$ suggests a critical temperature range of $T_{\mathrm{a}}-30<T(\mathrm{~K})<T_{\mathrm{a}}$ where $T_{\mathrm{a}}$ is the 0.85 solid fraction temperature. ${ }^{[181]}$ Increasing strain rate is reported to decrease the critical failure strain, ${ }^{[189]}$ perhaps because it lessens the time available for liquid feeding. ${ }^{[171]}$ Won suggests the following critical strain criterion for hot-tear cracking of plain-carbon steels, based on an empirical fit of many measurements ${ }^{[171]}$.

$$
\varepsilon_{\mathrm{c}}=\frac{0.02821}{\dot{\varepsilon}^{0.3131} \Delta T_{\mathrm{B}}^{0.8638}},
$$


where $\varepsilon_{\mathrm{c}}$ is the critical strain which when exceeded locally causes a hot tear; $\dot{\varepsilon}$ is the local strain rate; and $\Delta T_{\mathrm{B}}$ is the critical temperature range for the alloy, corresponding to the solid fraction range of 0.9 to 0.99 pct solid, which equals LIT - ZDT. Because strain and strain rate are tensors with different components which accumulate with time, attention should be paid to their directions, which could differ. ${ }^{[190]}$ It should be noted that this criterion predicts that high-carbon and high-alloy steels with high solidification temperature ranges (and large $\Delta T_{\mathrm{B}}$ ) experience smaller critical strains, so are easier to crack. In contrast, peritectic steels experience smaller solidification temperature ranges, and so have higher critical strains, which agrees with the high-temperature hot ductility findings discussed in the previous section. ${ }^{[171]}$ Higher strain rate also decreases the critical strain and makes cracks more likely, but is difficult to quantify.

Other researchers have suggested critical fracture stress in the mushy zone as a criterion for crack formation. ${ }^{[23,191-194]}$ The fracture stress of solidifying shell has been measured using submerged split chill tension testing method. ${ }^{[184,195]}$ According to this criterion, hot-tear cracks form in the mushy zone when the maximum principal stress exceeds the local tensile strength of the steel at that temperature. ${ }^{[196]}$ Other researchers ${ }^{[197]}$ using tensile testing at elevated temperature found that steels which undergo the peritectic reaction are more susceptible to crack formation, especially when the solidification experiences massive transformation, owing to the fast shrinkage contraction.

Another crack criterion is based on the difference of deformation energy in the brittle temperature range and is shown in Figure 36 as function of carbon content, along with an experimentally measured crack index. ${ }^{[171]}$ Peritectic steels $(0.12$ pct $\mathrm{C})$ are predicted to experience the largest tendency for cracking. This was attributed to the large $\delta / \gamma$ transformation strain during solidification leading to higher strain rates. High strain rates also decrease the critical strain for crack formation. These results have been confirmed by Bernhard et al. ${ }^{[198]}$

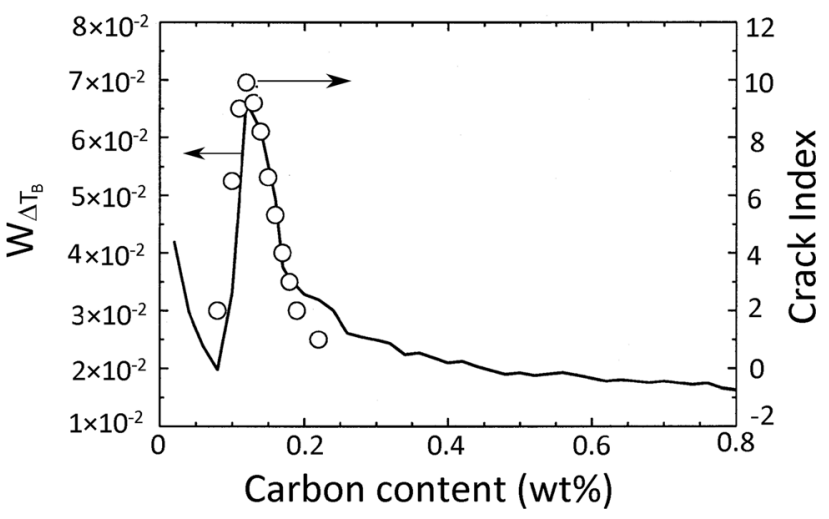

Fig. 36-Effect of carbon content on experimentally measured crack index and on difference of deformation energy in the brittle temperature range. Reprinted with permission from Ref. [171].
These predictions agree with other research that suggests that steels with carbon content of 0.1 to 0.14 pct $C$ are more susceptible to internal cracking. ${ }^{[14,199,200]}$ However, they appear to disagree with some of the critical strain predictions discussed earlier. This disagreement between different cracking criteria suggests that simple empirical relations are not easy to apply and that phenomena such as local shell thinning and strain concentration must be considered when predicting crack formation, as discussed in the next section.

\section{F. Longitudinal Surface Cracks}

Many studies ${ }^{[9,22,201,202]}$ have found carbon content to be the most critical factor which affects the formation of longitudinal surface cracks. Because they usually initiate during initial solidification near the meniscus, longitudinal surface cracks are governed by the same high-temperature ductility properties that govern internal cracks. In addition, they are greatly influenced by surface depressions, where strain can concentrate in the thin shell beneath them. Longitudinal surface cracks are formed most in the range of 0.09 to 0.18 pct $\mathrm{C}$ (hypo-peritectic range), as shown in Figure 37. ${ }^{[203]}$ This was attributed to the higher rate of shrinkage accompanying the $\delta / \gamma$ transformation, which can be represented by the corresponding density increase. ${ }^{[203]}$ Despite having high shrinkage, longitudinal cracks do not formed as much above 0.18 pct $\mathrm{C}$. This was suggested to be due to more liquid feeding available to compensate the shrinkage in these hyper-peritectic steels.

Other researchers ${ }^{[24]}$ have investigated critical strain for crack formation in different steel grades using tensile and bending tests, and found that critical strain in peritectic steel is almost two times that of non-peritectic steels (Figure 38). Thus, the longitudinal surface cracks which form during the continuous casting of peritectic steels are not caused by higher intrinsic crack sensitivity of these steels, but rather by the hot spots at the base of depressions caused by the $\delta$ to $\gamma$ phase transformation in the early stages of solidification.

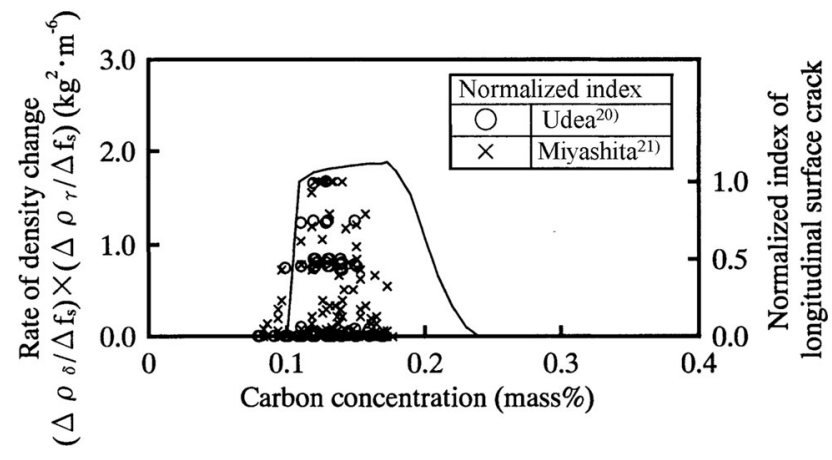

Fig. 37-Effect of carbon content on longitudinal surface crack index. Reprinted with permission from Ref. [203]. 


\section{G. Intermediate-Temperature Ductility Drop, Austenite Grain size, and Transverse Cracks}

Many surface cracks, especially transverse cracks, arise due to tensile stress and embrittlement of the austenite grain boundaries at intermediate temperatures. A significant drop of ductility of steel at intermediate temperatures, from $\sim 700{ }^{\circ} \mathrm{C}$ to above $900{ }^{\circ} \mathrm{C}$, has been the subject of many studies, reviewed elsewhere. ${ }^{[173]}$ This ductility drop or "trough" is due to the formation of precipitates, including sulfides and nitrides, which weaken the austenite grain boundaries, especially when soft and weak primary ferrite nucleates on the boundaries to form ferrite films or networks. Embrittlement is much more severe when the austenite $(\gamma)$ grains are very large, because any applied tensile strain concentrates within a small number of grain boundaries. ${ }^{[178,204-208]}$ Intermediate-temperature ductility loss is important to transverse surface cracks, because they tend to form due to axial and unbending strain low in a continuous

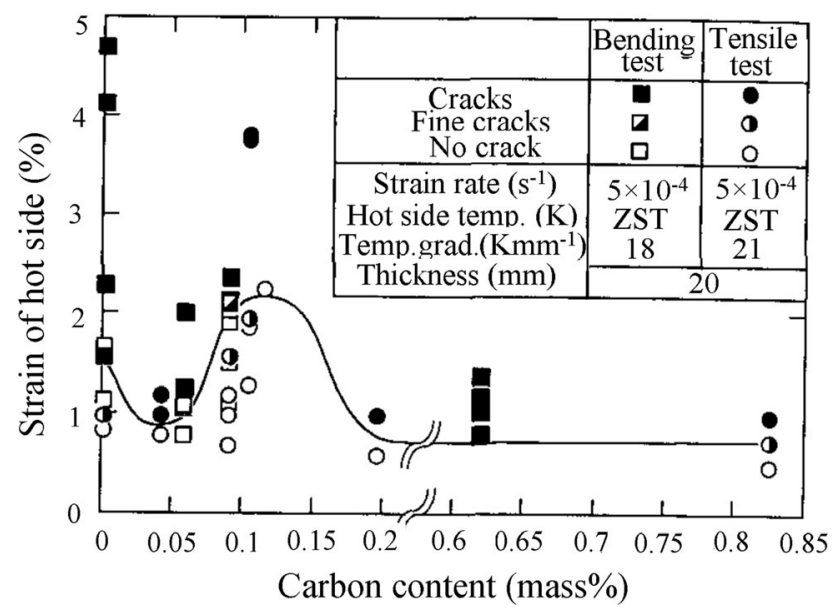

Fig. 38-Effect of carbon content on the critical strain for crack formation. Reprinted with permission from Ref. [24].

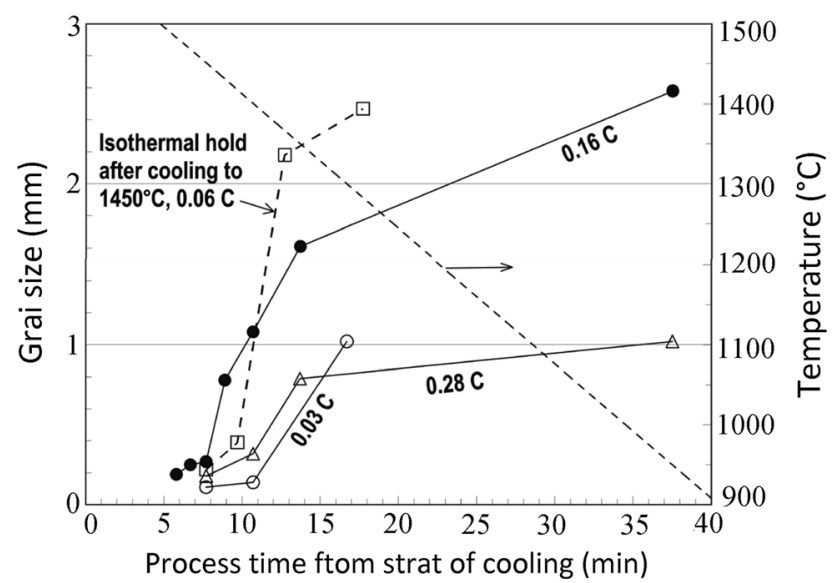

Fig. 39-Austenite grain growth with temperature and carbon content (in situ melted and cooled from $1580{ }^{\circ} \mathrm{C}$ to test temperature at $\left.16.8^{\circ} \mathrm{C} / \mathrm{min}\right)$. Reprinted with permission from Ref. [211]. casting machine, when surface temperatures often fall within the critical temperature range for the intermediate-temperature ductility trough.

It has been widely reported that transverse cracks form only in the presence of abnormally large austenite grains, where a film of ferrite or precipitate form along the boundaries. ${ }^{[209-211]}$ These abnormally large grains are sometimes referred to as "blown grains." Peritectic steels are reported to experience larger austenite grain size than steels with either lower or higher carbon content. ${ }^{[212]}$ Austenite grain size increases rapidly with increasing temperature, due to grain growth, as shown in Figure 39. ${ }^{[21]}$ This figure also shows that near-peritectic steel $(0.16$ pct $\mathrm{C})$ experiences grain growth earlier and eventually attains a larger size.

Other researchers have confirmed that near-peritectic steels, such as $0.17 \mathrm{pct} C$, have larger austenite grain size than other steels, as shown in Figure $40 . .^{[205,213]}$ It is suggested that ${ }^{[214]}$ because liquid and $\delta$ ferrite hinder the growth of $\gamma$ grains, ${ }^{[215]}$ austenite grains start to grow immediately after transformation into the single phase $\gamma$ region. ${ }^{[215,216]}$ Adding phosphorus to 0.1 pet $\mathrm{C}$ steel has been shown to decrease the primary austenite grain size. ${ }^{[217,218]}$ This was attributed to delaying the $\delta / \gamma$ transformation to a lower temperature range.

Austenite grain size can be predicted by ${ }^{[219]}$

$$
\bar{D}=9.1 \times T^{\prime}-3152\left[\frac{e^{\dot{T}}}{1+e^{\dot{T}}}\right]-9044,
$$

where $\bar{D}$ is the final austenite grain size in $\mu \mathrm{m} ; T^{\gamma}$ is the highest temperature of the totally austenitic region for the steel composition $\left({ }^{\circ} \mathrm{C}\right)$, and $\dot{T}$ is the local cooling cooling rate $\left({ }^{\circ} \mathrm{C} / \mathrm{s}\right)$. Predictions at 3 different cooling rates for steels with different carbon contents and 0.3 pet $\mathrm{Si}$ and 1.5 pct $\mathrm{Mn}$ all match closely with measurements for similar grades, as shown in Figure $41 .^{[219]}$ These results confirm that austenite grain size is larger in peritectic steels, with huge grains exceeding $1 \mathrm{~mm}$ diameter in many cases.

Transverse cracks are more severe with deep surface depressions and oscillation marks. ${ }^{[213,219-221]}$ This is expected because the greater interfacial resistance between the shell and the mold leads to lower heat flux,

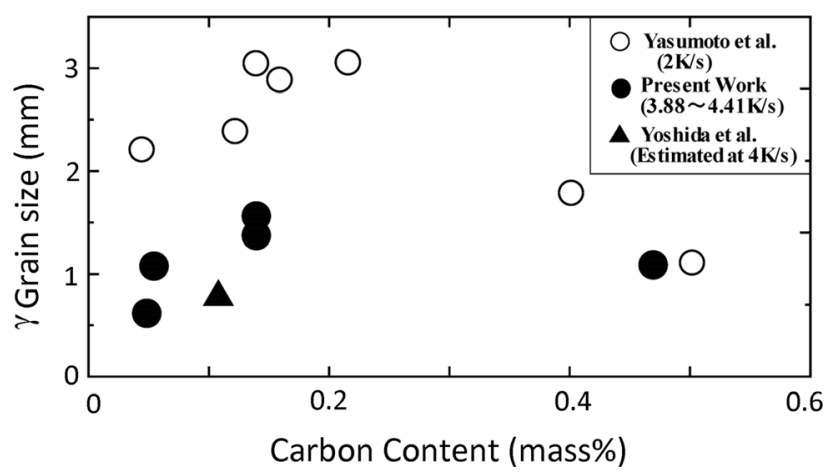

Fig. 40-The $\gamma$ grain size change by carbon content in terms of $\gamma$ single-phase temperature in Fe-C phase diagram. Reprinted with permission from Ref. [205]. 


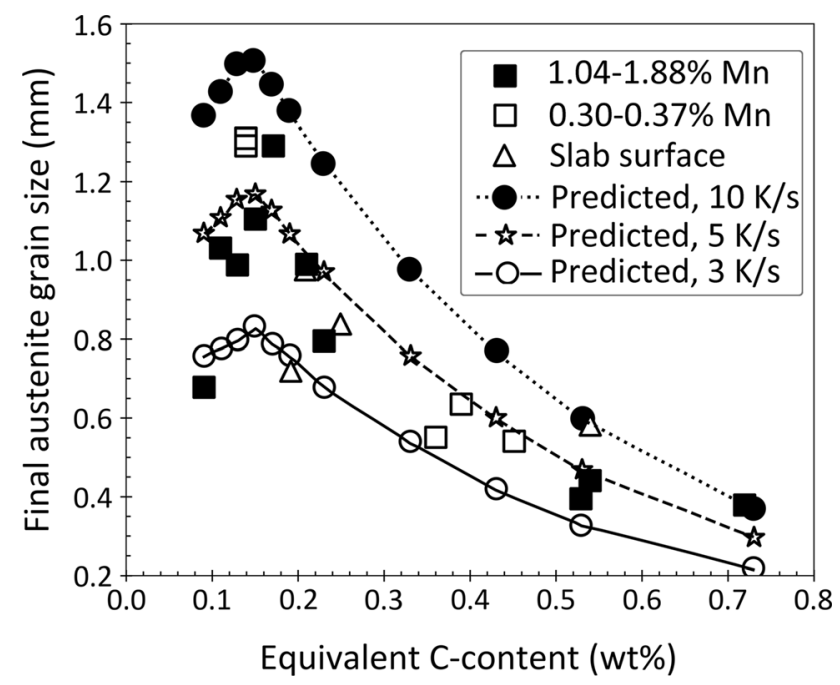

Fig. 41-Measured and predicted austenite grain size vs. equivalent carbon content. Reprinted with permission from Ref. [219].

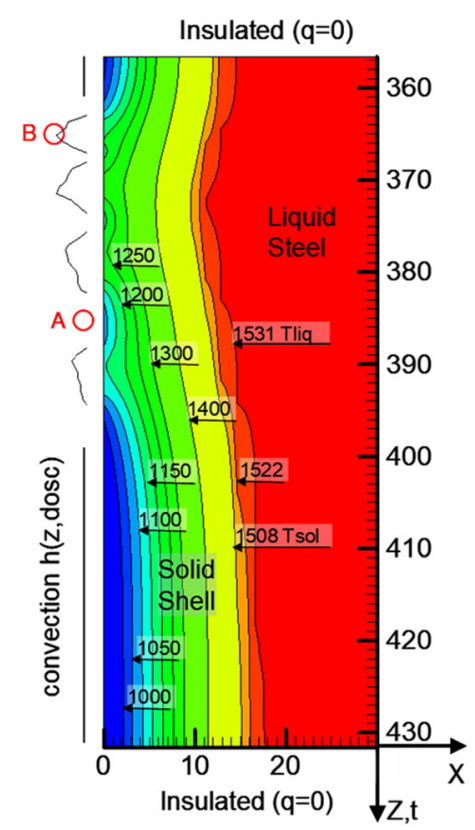

(a)

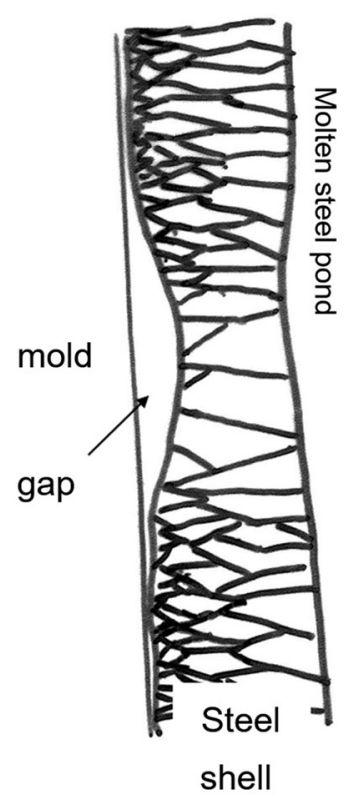

(b)
Fig. 42-Close-up of solidifying steel shell in the mold showing (a) simulated temperature contours near a group of deep oscillation marks and $(b)$ schematic of resulting grain structure leading to transverse cracks. Reprinted with permission from Ref. [153].

and a hotter, thinner, and weaker shell beneath the depression, as discussed earlier. Heat transfer model calculations in Figure 42(a) show the expected temperature distribution near a group of deep oscillation marks. Surface temperatures beneath the oscillation mark can increase up to several hundred degrees hotter than the nearby steel surface, owing to the lower heat transfer, especially if the interfacial gap contains air. ${ }^{[153]}$ The hotter surface causes a thinner and weaker shell, which matched thickness profile measurements on a breakout shell. The hotter surface also enables more grain growth, leading to coarse austenite grains and strain concentration in these areas, as shown schematically in Figure 42. ${ }^{[153]}$ Below the mold, spray cooling can make the strand surface temperature become more uniform, but cannot reduce the large austenite grain size on the surface. In summary, transverse cracks are more common in peritectic steel than in other steel grades for two reasons. Firstly, the increased shrinkage of these steels causes deeper oscillation marks and surface depressions, which result in higher surface temperatures beneath the depressions. Secondly, austenite grain growth in these steels begins at higher temperature, leading to generally larger austenite grains beneath the surface depressions. Both effects lead to decreased intermediate-temperature ductility, increased strain concentration, and increased transverse crack formation in peritectic steels.

\section{CONCLUSIONS}

This paper summarizes current understanding of peritectic solidification of steel, and its important effects on commercial casting operations. Specific findings include the following:

- Several empirical relations are available to predict if a steel alloy will exhibit peritectic behavior according to its composition, especially carbon content. These include criteria based on carbon equivalent ranges, alloy-dependent critical points, ferrite potential, and CALPHAD methods. Although already successful, further work is needed, as different relations differ regarding the influence of some alloying elements, including $\mathrm{Si}, \mathrm{Cr}, \mathrm{Ti}, \mathrm{V}, \mathrm{S}, \mathrm{P}, \mathrm{A}$, and $\mathrm{Nb}$. The trends are clear for austenite-forming elements $\mathrm{Mn}, \mathrm{Ni}, \mathrm{Cu}$, and $\mathrm{N}$ and ferrite-forming Mo.

- Fundamental mechanisms to explain peritectic solidification have been investigated using experiments which include calorimetry, diffusion couples, directional solidification, HT-CLSM, and X-ray imaging methods, and computational models which range from simple analytical diffusion equations to sophisticated phase-field simulations.

- Under equilibrium conditions, peritectic solidification proceeds in two distinct steps: the peritectic reaction and the peritectic transformation.

- The peritectic reaction takes places when austenite nucleates and grows as a thin layer along the liquid/ $\delta$-ferrite interface at or just below the peritectic temperature. It is governed by diffusion of solute (carbon in plain Fe-C steels), especially in the liquid, and likely also depends on microscale heat transfer that causes local re-melting of $\delta$-ferrite and liquid/solute mixing near the $\delta / \gamma / \mathrm{L}$ triple point.

- The peritectic transformation first involves growth of the austenite layer thickness in both directions: into the liquid $(\mathrm{L} \rightarrow \gamma)$ on one side, and into the $\delta$-ferrite interior $(\delta \rightarrow \gamma)$ on the other side, which separates the $\delta$-ferrite and liquid by a thickening layer of austenite. Some believe that this transformation is controlled by diffusion, especially with low undercooling below the peritectic temperature. At high undercooling, the 
transformation is extremely fast, so others believe that the $\delta \rightarrow \gamma$ transformation is controlled by massive transformation.

- At very high undercooling and transformation rates, some claim that the peritectic reaction is suppressed, due to either nucleation constraint, or to solute flux gradients, so the initial austenite layer never grows along the $\delta / \mathrm{L}$ interface and the entire peritectic solidification process is governed by massive transformation.

- Peritectic steels cause deeper oscillation marks and surface depressions in cast products, relative to other steel grades. This is due to the large shrinkage that accompanies the $\delta \rightarrow \gamma$ phase transformation, the higher transformation speed, the much higher strength of austenite relative to $\delta$-ferrite, complex thermal-mechanical behavior during solidification, and possibly other factors involving the microstructure evolution.

- Peritectic steels having deeper surface roughness leads to higher resistance to heat transfer across the interfacial gap during initial solidification in the mold, lower heat flux, uneven shell growth, and thin regions in the solidifying steel shell, which have hotter local surface temperature. These thin, weak, hot spots lead to local strain concentration and make peritectic steels more susceptible to breakouts and hot-tearing cracks, especially internal cracks and longitudinal surface cracks, relative to other grades.

- Peritectic steels experience faster austenite grain growth at high temperature, which leads to lower intermediate-temperature ductility. Together with the higher local temperatures found beneath oscillation marks and depressions, this makes peritectic steels more prone to cracks, especially transverse surface cracks.

- Many empirical indices and criteria have been developed to predict cracking due to hot tearing. Further research is needed, however, to better quantify both hot-tear crack formation and cracks related to intermediate-temperature embrittlement before crack formation in peritectic steels (and other grades) can be accurately predicted.

- Although significant progress has been made in recent years, much further research is needed to confirm and quantify the mechanisms that govern peritectic solidification, how they are affected by composition and casting conditions, and how they can be controlled to improve final product quality.

\section{ACKNOWLEDGMENTS}

The authors wish to thank the contributing companies of the Continuous Casting Center at the Colorado School of Mines for funding that enabled this research.

\section{REFERENCES}

1. J.K. Brimacombe and K. Sorimachi: Metall. Mater. Trans. B, 1977, vol. 8B, pp. 489-505.

2. M. Wolf and W. Kurz: Metall. Mater. Trans. B, 1981, vol. 12B, pp. 85-93.

3. B.G. Thomas, M.S. Jenkins, and R.B. Mahapatra: Ironmak. Steelmak., 2004, vol. 31, pp. 485-94.

4. J. Sengupta, H.J. Shin, B. Thomas, and S.H. Kim: Acta Mater., 2006, vol. 54, pp. 1165-73.

5. W. Kurz: la metall. ital., 2008, pp. 56-64.

6. H. Zhang and W. Wang: Metall. Mater. Trans. B, 2016, vol. 47B, pp. $920-31$.

7. V. Guyot, J.F. Martin, A. Ruelle, A. d'Anselme, J.P. Radot, M. Bobadilla, J.Y. Lamant, and J.N. Pontoire: ISIJ Int., 1996, vol. 36, pp. S227-30.

8. A. Badri, T. Natarajan, C. Snyder, K. Powers, F. Mannion, and A. Cramb: Metall. Mater. Trans. B, 2005, vol. 36B, pp. 355-71.

9. S.N. Singh and K.E. Blazek: JOM, 1974, vol. 26, pp. 17-27.

10. T. Emi and H. Fredriksson: Mater. Sci. Eng. A, 2005, vol. 413, pp. 2-9.

11. J. Konishi, M. Militzer, I.V. Samarasekera, and J.K. Brimacombe: Metall. Mater. Trans. B, 2002, vol. 33B, pp. 413-23.

12. J. Sengupta, C. Ojeda, and B. Thomas: Int. J. Cast Met. Res., 2009, vol. 22, pp. 8-14.

13. T.W. Clyne, M. Wolf, and W. Kurz: Metall. Trans. B, 1982, vol. 13B, pp. 259-66.

14. G. Xia, C. Bernhard, S. Ilie, and C. Fuerst: Steel Res. Int., 2011, vol. 82, pp. 230-36.

15. L.G. Zhu and R. Kumar: Ironmak. Steelmak., 2007, vol. 34, pp. 71-75.

16. K. Harste and K. Schwerdtfeger: ISIJ Int., 2003, vol. 43, pp. 1011-20.

17. M. Suzuki, C.H. Yu, H. Sato, Y. Tsui, H. Shibata, and T. Emi: ISIJ Int., 1996, vol. 36, pp. S171-74.

18. A. Grill, K. Sorimachi, and J.K. Brimacombe: Metall. Trans. B, 1976, vol. 7B, pp. 177-89.

19. M. Suzuki and Y. Yamaoka: Mater. Trans., 2003, vol. 44, pp. $836-44$

20. J. Xu, S. He, X. Jiang, T. Wu, and Q. Wang: ISIJ Int., 2013, vol. 53, pp. 1812-17.

21. A. Lagerstedt, J. Kron, F. Yosef, and H. Fredriksson: Mater. Sci. Eng. A, 2005, vol. 413, pp. 44-51.

22. A. Grill and J. Brimacombe: Ironmak. Steelmak., 1976, vol. 3, pp. 76-79.

23. K. Kim, H.N. Han, T. Yeo, Y. Lee, K.H. Oh, and D.N. Lee: Ironmak. Steelmak., 1997, vol. 24, pp. 249-56.

24. C.H. Yu, M. Suzuki, H. Shibata, and T. Emi: ISIJ Int., 1996, vol. 36, pp. S159-62.

25. R. Kuziak, R. Kawalla, and S. Waengler: Arch. Civ. Mech. Eng., 2008, vol. 8, pp. 103-17.

26. B. De Cooman: Curr. Opin. Solid State Mater. Sci., 2004, vol. 8, pp. 285-303.

27. P. Jacques: Curr. Opin. Solid State Mater. Sci., 2004, vol. 8, pp. 259-65.

28. I. Tamura, H. Sekine, and T. Tanaka: Thermomechanical Processing of High-Strength Low-Alloy Steels, 1st ed., Butterworth-Heinemann, London, 1988, pp. 50-77.

29. K.H. Lee, M.C. Kim, B.S. Lee, and D.M. Wee: J. Nucl. Mater., 2010, vol. 403, pp. 68-74.

30. H. Kerr and W. Kurz: Int. Mater. Rev., 1996, vol. 41, pp. 129-64.

31. S. Griesser, C. Bernhard, and R. Dippenaar: ISIJ Int., 2014, vol. 54, pp. 466-73.

32. H. Fredriksson and T. Nylen: Met. Sci., 1982, vol. 16, pp. 28394.

33. H. Shibata, Y. Arai, M. Suzuki, and T. Emi: Metall. Mater. Trans. B, 2000, vol. 31B, pp. 981-91.

34. H.W. Kerr, J. Cisse, and G. Bolling: Acta Metall., 1974, vol. 22, pp. $677-86$.

35. D.M. Stefanescu: ISIJ Int., 2006, vol. 46, pp. 786-94.

36. G. Wen, S. Sridhar, P. Tang, X. Qi, and Y. Liu: ISIJ Int., 2007, vol. 47, pp. 1117-25. 
37. M. Kawamoto, Y. Tsukaguchi, N. Nishida, T. Kanazawa, and S. Hiraki: ISIJ Int., 1997, vol. 37, pp. 134-39.

38. X. Long, S.P. He, J.F. Xu, X.L. Huo, and Q. Wang: J. Iron Steel Res. Int., 2012, vol. 19, pp. 39-45.

39. J. Brooks and A. Thompson: Int. Mater. Rev., 1991, vol. 36, pp. 16-44.

40. H. Yin: IOP Conf. Ser. Mater. Sci. Eng., 2019, vol. 529, p. 012073-73.

41. P. Presoly, R. Pierer, and C. Bernhard: Metall. Mater. Trans. A, 2013, vol. 44A, pp. 5377-88.

42. J. Ågren: Metall. Trans. A, 1979, vol. 10A, pp. 1847-52.

43. J. Chipman: Metall. Mater. Trans. B, 1972, vol. 3B, pp. 55-64.

44. M. Tisza: Physical Metallurgy for Engineers, 1st ed., ASM International, London, 2001, pp. 219-38.

45. P. Presoly, G. Xia, P. Reisinger, and C. Bernhard: $B H M$ Berg-Huettenmaenn. Monatsh., 2014, vol. 159, pp. 430-37.

46. E. Wielgosz and T. Kargul: J. Therm. Anal. Calorim., 2015, vol. 119, pp. 1547-53.

47. H. Chen, M. Long, W. He, D. Chen, H. Duan, and Y. Huang: in TMS Annual Meeting, The Minerals, Metals and Materials Society, Phoenix, AZ, 2018, pp. 419-30.

48. O. Martiník, B. Smetana, J. Dobrovská, S. Zlá, M. Kawuloková, K. Gryc, Ľ. Drozdová, P. Dostál, and B. Martiníková: J. Phase Equilib. Differ., 2019, vol. 40, pp. 93-103.

49. S. Abraham, R. Bodnar, J. Lonnqvist, F. Shahbazian, A. Lagerstedt, and M. Andersson: Metall. Mater. Trans. A, 2019 , vol. 50A, pp. 2259-71.

50. G. Xia, H. Narzt, C. Fürst, K. Mörwald, J. Moertl, P. Reisinger, and L. Lindenberger: Ironmak. Steelmak., 2004, vol. 31, pp. 364 70

51. A. Howe: Appl. Sci. Res., 1987, vol. 44, pp. 51-59.

52. M.M. Wolf: in Continuous Casting: Initial Solidification Strand Surface Quality of Peritectic Steels, M.M. Wolf, ed., Iron and Steel Society/AIME, Warrendale, PA, 1997, vol. 9, pp. 61-65.

53. J. Xu, S. He, T. Wu, X. Long, and Q. Wang: ISIJ Int., 2012, vol. 52, pp. $1856-61$.

54. A. Kagawa and T. Okamoto: Mater. Sci. Technol., 1986, vol. 2, pp. $997-1008$

55. R. Sarkar, A. Sengupta, V. Kumar, and S.K. Choudhary: ISIJ Int., 2015, vol. 55, pp. 781-90.

56. P. Presoly, R. Pierer, and C. Bernhard: IOP Conf. Ser. Mater. Sci. Eng., 2012, vol. 33, p. 012064.

57. D.S. Petrovič, G. Klančnik, M. Pirnat, and J. Medved: J. Therm. Anal. Calorim., 2011, vol. 105, pp. 251-57.

58. B. Cantor: J. Therm. Anal. Calorim., 1994, vol. 42, pp. 647-65.

59. G. Klančnik, J. Medved, A. Nagode, G. Novak, and D. Steiner Petrovič: J. Therm. Anal. Calorim., 2014, vol. 116, pp. 295-302.

60. W. Mingjia, C. Lei, W. Zixi, and B. Er: J. Rare Earths, 2011, vol. 29, pp. 1089-94.

61. S.H. Atapek, E. Erișir, and S. Gümüș: J. Therm. Anal. Calorim., 2013, vol. 114, pp. 179-83.

62. K. Hechu, C. Slater, B. Santillana, S. Clark, and S. Sridhar: Mater. Charact., 2017, vol. 133, pp. 25-32.

63. A. Howe: Segregation and Phase Distribution During Solidification of Carbon, Alloy and Stainless Steels, 1st ed., Commission of European Communities, Brussels, 1989, pp. 73-75.

64. A. Normsnton: Improving Surface Quality of Continuously Cast Semis by an Understanding of Shell Development and Growth, Technical Steel Research Series, $1^{\text {st }}$ ed., Luxembourg, 2005, p. 349.

65. A.K. Sinha: Physical Metallurgy Handbook, 1st ed., McGrawHill Professional Publishing, New York, 2003, pp. 594-600.

66. K.E. Blazek, O. Lanzi, P.L. Gano, and D.L. Kellogg: Iron Steel Technol., 2008, vol. 5, pp. 80-85.

67. Thermo-Calc Software TCFE9 Steels/Fe-Alloys Database, Råsundavägen, Sweden.

68. Y. Liu, X. Wang, M. Yao, X. Zhang, H. Ma, Z. Wang, J. Ma, X. Wang, and G. Shi: Ironmak. Steelmak., 2014, vol. 41, pp. 748-55.

69. S. McKay, N. Hunter, A. Normanton, V. Ludlow, P. Hewitt, and B. Harris: Ironmak. Steelmak., 2002, vol. 29, pp. 185-90.

70. S. Sridhar, K. Mills, O. Afrange, H. Lörz, and R. Carli: Ironmak. Steelmak., 2000, vol. 27, pp. 238-42.

71. J.-O. Andersson, T. Helander, L. Höglund, P. Shi, and B. Sundman: CALPHAD, 2002, vol. 26, pp. 273-312.

72. W. Bosze and R. Trivedi: Metall. Trans., 1974, vol. 5, pp. 511-12.
73. Y. Chuang, D. Reinisch, and K. Schwerdtfeger: Metall. Mater. Trans. A, 1975, vol. 6A, pp. 235-38.

74. H. Nassar: Ph.D. Thesis, KTH Royal Institute of Technology, 2009.

75. K. Matsuura, Y. Itoh, and T. Narita: ISIJ Int., 1993, vol. 33, pp. $583-87$.

76. D. Phelan, M. Reid, and R. Dippenaar: Mater. Sci. Eng. A, 2008, vol. 477 , pp. $226-32$

77. S. Griesser, C. Bernhard, and R. Dippenaar: Acta Mater., 2014, vol. 81, pp. 111-20.

78. M. Yoshiya, K. Nakajima, M. Watanabe, N. Ueshima, T. Nagira, and H. Yasuda: Mater. Trans., 2015, vol. 56, pp. 1461-66.

79. L. Luo, Y. Su, J. Guo, X. Li, S. Li, H. Zhong, L. Liu, and H. Fu: J. Alloys Compd., 2008, vol. 461, pp. 121-27.

80. Y. Arai, T. Emi, H. Fredriksson, and H. Shibata: Metall. Mater. Trans. A, 2005, vol. 36A, pp. 3065-74.

81. B.K. Dhindaw, T. Antonsson, H. Fredriksson, and J. Tinoco: Metall. Mater. Trans. A, 2004, vol. 35A, pp. 2869-79.

82. H. Yasuda, T. Nagira, M. Yoshiya, M. Uesugi, N. Nakatsuka, M. Kiire, A. Sugiyama, K. Uesugi, and K. Umetani: IOP Conf. Ser. Mater. Sci. Eng., 2012, vol. 27, p. 012084

83. J.S. Lee, S.G. Kim, W.T. Kim, and T. Suzuki: ISIJ Int., 1999, vol. 39 , pp. $730-36$.

84. M. Ohno and K. Matsuura: Acta Mater., 2010, vol. 58, pp. 5749 58.

85. M. Ohno and K. Matsuura: Acta Mater., 2010, vol. 58, pp. 6134 41.

86. Y. Ueshima, S. Mizoguchi, T. Matsumiya, and H. Kajioka: Metall. Trans. B, 1986, vol. 17B, pp. 845-59.

87. D. Phelan, M. Reid, and R. Dippenaar: Metall. Mater. Trans. A, 2006, vol. 37A, pp. 985-94.

88. S. Griesser, M. Reid, C. Bernhard, and R. Dippenaar: Acta Mater., 2014, vol. 67, pp. 335-41.

89. T. Nishimura, K. Morishita, T. Nagira, M. Yoshiya, and H. Yasuda: IOP Conf. Ser. Mater. Sci. Eng., 2015, vol. 84, p. 012062 .

90. K. Matsuura, H. Maruyama, Y. Itoh, M. Kudoh, and K. Ishii: ISIJ Int., 1995, vol. 35, pp. 183-87.

91. A. Titchener and J. Spittle: Met. Sci., 1974, vol. 8, pp. 112-16.

92. S.P. Gupta: Mater. Charact., 2002, vol. 49, pp. 321-30.

93. F. Bartels, J. Morris, G. Dalke, and W. Gust: J. Electron. Mater., 1994, vol. 23, pp. 787-90.

94. J.H. Dai, B. Jiang, C. Peng, and F.S. Pan: J. Alloys Compd., 2017, vol. 710 , pp. $260-66$

95. C.R. Hutchinson, A. Fuchsmann, H.S. Zurob, and Y. Brechet: Scripta Mater., 2004, vol. 50, pp. 285-90.

96. M. Mirjalili, M. Soltanieh, K. Matsuura, and M. Ohno: Intermetallics, 2013, vol. 32, pp. 297-302.

97. G.S. Kino and T.R. Corle: Confocal Scanning Optical Microscopy and Related Imaging Systems, 1st ed., Academic, San Diego, 1996, pp. 135-57.

98. N. McDonald and S. Sridhar: J. Mater. Sci., 2005, vol. 40, pp. 2411-16.

99. T. Liu, M. Long, D. Chen, S. Wu, P. Tang, S. Liu, H. Duan, and J. Yang: Mater. Charact., 2019, vol. 156, p. 109870.

100. H. Chikama, H. Shibata, T. Emi, and M. Suzuki: Mater. Trans., 1996, vol. 37, pp. 620-26.

101. In Situ Observation at Ultra High Temperature Confocal Scanning Laser Microscope (VL2000DX-SVF17S), 2018. https:// www.lasertec.co.jp/en/products/microscope/laser/vl2000dx.html.

102. W. Mu, P. Hedström, H. Shibata, P.G. Jönsson, and K. Nakajima: JOM, 2018, vol. 70, pp. 2283-95.

103. R.H. Mathiesen, L. Arnberg, K. Ramsøskar, T. Weitkamp, C. Rau, and A. Snigirev: Metall. Mater. Trans. B, 2002, vol. 33B, pp. 613-23.

104. H. Yasuda, T. Nagira, M. Yoshiya, N. Nakatsuka, A. Sugiyama, K. Uesugi, and K. Umetani: ISIJ Int., 2011, vol. 51, pp. 402-08.

105. M. Rappaz, F. Kohler, J. Valloton, A. Phillion, and M. Stampanoni: Metall. Mater. Trans. A, 2010, vol. 41A, pp. 563-67.

106. S.H. Davis: Theory of Solidification, 1st ed., Cambridge University Press, New York, 2001, p. 45

107. A. Karma, W.J. Rappel, B. Fuh, and R. Trivedi: Metall. Mater. Trans. A, 1998, vol. 29A, pp. 1457-70.

108. T.A. Lograsso, B. Fuh, and R. Trivedi: Metall. Mater. Trans. A, 2005, vol. 36A, pp. 1287-1300. 
109. D. Huntley and S.H. Davis: Acta Mater., 1993, vol. 41, pp. 2025 43.

110. G. Merchant and S.H. Davis: Acta Mater., 1990, vol. 38, pp. 2683-93.

111. H.Z. Fu and L. Liu: Proc. Mater. Sci. Forum, 2005, vol. 475, pp. $607-12$.

112. T.S. Lo, A. Karma, and M. Plapp: Phys. Rev. E, 2001, vol. 63, p. 031504.

113. J. Valloton, J.-D. Wagnière, and M. Rappaz: Acta Mater., 2012, vol. 60 , pp. $3840-48$

114. H. Fu and F. Xie: Sci. Technol. Adv. Mater., 2001, vol. 2, pp. 193-96.

115. H. Terasaki, Y. Komizo, M. Yonemuira, and T. Osuki: Metall. Mater. Trans. A, 2006, vol. 37A, pp. 1261-66.

116. H.N. Thi, H. Jamgotchian, J. Gastaldi, J. Härtwig, T. Schenk, H. Klein, B. Billia, J. Baruchel, and Y. Dabo: J. Phys. D, 2003, vol. 36, pp. A83-92.

117. N. McDonald and S. Sridhar: Metall. Mater. Trans. A, 2003, vol. 34A, pp. 1931-40.

118. M. Hillert: Solidification and Casting of Metals, 1st ed., The Metals Society, London, 1979, p. 413.

119. S. Pan, M. Zhu, and M. Rettenmayr: Acta Mater., 2017, vol. 132, pp. $565-75$.

120. D. Phelan, M. Reid, and R. Dippenaar: Comput. Mater. Sci., 2005, vol. 34, pp. 282-89.

121. B. Chalmers: Principles of Solidification, 1st ed., Wiley, Michigan, 1964, pp. 161-70.

122. A. Choudhury, B. Nestler, A. Telang, M. Selzer, and F. Wendler: Acta Mater., 2010, vol. 58, pp. 3815-23.

123. G. Boussinot, E. Brener, and D. Temkin: Acta Mater., 2010, vol. 58 , pp. $1750-60$.

124. E.A. Brener and D. Temkin: Acta Mater., 2007, vol. 55, pp. $2785-89$

125. G. Boussinot, C. Hüter, R. Spatschek, and E.A. Brener: Acta Mater., 2014, vol. 75, pp. 212-18.

126. H. Nassar and H. Fredriksson: Metall. Mater. Trans. A, 2010, vol. $41 \mathrm{~A}$, pp. $2776-83$.

127. H. Lopez: Acta Mater., 1991, vol. 39, pp. 1543-48.

128. H. Ha and J. Hunt: Metall. Mater. Trans. A, 2000, vol. 31A, pp. 29-34.

129. A. Das, I. Manna, and S. Pabi: Scripta Mater., 1997, vol. 36, pp. 867-74.

130. N. Liu, F. Liu, C. Yang, Y. Chen, G. Yang, and Y. Zhou: $J$. Alloys Compd., 2008, vol. 465, pp. 391-95.

131. S. Pan and M. Zhu: Acta Mater., 2018, vol. 146, pp. 63-75.

132. K. Matsuura, H. Maruyama, M. Kudoh, and Y. Itoh: ISIJ Int., 1995, vol. 35, pp. 1483-88.

133. K. Matsuura and M. Kudoh: Mater. Trans., 1998, vol. 39, pp. 203-10.

134. N. Moelans, B. Blanpain, and P. Wollants: CALPHAD, 2008, vol. 32 , pp. $268-94$

135. N. Provatas and K. Elder: Phase-Field Methods in Materials Science and Engineering, 1st ed., Wiley-VCH Verlag $\mathrm{GmbH}$, Weinheim, 2011, p. 139.

136. B. Nestler, H. Garcke, and B. Stinner: Phys. Rev. E, 2005, vol. 71, pp. 041609-19.

137. A. Karma and W.J. Rappel: Phys. Rev. E, 1998, vol. 57, pp. $4323-36$

138. M. Mamivand, M.A. Zaeem, and H. El Kadiri: Comput. Mater. Sci., 2013, vol. 77, pp. 304-11

139. M. Ohno and K. Matsuura: ISIJ Int., 2010, vol. 50, pp. 1879-85.

140. C.L.M. Alves, J.L.L. Rezende, D. Senk, and J. Kundin: J. Mater. Res. Technol., 2016, vol. 5, pp. 84-91.

141. M. Yoshiya, M. Watanabe, K. Nakajima, N. Ueshima K. Hashimoto, T. Nagira, and H. Yasuda: Mater. Trans., 2015, vol. 56 , pp. $1467-74$.

142. M. Hillert: Metall. Trans. A, 1984, vol. 15A, pp. 411-19.

143. M. Plichta, W. Clark, and H. Aaronson: Metall. Trans. A, 1984, vol. $15 \mathrm{~A}$, pp. $427-35$.

144. E. Pereloma and D.V. Edmonds: Phase Transformations in Steels: Fundamentals and Diffusion-Controlled Transformations, 1st ed., Woodhead Publishing Limited, Cambridge, 2012, pp. $125-29$.

145. E. Wilson: Met. Sci., 1984, vol. 18, pp. 471-84.
146. T. Massalski: Metall. Mater. Trans. A, 2002, vol. 33A, pp. 227783.

147. M. Hillert: Metall. Mater. Trans. A, 2004, vol. 35A, pp. 351-52.

148. H. Fredriksson and J. Stjerndahl: Met. Sci., 1982, vol. 16, pp. $575-86$.

149. M. Yoshiya, M. Sato, M. Watanabe, K. Nakajima, T. Yokoi, N. Ueshima, T. Nagira, and H. Yasuda: Mater. Sci. Eng., 2015, vol. 84, p. 012049-59.

150. S.C. Moon, R. Dippenaar, and S.-Y. Kim: in AISTech: Iron Steel Technol. Conf. Proc., Cleveland, Ohio, 2015, pp. 3338-50.

151. M.M. Wolf: Trans. ISIJ, 1980, vol. 20, pp. 718-24

152. W.H. Emling: Iron Steelmaker, 1994, vol. 5, pp. 50-59

153. B.G. Thomas: Brimacombe Continuous Casting Course, Vancouver, Canada, 2018.

154. J. Guo, G. Wen, D. Pu, and P. Tang: Materials, 2018, vol. 11, pp. $571-83$.

155. H. Cui, K. Zhang, Z. Wang, B. Chen, B. Liu, J. Qing, and Z. Li: Metals, 2019, vol. 9, pp. 204-12.

156. D. Pu, G. Wen, D. Fu, P. Tang, and J. Guo: Metals, 2018, vol. 8, pp. $982-94$

157. S. Dong, E. Niyama, and K. Anzai: ISIJ Int., 1995, vol. 35 , pp. $730-36$.

158. A. Jablonka, K. Harste, and K. Schwerdtfeger: Steel Res., 1991, vol. 62 , pp. $24-33$.

159. C. Bernhard, H. Hiebler, and M. Wolf: Ironmak. Steelmak., 2000, vol. 27, pp. 450-54.

160. C. Bernhard and G.J.I. Xia: Ironmak. Steelmak., 2006, vol. 33, pp. $52-56$.

161. H. Yasuda, T. Nagira, M. Yoshiya, A. Sugiyama, N. Nakatsuka, M. Kiire, M. Uesugi, K. Uesugi, K. Umetani, and K. Kajiwara: IOP Conf. Ser. Mater. Sci. Eng., 2012, vol. 33, p. 012036-48.

162. M. Wolf: Personal Communication, Lintz, Austria, 1999.

163. M.L. Zappulla, L.C. Hibbeler, and B.G. Thomas: Metall. Mater. Trans. A, 2017, vol. 48A, pp. 3777-93.

164. P. Wray: Model. Cast. Weld. Process, 1980, vol. 12, pp. 245-57.

165. B. Thomas and J. Parkman: in TMS Annual Meeting, The Minerals, Metals and Materials Society, Warrendale, PA, 1998, pp. 509-20.

166. B. Thomas, J. Brimacombe, and I. Samarasekera: ISS Trans., 1986, vol. 7, pp. 7-20.

167. B. Mintz and D. Crowther: Int. Mater. Rev., 2010, vol. 55, pp. $168-96$.

168. B. Mintz, S. Yue, and J. Jonas: Int. Mater. Rev., 1991, vol. 36, pp. $187-220$.

169. A. Yamanaka, K. Nakajima, and K. Okamura: Ironmak. Steelmak., 1995, vol. 22, pp. 508-12.

170. Y.M. Won, K.H. Kim, T.J. Yeo, and K.H. Oh: ISIJ Int., 1998, vol. 38, pp. 1093-99.

171. Y.M. Won, T.J. Yeo, D.J. Seol, and K.H. Oh: Metall. Mater. Trans. B, 2000, vol. 31B, pp. 779-94.

172. N. Pradhan, N. Banerjee, B. Reddy, S. Sahay, C. Viswanathan, P. Bhor, D. Basu, and S. Mazumdar: Ironmak. Steelmak., 2001, vol. 28, pp. 305-11.

173. B. Mintz: ISIJ Int., 1999, vol. 39, pp. 833-55.

174. B. Mintz and J. Arrowsmith: Met. Technol., 1979, vol. 6, pp. 24 32.

175. H.G. Suzuki, S. Nishimura, and Y. Nakamura: Trans. ISIJ, 1984, vol. 24, pp. 54-59.

176. C. Ouchi and K. Matsumoto: Trans. ISIJ, 1982, vol. 22, pp. 18189.

177. S.K. Kim, J.S. Kim, and N.J. Kim: Metall. Mater. Trans., 2002, vol. 33, p. 701.

178. Y. Maehara, K. Yasumoto, Y. Sugitani, and K. Gunji: Tetsu-to-Hagané, 1985, vol. 71, pp. 1534-41

179. K.H. Kim, T.J. Yeo, K.H. Oh, and D.N. Lee: ISIJ Int., 1996, vol. 36, pp. 284-89.

180. J. Miyazaki, K. Narita, and T. Nozaki: Trans. ISIJ, 1981, vol. 21, p. B210.

181. T. Matsumia, M. Ito, H. Kajoka, S. Yamaguchi, and Y. Nakamura: Trans. ISIJ, 1986, vol. 26, pp. 540-46.

182. K. Wünnenberg and R. Flender: Ironmak. Steelmak., 1985, vol. 12, pp. 22-29.

183. T. Kohno, T. Shima, T. Kuwabarak, S. Mizogucht T. Yamamoto, H. Misumi, and A. Tsuneoka: Tetsu-to-Hagané, 1982, vol. 68, pp. 1764-72. 
184. M. Suzuki, M. Suzuki, C. Yu, and T. Emi: ISIJ Int., 1997, vol. 37 , pp. $375-82$

185. H. Hiebler, J. Zirngast, C. Bernhard, and M. Wolf: Proc. Steelmak. Conf., 1994, vol. 77, pp. 405-16.

186. S. Nagata, T. Matsumiya, K. Ozawa, and T. Ohashi: Tetsu-to-Hagané, 1990, vol. 76, pp. 214-21.

187. J. Kristiansson: J. Therm. Stresses, 1984, vol. 7, pp. 209-26.

188. K. Sorimachi and J. Brimacombe: Ironmak. Steelmak., 1977, vol. 4, pp. $240-45$.

189. M. El-Bealy and H. Fredriksson: Metall. Mater. Trans. B, 1996, vol. 27B, pp. 999-1014.

190. C. Li and B.G. Thomas: Metall. Mater. Trans. B, 2004, vol. 35B, pp. 1151-72.

191. J.O. Kristiansson: J. Therm. Stresses, 1982, vol. 5, pp. 315-30.

192. B. Thomas, A. Moitra, and H. Zhu: in Model. Cast., Weld. Adv. Solidif. Process. VII, London, England, 1995, pp. 241-48.

193. B.G. Thomas, A. Moitra, and R. McDavid: Iron Steelmaker (USA), 1996, vol. 23, pp. 57-70.

194. B. Thomas, I. Samarasekera, and J. Brimacombe: Metall. Trans. $B, 1987$, vol. 18B, pp. 131-42.

195. M. Rowan, B.G. Thomas, R. Pierer, and C. Bernhard: Metall. Mater. Trans. B, 2011, vol. 42B, pp. 837-51.

196. J. Kelly, K. Michalek, T. O'Connor, B. Thomas, and J. Dantzig: Metall. Trans. A, 1988, vol. 19A, pp. 2589-2602.

197. B. Korojy, H. Nassar, and H. Fredriksson: Ironmak. Steelmak., 2010, vol. 37, pp. 63-72.

198. C. Bernhard, R. Pierer, A. Tubikanec, and C. Chimani: in Continuous-Casting Innovation Session, Linz, Austria, 2004, pp. $14-23$.

199. Y.M. Won, H.N. Han, T.J. Yeo, and K.H. Oh: ISIJ Int., 2000 , vol. 40, pp. 129-36

200. M.H. Trejo, E.A. Lopez, J.J.R. Mondragon, M.D.J.C. Roman, and H.S. Tovar: Met. Mater. Int., 2010, vol. 16, pp. 731-37.

201. W. Irving, A. Perkins, and R. Gray: Ironmak. Steelmak., 1984, vol. 11, pp. $146-51$

202. E.A. López, M.H. Trejo, J.J.R. Mondragón, M.D.J.C. Román, and H.S. Tovar: ISIJ Int., 2009, vol. 49, pp. 851-58.

203. H. Mizukami, A. Yamanaka, and T. Watanabe: ISIJ Int., 2002, vol. 42 , pp. $375-84$.

204. D. Crowther and B. Mintz: Mater. Sci. Technol., 1986, vol. 2, pp. $951-55$.
205. Y. Kobayashi, S. Iwasaki, K. Nakazato, T. Hibaru, S. Kuroda, N. Sakuma, N. Yoshida, and K. Nagai: ISIJ Int., 2008, vol. 48, pp. $344-49$.

206. K. Xu and B.G. Thomas: in AISTech: Iron Steel Technol. Conf. Proc., St. Louis, MO, 2009, pp. 20-32.

207. S. Tsuchiya, M. Ohno, K. Matsuura, and K. Isobe: Acta Mater., 2011, vol. 59, pp. 3334-42.

208. R. Dippenaar, C. Bernhard, S. Schider, and G. Wieser: Metall. Mater. Trans. B, 2014, vol. 45B, pp. 409-18.

209. L. Schmidt and A. Josefsson: Iron Steel Soc./AIME, 1997, vol. 8, pp. 49-55.

210. G. Alvarez de Toledo, A. Arteaga, and J. Laraudogoitia: Proc. Mater. Sci. Forum, 2005, vol. 500, pp. 163-70.

211. R.J. Dippenaar, S.-C. Moon, and E.S. Szekeres: in AISTech: Iron Steel Technol. Conf. Proc., Cleveland, OH, 2006, pp. 105-15.

212. K. Yasumoto, T. Nagamichi, Y. Maehara, and K. Gunji: Tetsu-to-Hagané, 1987, vol. 73, pp. 1738-45.

213. C. Bernhard, J. Reiter, and H. Presslinger: Metall. Mater. Trans. B, 2008, vol. 39B, pp. 885-95.

214. N. Yoshida, Y. Kobayashi, and K. Nagai: Tetsu-to-Hagané, 2004, vol. 90, pp. 198-205.

215. N.S. Pottore, C.I. Garcia, and A.J. DeArdo: Metall. Trans. A, 1991, vol. 22A, pp. 1871-80.

216. Y. Maehara, K. Yasumoto, H. Tomono, T. Nagamichi, and Y. Ohmori: Mater. Sci. Technol., 1990, vol. 6, pp. 793-806.

217. N. Yoshida, O. Umezawa, and K. Nagai: ISIJ Int., 2004, vol. 44, pp. 547-55.

218. H.S. Kim, Y. Kobayashi, and K. Nagai: Acta Mater., 2006, vol. 54 , pp. 2441-49.

219. J. Reiter, C. Bernhard, and H. Presslinger: in AISTech: Iron Steel Technol. Conf. Proc., Cleveland, OH, 2006, pp. 805-17.

220. J. Reiter, C. Bernhard, and H. Presslinger: Mater. Charact., 2008, vol. 59, pp. 737-46.

221. Y. Ohba, S.I. Kitade, and I. Takasu: ISIJ Int., 2008, vol. 48, pp. $350-54$.

Publisher's Note Springer Nature remains neutral with regard to jurisdictional claims in published maps and institutional affiliations. 